\title{
II. Der gewerbliche Mittelstand in der "nivellierten Mittelstandsgesellschaft"
}

Standen im ersten Teil der vorliegenden Studie die ökonomische Struktur des gewerblichen Mittelstandes und das wirtschaftliche Verhalten der Kleingewerbetreibenden im Mittelpunkt des Interesses, so wird nunmehr danach gefragt, inwieweit die rechtlich und ökonomisch definierten Berufsgruppen der Handwerker und Einzelhändler im Untersuchungszeitraum Merkmale eigenständiger sozialer Formationen aufwiesen. Im einzelnen ist zu klären, wie unterschiedlich die Existenzbedingungen innerhalb der mittelständischen Berufsgruppen waren und ob das Spektrum der Lebensverhältnisse im Untersuchungszeitraum homogener oder heterogener wurde. Darüber hinaus ist die Frage zu beantworten, ob die sozialstrukturellen Gemeinsamkeiten von Handwerkern und Einzelhändlern groß genug waren, um von einer typischen Soziallage des gewerblichen Mittelstandes sprechen zu können. In diesem Zusammenhang ist auch das Ausmaß der zwischen den mittelständischen Selbständigen und den Arbeitnehmern bestehenden Ungleicheit der Lebensbedingungen zu bestimmen. Bestätigt sich Schelskys These, daß sich der alte Mittelstand „der völligen Eingliederung in die nivellierte Mittelstandsgesellschaft entzieht, ohne jedoch zur tragenden Schicht einer anderen Sozialverfassung werden zu können"1? Ist es angesichts der vermeintlichen Sonderrolle des selbständigen Mittelstandes in den 50er Jahren überhaupt zulässig, von einer „Vereinheitlichung der sozialen und kulturellen Verhaltensformen in einem Lebenszuschnitt" $\mathrm{zu}$ sprechen, „den man [...] als kleinbürgerlich-mittelständisch bezeichnen könnte“ 2 ?

Gemeinsame sozioökonomische Existenzbedingungen stellen in der Regel zwar ein notwendiges, keinesfalls aber ein hinreichendes Kriterium für die Charakterisierung einer Vielheit von Personen als soziale Gruppe dar ${ }^{3}$. Aus diesem Grund sollen in einem zweiten Schritt die außerfamiliären und außerbetrieblichen Sozialbeziehungen untersucht werden. Besonderes Augenmerk gilt der Frage, in welchem Maße sich die Angehörigen der mittelständischen Berufsgruppen in sozialer Hinsicht als zusammengehörig betrachteten und ob diese Gruppenbindung primär auf interessenpolitische Motive oder auf traditional-affektive Gründe zurückzuführen ist ${ }^{4}$. Es geht mithin um das Fort-

\footnotetext{
${ }^{1}$ Schelsky, Wandlungen, S. 226.

${ }^{2}$ Schelsky, Bedeutung, S. 332. Schelsky versteht unter dem Begriff „mittelständische Lebensform ${ }^{\text {“ }}$ nicht die Lebensweise des traditionellen Mittelstandes, sondern eine im Zeichen des wachsenden Wohlstandes, der Massenproduktion und des hieraus resultierenden Übergangs zur Konsumgesellschaft stehende neue Form der Lebensführung. Zur Kritik an der zu Mißverständnissen verleitenden Terminologie von Schelsky vgl. Krisam, S. $352 \mathrm{f}$. Zur Nivellierung des Arbeiter-Angestellten-Unterschiedes vgl. Braun, passim. Eine gute Übersicht zum zeitgenössischen Diskussionsstand findet sich bei Kersig.

${ }^{3}$ Zur methodischen Problematik des Begriffes „soziale Gruppe“ vgl. Bahrdt, S. 86-136.

${ }^{4}$ Die theoretische Grundlage dieser Fragestellung bildet Webers Unterscheidung zwischen Gemeinschaft und Gesellschaft; vgl. Weber, S. 22. Haben die Bindungen zwischen Menschen in erster Linie zweckrationalen Charakter, so spricht Weber von Vergesellschaftung. Affektive und traditionale Beziehungen sind dieser Definition zufolge zentrale Merkmale der Vergemeinschaftung.
} 
wirken bzw. um die Erosion ständischer Rudimente in den 50er Jahren. Von der Analyse der sozialen Herkunft und der Berufsvererbung sind weitere Hinweise auf die soziale Abgeschlossenheit von Handwerk und Einzelhandel zu erwarten. Das Datenmaterial zur gesellschaftlichen Prestigestruktur soll daraufhin untersucht werden, inwieweit Handwerker und Einzelhändler als nach außen abgegrenzte Gruppen wahrgenommen wurden und wie sich die Mittelständler selbst in die soziale Schichtung einordneten.

Die am Beginn dieses Untersuchungsteils stehende Ungleichheitsanalyse konzentriert sich auf „objektive“ Lebensbedingungen (Einkommen, Wohnverhältnisse, Erwerbsbeteiligung der Haushaltsmitglieder usw. $)^{5}$, sofern diese nicht schon im Zusammenhang mit dem ökonomischen Verhalten der Mittelständler analysiert worden sind (z. B. Bildung, Altersstruktur). Bei der Analyse ist zu berücksichtigen, daß das ausgewertete Quellenmaterial überwiegend aus zeitgenössischen soziologischen Erhebungen stammt, die in empirischer und methodischer Hinsicht zum Teil äußerst disparat sind und nur begrenzt Aussagen über die subjektive Bewertung der faktischen Lebensverhältnisse durch die Betroffenen zulassen.

Die Analyse der Einkommens- und Vermögenslage soll Aufschluß darüber geben, wie die finanziellen Ressourcen, die den ökonomischen Rahmen der Lebensgestaltung abstecken, innerhalb der mittelständischen Berufsgruppen verteilt waren und inwieweit sich in dieser Hinsicht Handwerker und Einzelhändler von anderen Berufsgruppen abhoben. Aus den materiellen Lebensbedingungen lassen sich nicht zwangsläufig bestimmte Lebensformen ableiten. Die Lebensweise der selbständigen Mittelständler ist daher gesondert auf spezifische Kennzeichen hin zu untersuchen. Von besonderem Interesse sind der Zusammenhang zwischen Betrieb und häuslichem bzw. familiärem Bereich, die Arbeitszeit als Determinante der Freizeit ${ }^{6}$ sowie die private Lebensführung7, soweit sich diese in den Wohnverhältnissen, der Art des Güterkonsums und der Freizeitgestaltung ausdrückte.

${ }^{5}$ Zum Begriff der Lebensbedingungen vgl. Zapf, Wohlfahrt, S. 13-26.

- Sieht man von der weiter unten behandelten sozialen Wertschätzung der Selbständigkeit ab, so bleibt die soziale Bedeutung der Arbeitssituation, zu der neben der Arbeitszeit die Qualität und Intensität der Arbeit sowie das Verhältnis von Fremd- und Selbstbestimmung im Arbeitsprozeß zu zählen sind, im folgenden weitgehend unberücksichtigt. Der Verfasser ist sich bewußt, daß damit ein wichtiges soziales Unterscheidungsmerkmal zwischen Arbeitnehmern und mittelständischen Selbständigen nicht erfaßt wird.

7 Der Begriff „private Lebensführung“ ist der Weberschen Terminologie entlehnt; vgl. Weber, S. 283. Er ist von der „ökonomischen “ bzw. berufsbedingten Lebensführung, unter der im vorliegenden Fall z. B. der Zusammenhang zwischen Familie und Betrieb zu verstehen ist, ebenso zu unterscheiden wie von der „inneren“ Lebensführung, worunter Weber die der Lebensführung zugrunde liegende Gesinnung versteht (ebenda, S. 623). Letztere steht allerdings nicht im Mittelpunkt unserer Untersuchung, da sie quellenmäßig nur schwer nachweisbar ist. Der Untersuchungsschwerpunkt liegt vielmehr auf den Bedingungen für die Herausbildung bzw. Aufrechterhaltung einer berufsgruppenspezifischen Mentalität. Ausgangspunkt ist dabei die Annahme, daß "ein Bevölkerungsteil von bestimmter ökonomischer Lage [...] ein typisches Rekrutierungsfeld einer Schicht von bestimmter Mentalität" ist; vgl. Geiger, Schichtung, S. 5. Vor dem in der Literatur häufig anzutreffenden Mißverständnis, die Lebensführung sei per se ein Indikator für ständische Lagen, ist zu warnen. Sie ist es nur dann, wenn ${ }_{n}$ nicht eine bloß individuelle und sozial irrelevante Nachahmung fremder Lebensführung, sondern ein einverständliches Gemeinschaftshandeln dieses Charakters vorliegt" (Weber, S. 534). 
Ein weiteres Anliegen besteht darin, die sozialhistorischen Befunde für die ersten beiden Nachkriegsjahrzehnte zu den jeweiligen säkularen Trends in Beziehung zu setzen. Da die Sozialgeschichte des gewerblichen Mittelstandes in der Weimarer Republik und dem Dritten Reich noch weitgehend unerforscht ist ${ }^{8}$, kann dies im folgenden nur ansatzweise geleistet werden. Generative Aspekte wie z. B. die Abhängigkeit sozialer Einstellungen und Verhaltensweisen vom Alter der Betriebsinhaber spielen im weiteren Verlauf der Untersuchung nur eine untergeordnete Rolle, weil das herangezogene Datenmaterial derartige Differenzierungen kaum zuläßt.

\section{Materielle Lebensbedingungen}

\section{Die Einkommenslage im Handwerk}

\section{Binnendifferenzierung}

Für die Schätzung der Einkommensverhältnisse der selbständigen Handwerker werden im folgenden die Kostenstrukturerhebungen der Jahre 1950 und 1962, die das steuerliche Betriebsergebnis ermittelten, sowie die Handwerkszählung von 1963 und die Umsatzsteuerstatistik von 1950 herangezogen'. Dieser Vorgehensweise liegt die Annahme zugrunde, daß die Einkünfte aus einem Gewerbebetrieb bzw. das steuerliche Betriebsergebnis in etwa dem zu ermittelnden Bruttoeinkommen des Betriebsinhabers entsprachen $^{10}$. Die Einkommensteuerstatistik wird nur punktuell verwendet ${ }^{11}$.

Das Statistische Bundesamt nahm zwischen den Zählungsjahren 1950 und 1962 in bezug auf die Abgrenzung der Handwerkszweige zum Teil erhebliche kategoriale Veränderungen vor. Von den 72 bzw. 52 Wirtschaftsklassen, die in den Kostenstrukturerhebungen von 1950 und 1962 ausgewiesen werden ${ }^{12}$, lassen sich nur 18 miteinander ver-

${ }^{8}$ Haupt, Mittelstand, passim. Auch die Monographie von von Saldern läßt viele sozialhistorische Fragen offen.

9 Ergebnisse der Kostenstrukturerhebung 1950, H. 2. Die Kostenstruktur in der Wirtschaft 1962, Handwerk. Handwerkszählung 1963, H. 1-6.

${ }^{10}$ Das steuerliche Betriebsergebnis ist gleich der Differenz zwischen Rohertrag (= Umsatz-Wareneinsatz) und Kosten. Es enthält den kalkulatorischen Unternehmerlohn, den Lohn für mithelfende Familienangehörige sowie die Verzinsung des Eigenkapitals. Nebeneinkünfte aus unselbständiger Arbeit sind in dem Betriebsergebnis nicht enthalten. Dies dürfte insbesondere bei den Inhabern von Minderbetrieben zu einer Unterschätzung des Einkommensniveaus führen. Außerdem ist davon auszugehen, daß ein Teil des Betriebsergebnisses für zukünftige Nettoinvestitionen zurückgelegt wurde und somit für die private Lebensführung nicht zur Verfügung stand. Zur Vergleichbarkeit von Bruttoeinkommen der Arbeitnehmer und des Betriebsergebnisses vgl. Einkommensschichtung, Bd. 1, S. 20f. Der von Menges unternommene Versuch, das Einkommensniveau im Handwerk auf der Grundlage der Daten der volkswirtschaftlichen Gesamtrechnung zu berechnen, ist methodisch unzureichend, vgl. Menges, passim.

${ }_{11}$ In der Einkommensteuerstatistik von 1961 wurden die Einkommen der selbständigen Handwerker erstmals separat ausgewiesen. Eine Gliederung nach Einkommensklassen erfolgte allerdings nur für das produzierende Handwerk vgl. Ergebnisse der Einkommen- und Körperschaftsteuerstatistik 1961. Die Gewerbesteuerstatistik ist für unsere Zwecke ungeeignet, da sie Betriebe, die die Freigrenzen für den Gewerbeertrag unterschritten, nicht ausweist. Außerdem fanden umfassende Gewerbesteuererhebungen erst ab 1958 statt.

12 Die Wirtschaftsklassen sind im allgemeinen identisch mit den Handwerkszweigen, zum Teil disaggregieren sie diese aber auch nach wesentlicher und geringfügiger Handelstätigkeit. 
gleichen ${ }^{13}$. Trotz ihres begrenzten Umfangs kann diese Auswahl von Handwerkszweigen, die die empirische Grundlage für unsere Einkommensschätzung darstellt, insofern Anspruch auf Repräsentativität erheben, als sie fast ausschließlich handwerkliche Schüsselberufe enthält ${ }^{14}$. Die im Sample vertretenen Handwerkszweige umfassen 48,17\% aller handwerklichen Betriebe, 44,47\% des handwerklichen Gesamtumsatzes sowie $36,26 \%$ aller im Handwerk Beschäftigten ${ }^{15}$.

Die Berechnung der durchschnittlichen Einkommenshöhe sowie der Streuung des Einkommens von selbständigen Handwerkern erfolgt in Anlehnung an die Theorie der personellen Einkommensverteilung. Konkret wird die Standardabweichung der Einkommensverteilung innerhalb der Handwerkszweige und zwischen diesen errechnet und dann mit dem Durchschnittseinkommen des Gesamthandwerks bzw. der einzelnen Branchen in Beziehung gesetzt. Als Verteilungsmaß für die Relation zwischen durchschnittlichem Einkommen und Standardabweichung wird der Variationskoeffizient (V) gewähltt ${ }^{16}$. Der Anstieg dieses Koeffizienten deutet auf eine Polarisierung der Verteilung und damit der Einkommenslage hin. Ob allerdings die soziale Distanz zwischen den Einkommensempfängern primär von absoluten oder eher von relativen Einkommensdifferenzen beeinflußt wurde, läßt sich auf statistischem Wege nicht entscheiden. Dies hängt vielmehr von den quellenmäßig unzureichend überlieferten Wahrnehmungs- und Bewertungsstrukturen der Handwerker selbst $a b^{17}$. Die Datenstruktur der Kostenerhebung von 1962 ist problematisch, da im Gegensatz zur Erhebung von 1950 das in der höchsten Umsatzgrößenklasse erzielte Betriebsergebnis nicht ausgewiesen wird. Das bedeutet, daß die für 1962 errechneten Streuungswerte immer etwas niedriger ausfallen, als sie es tatsächlich waren. Diese systematische Verzerrung, die sich auch durch Schätzungen kaum beheben läßt, ist bei der Interpretation der Daten zu berücksichtigen.

Bei der Auswertung des Datenmaterials fällt zunächst auf ${ }^{18}$, daß die Einkommensdisparitäten zwischen den einzelnen Handwerkszweigen sowohl 1950 als auch 1962 beträchtlich waren. So verdiente z. B. ein selbständiger Kfz-Handwerker im Jahre 1950

${ }^{13}$ Die mangelnde Vergleichbarkeit der Daten resultiert vor allem daraus, daß in der Kostenstrukturerhebung von 1950 die Wirtschaftsklassen fast durchgehend nach wesentlicher und geringfügiger Handelstätigkeit disaggregiert werden, während dies in der Erhebung von 1962 nur teilweise der Fall ist. Folgende Handwerkszweige lassen sich vergleichen: Schmiede, Herrenschneiderei, Möbeltischlerei, Schuhmacherhandwerk, Bauklempnerei, Herrenfriseure, Damenfriseure, Kfz-Handwerk, Bäckerhandwerk, Fleischerei, Malerhandwerk, Schlosserei, Bautischler, Zimmerei, Dachdeckerei, Fahrradmechaniker-Handwerk, Landmaschinenmechaniker-Handwerk, Maschinenbauer-Handwerk.

${ }^{14}$ Das Statistische Bundesamt traf eine ähnliche Auswahl, wenn es in den Statistischen Jahrbüchern einen groben Überblick über die handwerkliche Kostenstruktur gab.

15 Eigene Berechnung nach: Handwerkszählung 1963, H. 1, S. 64-81.

${ }_{16} \mathrm{~V}=\sqrt{\Sigma}(\mathrm{xi}-\mu)^{2}$. fi $\div \mu$.

${ }_{17}$ Zur Interpretationsproblematik der absoluten Standardabweichung und des Variationskoeffizienten vgl. Blümle, S. $38 \mathrm{f}$.

${ }^{18}$ Die Berechnungen basieren auf folgenden Statistiken: Ergebnisse der Umsatzsteuerstatistik 1950, S. 136-153; Handwerkszählung 1963, H. 1, S. 64-81; Ergebnisse der Kostenstrukturerhebung 1950, S. 56-77; Kostenstruktur in der Wirtschaft 1962, S. 38-45. Aus der Umsatzsteuerstatistik und der Handwerkszählung geht die Umsatzgrößenklassenverteilung der Betriebe hervor. Mit Hilfe dieser Statistiken können die ebenfalls nach Umsatzgrößenklassen ausgewiesenen Betriebsergebnisse gewichtet werden. 
fast zweieinhalbmal und 1962 etwa fünfmal soviel wie ein Herrenfriseur. Legt man den Variationskoeffizienten (V) als Streuungs- und damit als Ungleichheitsmaß zugrunde, so ist, bezogen auf unser Sample, festzustellen, daß die Unterschiede zwischen den Durchschnittseinkommen der einzelnen Handwerkszweige im Zeitraum von 1950 bis 1962 zunahmen (V1950=0,41/V1962=0,52). Das (ungewichtete) Durchschnittseinkommen der betrachteten Handwerkszweige stieg um den Faktor 2,67 - zum Vergleich: der Lebenshaltungsindex für einen 4-Personen-Arbeitnehmerhaushalt erhöhte sich im gleichen Zeitraum um den Faktor 1,28 ${ }^{19}$. Den mit Abstand größten Kaufkraftzuwachs hatten die Maschinenbau-Handwerker, Schlosser, Möbeltischler und Kfz-Handwerker, den geringsten die Zimmerer und Herrenfriseure zu verzeichnen.

Die Berechnung der Einkommensentwicklung innerhalb der einzelnen Handwerkszweige gibt aus einer anderen Perspektive Aufschluß über die einkommensmäßige Binnendifferenzierung des Handwerks. In 14 von 18 untersuchten Handwerkszweigen ist ein signifikanter Anstieg der (absoluten) Standardabweichung zu verzeichnen. In zwei Fällen stagniert sie, und in weiteren zwei Handwerken nimmt sie ab (Zimmerei, Herrenschneiderei). Der Variationskoeffizient steigt in nur einem Drittel der untersuchten Handwerkszweige an. In 10 Fällen, also in etwas mehr als der Hälfte der im Sample enthaltenen Branchen, geht die Streuung relativ zum Anstieg des durchschnittlichen Betriebsergebnisses signifikant zurück. In zwei Handwerkszweigen bleibt sie in etwa auf dem gleichen Niveau. Daraus folgt, daß in der Mehrzahl der Handwerkszweige die brancheninterne Einkommensverteilung in Relation zum durchschnittlichen Betriebsergebnis nicht heterogener, sondern teilweise sogar homogener wurde. Polarisierungstendenzen traten vor allem in den ökonomisch erfolgreicheren Handwerken auf.

Die vom Deutschen Institut für Wirtschaftsforschung für die Jahre 1950 und 1955 errechnete Einkommensschichtung im Gesamthandwerk läßt erkennen, daß der Anstieg der Standardabweichung etwas geringer ist als der durchschnittliche Einkommenszuwachs (V1950=1,41; V1955=1,35). Diese Daten bestätigen zumindest für die erste Hälfte der 1950er Jahre die Vermutung, daß auf der Ebene des Gesamthandwerks die Einkommensverteilung tendenziell homogener wurde. Dieser Befund ist angesichts des starken Rückgangs der Kleinbetriebe (bis einschließlich 4 Beschäftigte) durchaus plausibel. Betrachtet man indes die Entwicklung der absoluten Einkommensdifferenzen, so ist eine Zunahme der Ungleichheitsspanne zu konstatieren (die Standardabweichung steigt von $8025 \mathrm{DM}$ im Jahre 1950 auf $11588 \mathrm{DM}$ im Jahre 1955) ${ }^{20}$.

\section{Vergleich mit Arbeitnehmern}

Die Erforschung der Einkommensrelationen zwischen selbständigen Handwerkern und Arbeitnehmern läßt die Beantwortung gleich mehrerer sozialgeschichtlich zentraler Fragestellungen erhoffen: Nahmen die Einkommensunterschiede zwischen selbständigen Handwerksmeistern und ihren Gesellen, soweit vorhanden, zu oder ab? Wie

19 Bei der Berechnung des Durchschnittseinkommens der im Sample enthaltenen Handwerkszweige wurde jede Branche gleich gewichtet. Die hieraus resultierenden Verzerrungen halten sich in Grenzen: Der errechnete Mittelwert (5384 DM im Jahre 1950) stimmt fast genau mit dem von Göseke systematisch ermittelten Durchschnittseinkommen der Handwerker im Jahre 1950 überein (5420 DM); vgl. Einkommensschichtung, Tab. 192. Zur Entwicklung des Preisindexes vgl. Statistisches Jahrbuch 1964, S. 489.

20 Berechnet nach: Einkommensschichtung, Tabellenteil, Tab. 192. 
hoch war der Anteil derjenigen Handwerker, deren Einkommen das eines Arbeiters nicht überstieg? Vergrößerte oder verringerte sich die ökonomische Attraktivität der Selbständigenposition im Handwerk unter dem Aspekt der Verdienstmöglichkeiten?

Die einkommensmäßige Meister-Gesellen-Differenz ist ein klassisches Thema sozialgeschichtlicher Studien zum Handwerk. Leider existieren amtliche Statistiken zur Lohnstruktur der Arbeiter im Handwerk erst ab 1958. Für den angestrebten Längsschnittvergleich muß daher auf Daten zu Industriearbeitern zurückgegriffen werden. Der Bruttojahresverdienst (ohne Sonderzuwendungen) der männlichen Facharbeiter in der Industrie erscheint zum einen wegen des gerade in der Nachkriegzeit häufigen Wechsels von selbständigen Handwerkern in Facharbeiterpositionen und zum anderen wegen des hohen Männeranteils unter den Betriebsinhabern als sinnvolle Vergleichsgröße 21 .

Der Bruttojahresverdienst (nicht deflationiert) der industriellen männlichen Facharbeiter (ohne Bergbau) stieg im Bundesgebiet von 1950 bis 1962 (Nov.) um 141\% (Basisjahr 1950). Bezöge man die Sonderzuwendungen mit ein, fiele dieser Wert noch etwas höher aus. In absoluten Zahlen ausgedrückt, erhöhte sich der durchschnittliche Jahresverdienst dieses Segments der Arbeiterschaft von 3819 auf 9110 DM. Von den untersuchten Handwerkszweigen hatten 9 einen steileren prozentualen Einkommensanstieg zu verzeichnen. Zwei Handwerke wiesen einen ähnlich hohen Einkommenszuwachs wie die industrielle Facharbeiterschaft auf. Die restlichen 7 Handwerksbranchen blieben deutlich unter der genannten Zuwachsrate des Facharbeitereinkommens. An diesem Befund würde sich wohl auch dann nichts Grundlegendes ändern, wenn man in Rechnung stellte, daß die Schätzungen des Handwerkereinkommens für das Jahr 1962 aufgrund der unzureichenden statistischen Angaben in der höchsten Einkommensklasse tendenziell zu niedrig ausfallen. Das durchschnittliche Einkommen wuchs in etwa der Hälfte der Handwerkszweige schneller als in der männlichen Industriearbeiterschaft (Facharbeiter bzw. Leistungsgruppe 1).

Die Berechnung der absoluten Einkommensunterschiede zwischen selbständigen Handwerkern und Facharbeitern zeigt, daß sowohl 1950 als auch 1962 das durchschnittliche Betriebsergebnis in einem Drittel der untersuchten Branchen geringer war als das durchschnittliche Bruttojahreseinkommen der industriellen Facharbeiter. Die hiervon betroffenen Branchen blieben im Untersuchungszeitraum weitgehend identisch.

Angaben zur Einkommensschichtung, die sich auf das gesamte Handwerk beziehen, liegen, wie bereits erwähnt, für die Jahre 1950 und 1955 vor $^{22}$. Das Betriebsergebnis von rund $58 \%$ der Handwerker lag 1950 nicht höher (bis 4000 DM) als das durchschnittliche Bruttojahreseinkommen eines männlichen Facharbeiters in der Industrie (ohne Bergbau). Bis 1955 reduzierte sich dieser Anteil auf rund 46\% ${ }^{23}$. Das durchschnittliche Bruttoeinkommen der Handwerker stieg in diesem Zeitraum schneller (Zuwachsrate von $90 \%$ ) als das der männlichen Facharbeiter (Zuwachsrate von 44\%). Gegenüber den 20er und 30er Jahren dürfte sich der Anteil derjenigen Handwerker, die kaum das

\footnotetext{
${ }^{21}$ Berechnet nach: Statistisches Jahrbuch 1953, S. 506; zu den Arbeiterverdiensten in der Industrie vgl. für 1962: Arbeitnehmerverdienste, S. 32.

22 Einkommensschichtung, Tabellenband, Tab. 192.

${ }^{23}$ Ebenda; zum Facharbeitereinkommen vgl. Statistisches Jahrbuch 1957, S. 516.
} 
Durchschnittseinkommen von Gesellen oder gelernten Arbeitern erreichten, signifikant verringert haben ${ }^{24}$.

Auf Branchenebene gab es massive Unterschiede: So lag z. B. im Nahrungsmittelhandwerk des Jahres 1950 die Quote derjenigen handwerklichen Betriebsinhaber, deren Bruttoeinkommen das eines industriellen Facharbeiters nicht überstieg, bei 22,5\%, während sie im Bekleidungs-, Leder- und Textilhandwerk $86 \%$ betrug.

Wie entwickelte sich die Arbeitnehmer-Arbeitgeber-Differenz bis Anfang der 60er Jahre? Geht man von den Angaben der Einkommensstatistik von 1961 zum produzierenden Handwerk aus, so reduzierte sich der Anteil an Betriebsinhabern, die nicht mehr als Facharbeiter verdienten, auf ca. 35 bis $40 \%{ }^{25}$. Die Selbständigen setzten sich also, aufs Ganze gesehen, einkommensmäßig von den Industriearbeitern ab.

Vergleicht man das Betriebsergebnis der selbständigen Handwerker mit dem Bruttojahresverdienst ihrer eigenen Gesellen im Jahre 1962, so fallen selbst bei einem kleinen Sample von nur acht Handwerkszweigen die enormen berufsspezifischen Unterschiede auf ${ }^{26}$ : Im Kfz-Handwerk verdiente ein selbständiger Meister durchschnittlich 3,2mal soviel wie ein Vollgeselle derselben Branche; ein selbständiger Maler verdiente dagegen nur 1,6mal mehr als seine Gesellen. In der Mehrzahl der Handwerkszweige dürften auch Anfang der 60er Jahre 30 bis $40 \%$ der Betriebsinhaber (einschließlich der Alleinmeister!) nicht mehr verdient haben als die Handwerksgesellen derselben Branche. Generell gilt, daß das Einkommen der Gesellen unter dem industrieller Facharbeiter lag. Was die Entwicklung der Einkommensunterschiede zwischen handwerklichen Betriebsinhabern und ihren Gesellen angeht, so ist wie bei der Facharbeiterschaft von einer Polarisierung auszugehen ${ }^{27}$.

Faßt man die Ergebnisse zur Entwicklung der Einkommensverteilung im Handwerk zusammen, so sind vor allem die z.T. beträchtlichen Einkommensunterschiede zwischen den Branchen zu betonen. Die Bedeutung der Branchenzugehörigkeit für den Lebensstandard der Handwerker nahm im Untersuchungszeitraum zu. Dieser Prozeß dürfte ständische Bewußtseinsformen und Vergemeinschaftungstendenzen, sofern sie sich nicht nur auf einzelne Branchen, sondern auf das gesamte Handwerk bezogen, nicht gefördert haben. Innerhalb der einzelnen Handwerkszweige gingen die relativen Einkommensunterschiede teils zurück, teils vergrößerten sie sich. Auf der Ebene des Gesamthandwerks, also ungeachtet der Unterschiede zwischen den Branchen, wurde die Einkommensverteilung im Laufe der 50er Jahre relativ zur Erhöhung des Durchschnittseinkommens homogener, was insbesondere auf den starken quantitativen Rückgang der Kleinstbetriebe und, damit einhergehend, der proletaroiden Meisterexistenzen zurückzuführen ist. Die absoluten Einkommensdifferenzen vergrößerten sich hinge-

${ }^{24}$ Lenger, Sozialgeschichte, S. 182 f.; Haupt, Mittelstand, S. 223, 227. Zu den Einkommensverhältnissen der Kleingewerbetreibenden im Wilhelminischen Kaiserreich vgl. Hentschel, Erwerbsund Einkommensverhältnisse, S. 63, sowie Haupt, Kleinhändler, S. 107-109. Für die 1890er Jahre vgl. Volkov, S. 84-94, und Rothenbacher, S. 355 f., Tab. A53. Zum Dritten Reich vgl. Saldern, S. 95 und 107.

${ }^{25}$ Ergebnisse der Einkommensteuerstatistik 1961, S. $114 \mathrm{f}$.

26 Das Sample beteht aus folgenden Handwerken: Kraftfahrzeugreparatur-Handwerk, Schlosserei, Bau- und Möbeltischlerei, Bäckerei, Fleischerei, Klempnerei, Malerhandwerk. Vgl. Arbeiterverdienste im Handwerk, November 1962, S. 3.

${ }^{27}$ Dieser Befund bestätigt Lengers These von der Polarisierung der Lebenslagen der im Handwerk Beschäftigten; vgl. Lenger, Sozialgeschichte, S. 220. 
gen. Die materiellen Lebensbedingungen der Handwerker wurden mithin, relativ betrachtet, einheitlicher und, absolut betrachtet, uneinheitlicher. Die Entwicklung der Einkommensverteilung kann folglich - je nach Perspektive - dazu beigetragen haben, die soziale Distanz zwischen den Handwerkern zu vergrößern oder zu verringern ${ }^{28}$. Welche Tendenz dominierte, läßt sich nicht unabhängig von der Wahrnehmung der Betroffenen beurteilen. Hierzu liegen jedoch nur verstreute Indizien vor. So deuten z. B. Sacks Ergebnisse zu den Tischlern darauf hin, daß Anfang der 60er Jahre ein signifikanter Zusammenhang zwischen Einkommenshöhe und Berufszufriedenheit bestand ${ }^{29}$.

Die Einkommensdifferenz zwischen selbständigen Handwerkern und männlichen industriellen Facharbeitern nivellierte sich in nur einem Drittel bis zur Hälfte der Handwerkszweige. In den übrigen Branchen wuchsen die Unterschiede sowohl absolut als auch relativ. Betrachtet man die Einkommensschichtung des Gesamthandwerks, so deutet im Hinblick auf das Einkommen einiges auf eine Vergrößerung des ArbeitnehmerArbeitgeber-Unterschiedes hin. Die Selbständigkeit wurde im Hinblick auf die Verdienstmöglichkeiten in der Mehrzahl der Branchen attraktiver ${ }^{30}$. Der Unternehmerstatus trat infolgedessen auch in sozialer Hinsicht klarer zutage. Diese Schlußfolgerung gilt allerdings nur für das Handwerk als Ganzem. Es steht zu vermuten, daß die durchschnittliche Einkommenssteigerung nicht zuletzt mit dem Ausscheiden vieler Kleinstbetriebe zusammenhing. $\mathrm{Da}$ die zeitgenössischen Kostenstrukturerhebungen das Betriebsergebnis nicht in Abhängigkeit von der Beschäftigtenzahl erfaßten, muß allerdings offenbleiben, inwieweit der einzelne Handwerker bei gleichbleibender Betriebsgröße Einkommenszuwächse zu verzeichnen hatte.

\section{Die Einkommenslage im Einzelhandel}

Aus den Kostenstrukturstatistiken von 1950 und 1961 lassen sich kaum repräsentative Aussagen zur Entwicklung der Einkommensverteilung im Einzelhandel ableiten, da nur sieben Einzelhandelsbranchen zu den beiden Erhebungszeitpunkten 1950 und 1961 kategorial übereinstimmten ${ }^{31}$. Es erscheint daher sinnvoll, zunächst auf das vom Deutschen Institut für Wirtschaftsforschung erstellte Datenmaterial zur Einkommensschichtung im Einzelhandel einzugehen.

Das Einkommensniveau des Einzelhandels lag im Jahre 1950 um 13\% höher als im Handwerk (6110 DM gegenüber 5420 DM) ${ }^{32}$. Den Angaben der Einkommensteuersta-

${ }^{28} \mathrm{Zu}$ den Grenzen der Aussagekraft der verwendeten statistischen Methoden vgl. Blümle, S. 38.

29 Sack, S. 176.

${ }^{30}$ Hierin ist vermutlich auch eine der Ursachen für den seit Ende der 50er Jahre zu beobachtenden betrieblichen Fluktuationsanstieg im Handwerk zu sehen; vgl. Flick, S. 84.

${ }^{31}$ Ergebnisse der Kostenstrukturerhebung 1950, H. 4: Einzelhandel, S. 57-87; die Kostenstruktur in der Wirtschaft 1961, S. 58-71. Die sieben Einzelhandelszweige sind: Einzelhandel mit Tuchen, Futterstoffen und Meterware, mit Landmaschinen und landwirtschaftlichen Geräten, mit Rundfunk-, Fernseh- und Photogeräten sowie mit Schallplatten, mit Brennstoffen, mit Kraftfahrzeugen und Krafträdern, mit Büromaschinen und Organisationsmitteln, mit feinmechanischen und optischen Erzeugnissen.

32 Einkommensschichtung, Tab. 192 und 200. Die Ergebnisse der vom Institut für Handelsforschung durchgeführten Betriebsvergleiche im Einzelhandel wurden nicht herangezogen, da von diesen Erhebungen vor allem größere Betriebe mit einem überdurchschnittlich hohen Betriebsergebnis erfaßt wurden; vgl. Entwicklungstendenzen, S. 127 f., Tab. 52, und S. 194, Tab. 103. 
tistik von 1961 zufolge erhöhte sich das Durchschnittseinkommen im Einzelhandel auf $17854 \mathrm{DM}^{33}$. Das entspricht einem Einkommenszuwachs von 192\%. Die Standardabweichung nahm dagegen nur um $160 \% \mathrm{zu}$, d. h. die Streuung ging relativ zum Anstieg des Durchschnittseinkommens zurück ${ }^{34}$. Der entscheidende Einkommensschub erfolgte nach 1955. Ähnlich wie im Handwerk stieg auch im Einzelhandel die Kaufkraft der Selbständigen deutlich ${ }^{35}$. In den Jahren 1950 und 1955 waren im Einzelhandel sowohl die absolute Standardabweichung als auch der Variationskoeffizient (V1950=2,39/ V1955=2,28) höher als im Handwerk. Was die Einkommensverteilung betrifft, war das Handwerk folglich homogener als der Einzelhandel, wenngleich sich die relativen Unterschiede im Zeitverlauf verringerten. Wie an den Variationskoeffizienten zum Einzelhandel ersichtlich, nahm die relative Streuung der Einkommen in den 1950er Jahren ab. Ob diese „objektive" Homogenisierung der Lebensbedingungen auch von den Betroffenen als solche empfunden wurde, muß aus den schon im Zusammenhang mit der Einkommensentwicklung im Handwerk erörterten Gründen offenbleiben.

Welche Aussagen lassen sich zur Entwicklung des Verhältnisses zwischen Arbeitgeber- und Arbeitnehmereinkommen im Einzelhandel treffen? Stellt man der Einkommensschichtung von 1961 den Bruttojahresverdienst der kaufmännischen Angestellten männlichen Geschlechts (8904 DM ohne Sonderzuwendungen) gegenüber ${ }^{36}$, so zeigt sich, daß mehr als ein Drittel der selbständigen Einzelhändler unter dem Einkommensdurchschnitt dieser Angestelltengruppe lag. Rund 16\% der Einzelhändler verdienten weniger als die weiblichen Angestellten im kaufmännischen Bereich, deren Bruottojahresverdienst 1961 bei 5496 DM lag. 1950/51 verdienten rund 70\% der selbständigen Einzelhändler nicht mehr als die männlichen (4 963DM) und rund $48 \%$ nicht mehr als die weiblichen kaufmännlichen Angestellten (3 059) ${ }^{37}$. Da aber davon auszugehen ist, daß im Einzelhandel überwiegend junge weibliche Arbeitskräfte der beiden untersten Leistungsgruppen beschäftigt wurden, dürfte sich diese Relation zugunsten der Betriebsinhaber verschoben haben.

Der Bruttojahresverdienst der männlichen kaufmännischen Angestellten erhöhte sich im Zeitraum von 1950 bis 1961 um 79\%, der der weiblichen kaufmännischen Angestellten um $80 \%{ }^{38}$. Die Betriebsinhaber der im Sample enthaltenen Einzelhandelszweige hatten demgegenüber im Durchschnitt einen höheren Einkommenszuwachs zu verzeichnen als ihre Angestellten. Man wird daher auch im Einzelhandel von einer Vergrößerung der Arbeitnehmer-Arbeitgeber-Differenz ausgehen können. Ähnlich wie im Handwerk scheinen die Unterschiede bezüglich des Einkommensniveaus zwischen den verschiedenen Einzelhandelszweigen teilweise größer gewesen zu sein als die Differenz zwischen dem branchenunspezifischen Durchschnittsverdienst der selbständigen Einzelhändler und dem durchschnittlichen Einkommen der kaufmännischen Angestellten.

33 Ergebnisse der Einkommensteuerstatistik 1961, S. 115.

34 Ergebnisse der Einkommensteuerstatistik 1961, S. 114.

${ }^{35}$ Statistisches Jahrbuch 1964, S. 489: Der Lebenshaltungsindex erhöhte sich zwischen 1950 und 1961 von 100 auf 123,6 Punkte.

$36 \mathrm{Zu}$ den folgenden Angaben vgl. Statistisches Jahrbuch 1963, S. 506.

${ }^{37}$ Errechnet nach: Einkommensschichtung, Tab. 200; die Angaben zum Angestellteneinkommen beziehen sich auf das Jahr 1951, während die Daten zum Betriebsergebnis der Einzelhändler aus dem Jahre 1950 stammen.

38 Errechnet nach: Statistisches Jahrbuch 1963, S. 506; Statistisches Jahrbuch 1954, S. 503. 


\section{Vermögensungleichbeit}

Bei der Analyse der Vermögensverhältnisse ist grundsätzlich zwischen Geld- und Sachvermögen zu unterscheiden, wobei sich letzteres in betriebliches Vermögen einerseits und privaten Haus- und Grundbesitz sowie privates Sachvermögen andererseits glie$\operatorname{dert}^{39}$. Ein Mischverhältnis dieser Vermögensarten liegt vor, wenn das Hauseigentum sowohl zu gewerblichen als auch zu privaten Zwecken genutzt wird. Bevor wir diesem gerade im Kleingewerbe sehr verbreiteten Phänomen nachgehen, soll festgestellt werden, inwieweit die Handwerker und Einzelhändler über eigene Arbeits- bzw. Geschäftsräume verfügten. Abschließend ist dann auf den Stellenwert der übrigen Vermögensarten im gewerblichen Mittelstand einzugehen. Das betriebliche Vermögen im engeren Sinne wird mangels repräsentativer Daten nicht analysiert.

Im Handwerk erhöhte sich im Zeitraum von 1949 bis 1963 die Quote derjenigen Selbständigen, deren Betrieb sich überwiegend auf eigenem Grundstück und in eigenen Räumen befand, von $48,5 \%$ auf $61,2 \%{ }^{40}$. Der entscheidende Entwicklungsschub erfolgte offenbar in der ersten Hälfte der 1950er Jahre ${ }^{41}$. Die Zahl der in eigenen Gebäuden bzw. auf eigenen Grundstücken arbeitenden Betriebe nahm nicht nur relativ, sondern auch absolut zu (allein zwischen 1956 und 1963 um 7\%)

Sowohl am Anfang als auch am Ende des Untersuchungszeitraumes waren die Unterschiede zwischen den Branchen beträchtlich. So wurden 1949 in der Handwerksgruppe Nahrung 69,5\% der Betriebe und in der Handwerksgruppe Holz 66,8\% der Betriebe auf eigenem Grundstück und in eigenen Räumen betrieben, wohingegen es auf dem Gebiet der Körperpflege nur 25,9\% und im Papierhandwerk 31,8\% waren. Bis 1963 blieb die Relation zwischen den Handwerksgruppen im großen und ganzen erhalten. Lediglich im Bauhandwerk vergrößerte sich der Eigentumsanteil an Betriebsgrundstücken sprunghaft (von 49,1 auf $67,8 \%$ ).

Wovon hingen diese handwerksinternen Besitzunterschiede ab? Ein Bestimmungsgrund ist in dem unterschiedlichen Tätigkeitsfeld der einzelnen Handwerke zu sehen. Einige Handwerke hatten keine eindeutige, räumlich festgelegte Produktionsstätte (wie z. B. Schornsteinfegerhandwerk, Gebäudereinigung). Der Standort der Handwerkszweige dürfte allerdings in bezug auf den Besitz an Betriebsräumen die wichtigste Rolle gespielt haben. Branchen, die ihren örtlichen Schwerpunkt überwiegend in ländlichen Gebieten hatten, wiesen einen überdurchschnittlich hohen Eigentümeranteil auf. In jenen Handwerksbranchen, die in den Stadtzentren überrepräsentiert waren, wie z. B. die Luxus- und Körperpflegehandwerke, überwog die Anmietung von Geschäftsräumen ${ }^{43}$. Errechnet man den Eigentümeranteil auf der Ebene der Handwerkszweige, so bestätigen sich diese Beobachtungen. In unserem Sample, das 18 Handwerkszweige umfaßt und das auf der Kostenstrukturerhebung des Jahres 1950 beruht, weisen die Landmaschinenhandwerker $(80 \%)$, die Bautischler (77\%) und die Schmiede (74\%) den höch-

${ }^{39}$ Bolte/Hradil, S. 128. Langlebige Gebrauchsgüter werden im folgenden nicht als privates Sachvermögen definiert.

40 Handwerkszählung 1949, Bd. 6, S. 25; Handwerkszählung 1963, H. 4, S. 20.

${ }^{41}$ Handwerkszählung 1956, H. 7, S. 45. Da in der Erhebung von 1956 die Betriebsstätte anders definiert ist als 1949 und 1963 - Büro-, Lager- oder Aufenthaltsräume werden nicht als Betriebsstätten gezählt - , sind die verschiedenen Zählungen nur unter Vorbehalt vergleichbar.

42 Handwerkszählung 1963, H. 4, S. 20.

${ }^{43}$ Ebenda. 
sten Eigentümeranteil und die schwerpunktmäßig in den Städten beheimateten Herren$(6,3 \%)$ und Damenfriseure (26\%) sowie die Fahrradmechaniker $(27 \%)$ und Herrenschneider (35\%) den niedrigsten Eigentümeranteil auf ${ }^{44}$.

Die Hypothese, je höher das durchschnittliche Betriebsergebnis einer Branche sei, desto verbreiteter sei der Besitz von Betriebsgrundstücken und -räumen, bestätigt sich zumindest für das Jahr 1950 nicht $^{45}$. Auch innerhalb der einzelnen Handwerkszweige korreliert der Anteil der Betriebe mit eigenen Betriebsräumen nur in Ausnahmefällen positiv mit dem Anstieg des umsatzgrößenklassenspezifischen Betriebsergebnisses (von 18 Handwerkszweigen ist dies nur bei den Schlossern und KfZ-Handwerkern der Fall). Die Faktoren Standort und Tätigkeitsfeld waren für den Besitz eigener Betriebsräume offenbar von größerer Bedeutung als die Einflußgröße Einkommensniveau bzw. Gewinn.

Im Einzelhandel bestand ebenfalls kein signifikanter Zusammenhang zwischen dem branchenspezifischen Einkommensniveau und dem durchschnittlichen Eigentum an gewerblich genutzten Grundstücken und Gebäuden in dieser Branche ${ }^{46}$. Die höchste Eigentümerquote wies der Einzelhandel mit Landmaschinen und landwirtschaftlichen Geräten (60\%) auf, gefolgt von Gemischtwarengeschäften (52\%) und dem Einzelhandel mit Seife, Bürsten usw. (51\%). Die niedrigsten Quoten (9\%) finden sich im Einzelhandel mit Büromaschinen und -möbeln sowie im Einzelhandel mit Spielwaren (8\%). Diese Daten lassen darauf schließen, daß der Besitzanteil in den einzelnen Branchen in erster Linie vom Standort der Betriebe abhing (Stadt-Land, City-Peripherie). Auch innerhalb der Einzelhandelszweige liegt keine positive Korrelation zwischen der Höhe des Betriebsergebnisses und dem Besitz von Betriebsräumen vor.

Die auf der Basis des bereits im Zusammenhang mit der Einkommensabschätzung vorgestellten Samples errechnete Eigentümerquote lag $1950 \mathrm{im}$ Einzelhandel bei $31 \%{ }^{47}$. Sie war damit fast $20 \%$ niedriger als im Handwerk. In Anbetracht der verhältnismäßig ähnlichen Einkommensverteilung in Handwerk und Einzelhandel liegt die Vermutung

44 Zum Sample vgl. Anm. 13.

45 Der auf der Grundlage des Samples berechnete (lineare) Korrelationskoeffizient beträgt 0,25. Dabei wurde zunächst der in der Kostenstrukturerhebung von 1950 erfragte branchenspezifische Anteil an eigenen Räumen errechnet und dann in Beziehung gesetzt zu dem durchschnittlichen Betriebsergebnis des jeweiligen Handwerkszweiges. Die verwendete Formel lautet wie folgt: $\mathrm{r}=$ $(\Sigma$ xi yi $\left.-\mathrm{nx} y) \div \sqrt{(\Sigma} \mathrm{x}^{2} \mathrm{i}-\mathrm{n} \mathrm{x}^{2}\right)\left(\Sigma \mathrm{y}^{2} \mathrm{i}-\mathrm{n} \mathrm{y}^{2}\right)$.

${ }_{46}$ Diese Daten wurden analog zum Handwerk anhand eines Samples errechnet, das 20 von 64 Einzelhandelszweigen umfaßt und sich ebenfalls auf die Angaben der Kostenstrukturstatistik von 1950 in Verbindung mit der Umsatzsteuerstatistik von 1950 stützt. Der errechnete Korrelationskoeffizient beträgt - 0,23. Es wurden jene Einzelhandelszweige ausgewählt, die sowohl in der Umsatz- als auch in der Kostenstrukturstatistik kategorial übereinstimmten: Einzelhandel mit Gemischtwaren und sonstigen Waren, mit Schokolade, Süßwaren und Speiseeis, mit Oberbekleidung, Wirk- und Strickwaren, mit Kürschnerwaren, mit Leder- und Schuhmacherbedarf, mit Brennmaterial, mit Altwaren, mit Nähmaschinen und Zubehör, mit Büromaschinen und Büromöbeln, mit Fahrrädern, mit Tankstellen, mit Spielwaren, mit Galanterie- und Lederwaren, mit Seifen, Bürstenwaren, Ölen usw., mit optischen und keramischen Instrumenten, Foto- und Kinoapparaten, mit Landmaschinen und landwirtschaftlichen Geräten, mit Rundfunk-, Fernsehund Schallplattengeräten, mit Dreh- und Drechslerwaren usw., mit Musikinstrumenten, mit kunstgewerblichen Gegenständen.

${ }^{47}$ Wie sich die Quote im Einzelhandel bis Anfang der 60er Jahre entwickelte, läßt sich anhand der amtlichen Statistik nicht rekonstruieren. 
nahe, daß die Unterschiede bezüglich der Besitzquote in erster Linie auf Differenzen in der Standortverteilung zurückzuführen sind.

Die meisten zeitgenössischen Erhebungen fragen nicht nach Eigentum an Geschäftsräumen, sondern allgemeiner nach Grund- und Hausbesitz, also nach Gebäuden, die sowohl privat als auch gewerblich genutzt werden konnten. Einer repräsentativen Befragung aus dem Jahre 1963 zufolge besaßen 69\% aller Einzelhändler und 66\% aller Handwerker ein Haus ${ }^{48}$. Nimmt man noch die Großhändler, die freien Berufe sowie die Inhaber von Dienstleistungsbetrieben und mittelständischen Industriebetrieben hinzu, so belief sich die Eigentümerquote auf $66 \%$. Von den einkommensschwächeren Selbständigen (monatliches Nettoeinkommen unter 799 DM) waren 57\% Hausbesitzer. In Wohnorten unter 50000 Einwohnern bezifferte sich der entsprechende Anteil dieser Einkommensgruppe auf $67 \%$, während er in größeren Städten lediglich $39 \%$ betrug. Die Hausbesitzerquote hing also stärker von der Wohnortgröße als von der Einkommenssituation $\mathrm{ab}^{49}$. Hierin ist allerdings keine Besonderheit des selbständigen Mittelstandes zu sehen: in der ländlichen Arbeitnehmerschaft war der Anteil der Hausbesitzer ebenfalls wesentlich höher als in der städtischen ${ }^{50}$. Allerdings war auch in den unteren Gemeindegrößenklassen der Hausbesitz bei Handwerkern und Einzelhändlern verbreiteter als bei Facharbeitern und Angestellten, wenngleich dieser Unterschied auf dem Land geringer war als in der Stadt.

Krisam stellt in seiner 1959 durchgeführten Lokalstudie zu einer mittleren Industriestadt der Rhein-Ruhr-Industrieballungszone fest, daß der Anteil der Hauseigentümer im Handwerk $41 \%$ und im Einzelhandel $32 \%$ betrug, während nur $14 \%$ der Arbeiter (Facharbeiter: 16\%) und 17\% der Angestellten und Beamten ein Haus besaßen ${ }^{51}$. Der Hausbesitzeranteil im gewerblichen Mittelstand liegt hier erheblich niedriger als bei Leverkus/Wieken, doch ändert dies nichts an den Ungleichheitsrelationen gegenüber den anderen Berufsgruppen.

Der Vergleich mit den Arbeitnehmern zeigt, daß das Wohnungs- bzw. Hauseigentum in den späten 1950er Jahren ein nicht allein mit Einkommensdifferenzen zu erklärendes Charakteristikum der selbständigen Mittelstandes war. Diese Schlußfolgerung legt auch eine in Köln durchgeführte Verbraucherstichprobe aus dem Jahre 1958 nahe. Verfügten $37 \%$ der Selbständigen und Freiberufler mit einem monatlichen Familieneinkommen unter $500 \mathrm{DM}$ über ein Haus, so waren es in derselben Einkommensklasse bei den Arbeitern 22\%, bei den Beamten 21\% und bei den Angestellten gar nur $9 \%$. Diese berufsgruppenspezifischen Unterschiede sind vor allem darauf zurückzuführen,

${ }^{48}$ Leverkus/Wieken, S. 52. Hagemanns Ergebnis zur Haus- und Grundbesitzerquote im Lebensmitteleinzelhandel aus dem Jahre 1958 fällt dagegen mit 27,2\% wesentlich niedriger aus - vermutlich weil er großstädtische Verhältnisse untersucht, vgl. Hagemann, S. 257.

${ }^{49}$ Ebenda. Diese Feststellung steht nicht im Widerspruch zu den oben angestellten Berechnungen, die sich nicht auf den Hausbesitz allgemein, sondern auf das Eigentum an Betriebsräumen beziehen.

50 Aus einer 1955/56 durchgeführten repräsentativen Untersuchung geht hervor, daß in Gemeinden bis unter

5000 Einwohnern 54\% der Facharbeiter, 44\% der angelernten Arbeiter sowie $42 \%$ der Angestellten und Beamten „Haus, Garten, Land und Kombinationen aus diesen“ besaßen; vgl. Deenen, S. 60-62. Vgl. ferner Häußermann, Wandel, S. 659.

${ }^{51}$ Krisam, S. 136-138.

52 Tensi, S. 203-213, hier 212. Vgl. ferner Leverkus/Wieken, S. 52. 
daß die selbständigen Mittelständler Hauseigentum nicht nur zu privaten, sondern in erheblichem Umfang auch zu betrieblichen Zwecken nutzten. Hausbesitz bedeutete für die mittelständischen Gewerbetreibenden sowohl existentielle als auch berufliche Sicherheit. Hierin ist allerdings nur mit Blick auf die Arbeitnehmer ein typisches Kennzeichen des gewerblichen Mittelstandes zu sehen. Innerhalb von Handwerk und Einzelhandel waren die Besitzunterschiede nämlich beachtlich. Angesichts dieser Besitzdichotomie im kleingewerblichen Bereich verbietet es sich, das Hauseigentum als charakteristisches Merkmal „des“ Handwerkers oder „des“ Einzelhändlers anzusehen.

Zur langfristigen Entwicklung der berufsspezifischen Hauseigentümerquote liegen nur vereinzelte Daten vor. Legt man Wernets Erhebung aus dem Jahre 1931 zugrunde ${ }^{53}$, so verfügten am Ende der Weimarer Republik rund $49 \%$ der handwerklichen Betriebsinhaber über Hauseigentum. Die regionalen Schwankungen waren beachtlich: Im Handwerkskammerbezirk Passau betrug der Anteil der Hausbesitzer 61\%, während er sich im Kammerbezirk Dortmund auf 33,8\% belief. Wiederum zeigt sich, daß die Besiedlungsdichte bzw. die Wohnortgröße eine entscheidende Determinante für die Verbreitung des Hausbesitzes darstellte ${ }^{54}$. Aufschlußreich sind auch Wernets branchenspezifische Daten: Den höchsten Hausbesitzeranteil hatten die Müller $(73,7 \%)$, die Bäcker $(73,4 \%)$ und die Schmiede (71,7\%). Am niedrigsten war der entsprechende Prozentsatz bei den Schneidern (22,1\%), den Friseuren (22,2\%) und den Putzmacherinnen (26,0\%). Die Gründe für diese handwerksinternen Unterschiede dürften dieselben gewesen sein, die bereits im Zusammenhang mit dem Eigentum an Betriebsräumen erörtert wurden. Wie sich der Hausbesitzeranteil im ersten Nachkriegsjahrzehnt entwickelte, läßt sich aufgrund der fehlenden Quellen nicht rekonstruieren. Der durchschnittliche Einkommenszuwachs in Handwerk und Einzelhandel spricht für die Erhöhung des Hausbesitzeranteils. Wie sich die zunehmende infrastrukturelle Erschließung und Urbanisierung ländlicher Regionen auf die Verbreitung des Hausbesitzes auswirkte, läßt sich schwer abschätzen.

Was den berufsgruppenspezifischen Hausbesitzeranteil betrifft, scheint sich der Unterschied zwischen selbständigen Mittelständlern und Arbeitern in den 50er Jahren kaum verringert zu haben: 1950 verfügten erst $6 \%$ aller Arbeiter über Wohngebäude, 1957 waren es $7-8 \% 55$. Bis 1968 erhöhte sich die Hauseigentümer-Quote auf $32 \%{ }^{56}$,

${ }^{53}$ Wernet, Statistik, S. 40.

${ }^{54}$ Ebenda; in der 5000 Einwohner zählenden Stadt Alsfeld betrug der Hausbesitzeranteil im Jahre $192376 \%$; errechnet nach den Angaben von Cahn, S. 17.

55 Errechnet nach Angaben von Konrad Kratzsch, Arbeitnehmer, S. 116. Bei der Prozentberechnung mußte die Gesamtzahl der Arbeiter für die Jahre 1951 und 1957 geschätzt werden. Die hierdurch möglicherweise bedingten Verzerrungen können die Grundaussage jedoch nicht in Frage stellen.

56 Osterland, S. 170. Die Angaben sind allerdings nur bedingt vergleichbar, da sich der Zahlenwert zum Jahre 1950 auf Eigentum an Wohngebäuden bezieht, während bei der Erhebung von 1968 auch andere Eigentumsformen berücksichtigt wurden. Der Hausbesitzeranteil der Arbeiter fällt - auch im Vergleich zu den Selbständigen - höher aus, wenn man als Bezugsgröße den Haushalt wählt: 1957 betrug er bei Arbeiterhaushalten 22,8\% und bei Haushalten von Selbständigen 66,5\%; vgl. Konrad Kratzsch, Wohnungsversorgung, S. 215. Zur langfristigen Entwicklung gibt es eine neuere Untersuchung zu Bremen, derzufolge 1925 26,2\% und $196823,2 \%$ aller Arbeiterhaushalte über Wohnungseigentum verfügten, vgl. Häußermann/Petrowsky, S. 83. 
was darauf schließen läßt, daß die Nivellierung der Besitzverhältnisse erst in den 60er Jahren ihre wesentlichen Impulse bekam.

Besonders ausgeprägt war die Spartätigkeit der kleinen Selbständigen. Dies kommt in ihren im Vergleich zu anderen Schichten hohen Geldreserven und in der großen Verbreitung von Bausparverträgen zum Ausdruck ${ }^{57}$. Das Sparen auf Hausbesitz war insofern rational, als viele Handwerker und Einzelhändler über keine Alterssicherung verfügten, die der von Arbeitnehmern vergleichbar gewesen wäre. Unter diesen Bedingungen war es notwendig, bereits im Erwerbsleben für den Lebensabend vorzusorgen, und ein eigenes Haus bedeutete in diesem Sinne ein Stück Sicherheit. Interessant ist, daß die Selbständigen in Handwerk und Einzelhandel im Vergleich zu anderen Unternehmern viel seltener Wertpapiere als Anlageform wählten ${ }^{58}$. Diese Zurückhaltung dürfte überwiegend mentalitätsbedingt gewesen sein, zum Teil aber auch auf der Unkenntnis der Anlagemöglichkeiten beruht haben.

\section{Charakteristische Merkmale der mittelständischen Lebensform}

\section{Zum sozialökonomischen Stellenwert der Familie in Handwerk und Einzelhandel}

Im gewerblichen Mittelstand war die ökonomische Bedeutung der Verwandtschaftsbeziehungen stets geringer als in der Landwirtschaft ${ }^{59}$. Nimmt man indes die Verhältnisse in anderen gesellschaftlichen Gruppen zum Maßstab, so kann die Verflechtung zwischen Betrieb und Familie als eines der zentralen Charakteristika der mittelständischen Lebensform gelten. Im folgenden soll der Frage nachgegangen werden, wie sich der räumliche und personelle Zusammenhang von Arbeits- und Privatsphäre in den 50er Jahren entwickelte.

Leverkus/Wieken weisen in ihrer Untersuchung, die auf einer Erhebung aus dem Jahre 1963 basiert, nach, daß 63\% der Handwerker und 56\% der Einzelhändler, die ein Haus besaßen, dieses gewerblich nutzten ${ }^{60}$. In der von Krisam untersuchten Industriestadt betrugen die entsprechenden Anteilswerte 83\% (Handwerker) und 91\% (Einzelhändler) ${ }^{61}$. Sieht man von den Eigentumsverhältnissen ab und fragt lediglich nach der räumlichen Nähe von Betrieb und Wohnung, so stellt sich auf der Grundlage von Krisams Erhebung heraus, daß im mittelständischen Einzelhandel $61 \%$ und im Handwerk $64 \%$ der Betriebsinhaber ihren Betrieb und ihre Wohnung im gleichen Haus hatten. Bei weiteren 11 bzw. 12\% befand sich der Betrieb unmittelbar neben dem Wohnhaus ${ }^{62}$. Rd. drei Viertel der selbständigen Handwerker und Einzelhändler verbrachten ihren Arbeitsalltag also in unmittelbarer Nähe zur Familie. Der überwiegende Teil der abhängig Beschäftigten hatte dagegen, wie eine Umfrage aus dem Jahre 1960 belegt, mittlere (15

\footnotetext{
${ }^{57}$ Leverkus/Wieken, S. $53 \mathrm{f}$.

58 Ebenda, S. $57 \mathrm{f}$.

${ }^{59}$ Mitterauer, S. 190-219. Die Gleichsetzung von Bauern- und Handwerkerfamilie, wie sie beispielsweise von Mitgau (S. 19) vorgenommen wurde, gilt mittlerweile als überholt.

${ }^{60}$ Leverkus/Wieken, S. 52.

${ }^{61}$ Errechnet nach Krisam, S. 136.

62 Krisam, S. 309.
} 
bis 30 Minuten) bis lange Wegzeiten (über 60 Minuten), um von der Wohnung bis zum Arbeitsplatz zu gelangen ${ }^{63}$. Dies erklärt, warum die mittelständischen Betriebsangehörigen, zumal unter der Woche, weit häufiger mit ihrer Familie zu Mittag essen konnten als die Arbeitnehmer ${ }^{64}$. Daß die räumliche Nähe von Privat- und Arbeitsräumen ein Charakteristikum der selbständigen Mittelständler war, erhellt auch aus einer 1955 in Marl durchgeführten Umfrage, derzufolge nur 19,5\% der selbständigen Handwerker und Geschäftsleute ein Verkehrsmittel benutzten, um zur Arbeitsstätte zu kommen. Bei Beamten und Angestellten bezifferte sich der Anteil der Verkehrsmittelbenutzer auf 45 und bei Arbeitern auf über 50\% ${ }^{65}$. Die räumlich bedingte Verflechtung zwischen Arbeits- und Privatleben bedeutete nicht die Aufhebung der innerfamiliären Arbeitsteilung, im Gegenteil: der Anteil derjenigen Männer, die keine Hausarbeiten erledigten, war unter den mittelständischen Betriebsinhabern signifikant höher (72\%) als in der Angestellten- (36\%) und Arbeiterschaft (44\%) ${ }^{66}$. Selbst wenn man die größere zeitliche Arbeitsbelastung der mittelständischen Selbständigen berücksichtigt, spricht viel dafür, diesen Befund als Ausdruck einer patriarchalischen Gesinnung zu deuten. Darüber hinaus steht zu vermuten, daß allein schon wegen der dargestellten räumlichen Gegebenheiten in Handwerkerhaushalten eine arbeitsfreie Privatsphäre weniger weit entwickelt war als in Arbeitnehmerhaushalten.

Geht man von den Ergebnissen der Mittelstandsuntersuchung von 1959 aus, so wich die Struktur der Haushalte mittelständischer Betriebsinhaber in den 1950er Jahren nicht nennenswert von der Haushaltsstruktur der Angestellten und Beamten sowie der gewerblichen Arbeiter ab. Weder die Personenzahl pro Haushalt noch die qualitative Zusammensetzung der Haushaltsmitglieder (Kinder, Ehegatten, andere Verwandte) weisen auf eine Sonderstellung der mittelständischen Selbständigenhaushalte hin ${ }^{67}$.

Ein zentraler Indikator für den Zusammenhang zwischen der Arbeitswelt der Mittelständler und der Lebenswelt ihrer Familien ist die Mitarbeit von Familienangehörigen im Betrieb. Hierbei ist zu unterscheiden zwischen Verwandten, die sich als Gesellen, Lehrlinge oder Angestellte in einem formellen Arbeitsverhältnis befanden, und zwischen mithelfenden Familienangehörigen, die zwar im Betrieb tätig waren, für die aber keine Beiträge zur Angestellten- oder Invalidenversicherung entrichtet wurden. Bei der Beurteilung dieser zweiten Personengruppe gilt es zu berücksichtigen, daß hierin nur Personen enthalten waren, die die mithelfende Tätigkeit beruflich ausübten, $d$. h. diejenigen, die nur gelegentlich im Betrieb aushalfen, wurden nicht als Mithelfende einge-

\footnotetext{
${ }^{63}$ Hartenstein/Liepelt, S. 28.

${ }^{64}$ Ebenda, S. 295.

65 Kieslich, S. 114.

${ }^{66}$ Krisam, S. 296.

${ }^{67}$ Ebenda, S. 271 f. Vgl. ferner Mayntz, Schichtung, S. 127. Vgl. ferner Jürgens, S. 60. Vgl. auch Haack, S. 87, Tab. II, 16: In dieser Untersuchung, die sich schwerpunktmäßig auf Datenmaterial aus den Jahren 1950/51 stützt, finden sich Angaben zur Kinderzahl in Abhängigkeit vom Vaterberuf. Untersuchungsorte waren Essen und Köln. Die kleinen Selbständigen wiesen in bezug auf die Anzahl der Kinder eine ähnliche Häufigkeitsverteilung auf wie die Facharbeiter. Nennenswerte Unterschiede ergaben sich nur im Vergleich mit den ungelernten und angelernten Arbeitern sowie mit den gehobenen Selbständigen: Beide Gruppen wiesen einen höheren Anteil von Familien mit fünf und mehr Kindern auf.
} 
stuft. Dies ist insofern bedauerlich, als gerade die gelegentlichen Aushilfsarbeiten ein wesentliches Charakteristikum der Kleinbetriebe darstellten ${ }^{68}$.

Der relative Anteil mithelfender Familienangehöriger im Betrieb des Familienvorstandes war in den 1950er Jahren, gemessen an der Gesamtbeschäftigtenzahl, sowohl im Handwerk als auch im Einzelhandel leicht rückläufig. Auf 100 im Handwerk beschäftigte Personen entfielen 1931 7,1 mithelfende Familienangehörige $e^{69}$. Bis 1939 stieg dieser Anteil auf 8,4\%. In der Nachkriegszeit setzte offenbar eine Trendwende ein: Der Anteil der mithelfenden Familienbeschäftigten betrug $19507,7 \%$, er reduzierte sich bis 1956 auf $7,5 \%$ und ging schließlich bis 1963 auf $6,9 \%$ zurück $^{70}$. Trotz dieses relativen Rückgangs nahm die absolute Zahl der mithelfenden Familienangehörigen im Handwerk insbesondere zwischen 1949 und 1956 deutlich zu (von 235258 auf 271 547, das ist ein Zuwachs von 15,43\%) ${ }^{71}$. Wenn man die gleichzeitig sinkenden Betriebs- und Inhaberzahlen in Rechnung stellt, ist zu konstatieren, daß die Verflechtung zwischen Familie und Betrieb bzw. Inhaber im Laufe der 50er Jahre enger wurde. Diese Entwicklung deckt sich mit dem säkularen Trend ${ }^{72}$.

Den weitaus größten Anteil mithelfender Familienangehöriger an den Beschäftigten wies im Untersuchungszeitraum die Handwerksgruppe Nahrung auf (1949: 23,9\%, 1950: 23,0\%). In den Bauhandwerken waren dagegen mithelfende Familienangehörige eine Randerscheinung (1949: 3,0\% - 1956: 2,1\%). Hier war auch der Anteil der Frauen unter den mithelfenden Familienangehörigen am niedrigsten (1949: 25,2\% - 1956: 33,3\%). Im Nahrungsmittelhandwerk war der entsprechende Anteil am höchsten (1949: 72,4\% - 1956: 79,9\%). Eine „Verweiblichung“ der mithelfenden Familienangehörigen ist auch in den übrigen Handwerksgruppen festzustellen ${ }^{73}$. Insgesamt stieg im Handwerk der Frauenanteil in dieser Beschäftigtengruppe von 56,1\% im Jahre 1949 auf 66,1\% 1956 und 72,3\% im Jahre 196374. Diese Entwicklung, die vor allem der zunehmenden Mitarbeit der Ehefrauen geschuldet war, stellte gewissermaßen das Pendant zu der in den 50er Jahren zu beobachtenden rapiden Zunahme abhängiger Erwerbsarbeit

${ }^{68}$ Handwerkszählung 1949, Bd. 6, S. 14.

69 Wernet, Statistik, S. 73. Diese Angabe beruht auf einer Stichprobe, von der $38 \%$ aller Handwerksbetriebe erfaßt wurden. Vgl. ferner Wernet, Grundzüge, S. 39; Wernet äußerte in den 60er Jahren die Vermutung, daß in den Vorkriegserhebungen die Zahl der mithelfenden Familienangehörigen zu niedrig ausgewiesen worden sei. Dies erscheint insofern nicht abwegig, als sich die Erhebungsmethoden in der Weimarer Republik von denen in der Bundesrepublik unterschieden. Zum Rückgang des Anteils der mithelfenden Familienangehörigen an den Erwerbspersonen zwischen 1880 und 1970 vgl. Borchardt, Die Bundesrepublik in den säkularen Trends, S. 125.

${ }^{70}$ Handwerkszählung 1949, Bd. 6, S. 8; Handwerkszählung 1956, H. 7, S. 21; Handwerkszählung 1963, H. 4, S. 23.

71 Ebenda. Bis 1963 blieb dann die Zahl der mithelfenden Familienangehörigen in etwa auf dem gleichen Niveau, vgl. Handwerkszählung 1963, H. 4, S. 25.

72 Geiger, Schichtung, S. 85: Im Zeitraum von 1907 bis 1925 erhöhte sich die Zahl der hauptberuflich Mithelfenden in Handwerk und Handel von 3,77 auf 5,44 Mio.

${ }^{73}$ Der Anstieg der weiblichen Mithelfenden-Quote war ein säkularer und - von Ausnahmen abgesehen - ein branchenübergreifender Trend; vgl. Stockmann, Gewerbliche Frauenarbeit, S. 472.

${ }^{4}$ Handwerkszählung 1956, H. 7, S. 35; Handwerkszählung 1963, H. 4, S. 23. 
bei verheirateten Frauen dar 75 . Aus der Arbeiterschaft und der unteren Angestelltenschicht stammende Ehefrauen entschieden sich in der Nachkriegszeit besonders häufig für die Erwerbstätigkeit ${ }^{76}$. Folgt man den Ergebnissen der zeitgenössischen soziologischen Erhebungen, so waren für diese Entwicklung vor allem ökonomische Motive maßgebend. Ungeachtet der Frage, ob vor dem Hintergrund des damaligen Zeitgeistes das Selbstverwirklichungsstreben der Ehefrauen als Beweggrund für die Erwerbstätigkeit unterschätzt wurde ${ }^{77}$, ist grundsätzlich davon auszugehen, daß bei den mithelfenden Ehefrauen derartige Ambitionen eine geringere Rolle spielten als bei lohnabhängigen Ehefrauen.

Die aus der Verbindung von Erwerbs- und Familienrolle erwachsenden Konsequenzen für das familiäre Zusammenleben waren im gewerblichen Mittelstand andere als in der Arbeitnehmerschaft: die gemeinsame Arbeit mit dem Ehegatten bzw. mit der Ehegattin ist hier als Unterscheidungsmerkmal ebenso zu nennen wie der besondere soziale Status der mithelfenden Familienangehörigen im Betrieb und die räumliche Nähe zum Privathaushalt, die die Aushäusigkeit beider Elternteile zur Ausnahme machte. Daß die Entlohnung und die Arbeitszeitregelung nicht zu vergleichen sind, liegt auf der $\mathrm{Hand}^{78}$.

Auf der Grundlage der Handwerkszählung von 1963 läßt sich die quantitative Relation zwischen tätigen Inhabern und mithelfenden Familienangehörigen in den einzelnen Beschäftigtengrößenklassen errechnen. In der Betriebsgrößenklasse mit drei bis vier und fünf bis neun Beschäftigten entfielen auf 100 tätige Inhaber rund 60 mithelfende Familienangehörige. In größeren Handwerksbetrieben (10 bis 19 Beschäftigte) lag die entsprechende Quote bei 50\%. In handwerklichen Kleinstbetrieben (zwei Beschäftigte einschließlich Inhaber) kamen auf 100 tätige Inhaber 46 mithelfende Familienangehörige ${ }^{79} .76 \%$ derjenigen Handwerker, die weder Arbeitnehmer noch Lehrlinge beschäftigten und daher als Alleinmeister bezeichnet werden können, verzichteten auf die Mitarbeit von Familienangehörigen ${ }^{80}$. Dies widerspricht der Vorstellung, gerade die ökonomisch schwächeren Betriebsinhaber seien auf die Mitarbeit von Familienangehörigen angewiesen, „da Rentabilitätsrücksichten in vielen Fällen die Beschäftigung einer fremden Arbeitskraft nicht zulassen"81. Dieser Mechanismus griff schon deshalb nicht, weil die Mehrzahl der Mithelfenden nicht in der Produktion beschäftigt wurde und somit auch keine Gesellen ersetzte. Der hohe Anteil mithelfender Familienangehöriger in den Handwerksgruppen, deren Betriebe in der Regel mit einem Ladengeschäft verbunden waren, deutet vielmehr darauf hin, „daß die mithelfenden Familienangehörigen

\footnotetext{
75 Die Frau in Haushalt und Beruf, in: Wirtschaft und Statistik 6 (1954), S. 326-330; vgl. Schmukker, S. 43: 1950 arbeiteten noch mehr als zwei Drittel der erwerbstätigen Frauen als mithelfende Familienangehörige. Bis 1957 ging dieser Anteil auf 54\% zurück. Die Bedeutung abhängiger Erwerbsarbeit nahm folglich in der Kategorie der erwerbstätigen Ehefrauen zu. Vgl. auch Dunckelmann, passim.

76 Walter Müller, Frauenerwerbstätigkeit, S. 74-81.

77 Sommerkorn, S. 129.

${ }^{78}$ Schmucker, S. 44.

${ }^{79}$ Bei rund der Hälfte der Betriebe mit zwei Beschäftigten handelt es sich im umgangssprachlichen Sinne um Alleinmeisterbetriebe, wenn man darunter Betriebe ohne familienfremde Arbeitskräfte versteht. Die mithelfenden Familienangehörigen werden nämlich als Beschäftigte gezählt; vgl. Handwerkszählung 1963, H. 2, S. 4.

${ }^{80}$ Errechnet nach: Handwerkszählung 1963, H. 2, S. 4.

${ }^{81}$ Brodmeier, S. 75.
} 
hauptsächlich mit Vertriebs- und Verwaltungsarbeiten beschäftigt “ waren ${ }^{82}$. Mit zunehmender Betriebsgröße übernahmen die mithelfenden Familienangehörigen in verstärktem Maße Buchführungstätigkeiten ${ }^{83}$. Einige Handwerkskammern hatten bereits um die Jahrhundertwende kaufmännische Fortbildungskurse für Meisterfrauen eingerichtet $^{84}$. Das Hauptbetätigungsfeld der mithelfenden Frauen lag also - von Ausnahmen abgesehen $^{85}$ - auf dem Gebiet des Verkaufs und der Verwaltung. Da die Kleinstbetriebe gerade in diesen Bereichen unterentwickelt waren, verwundert es nicht, daß dort die Mitarbeit von Familienmitgliedern weniger verbreitet war. Der im Verhältnis zur Inhaberzahl niedrige Anteil der mithelfenden Familienangehörigen in handwerklichen Großbetrieben mit 20 und mehr Beschäftigten ist insbesondere damit zu erklären, daß ab einer gewissen Betriebsgröße die Verwaltungstätigkeit aufgrund der steigenden Komplexität des administrativen Bereichs mehr Zeit und Kenntnisse erforderte und daher die Einstellung professionellen Personals notwendig machte.

Im Einzelhandel lag der Anteil der mithelfenden Familienangehörigen an der Gesamtbeschäftigtenzahl mehr als doppelt so hoch wie im Handwerk. Er ging von 16,02\% im Jahre 1950 auf 13,1\% im Jahre 1961 zurück. Am höchsten war der Anteil der mithelfenden Familienangehörigen im Nahrungs- und Genußmitteleinzelhandel (1950: 21,8\% 1961: 19,53\%), im Einzelhandel mit Kohle und Mineralölerzeugnissen (1961: 16,97\%) und im Einzelhandel mit Papier- und Druckerzeugnissen (1950: 13,92\% - 1961: 13,29\%). Am niedrigsten war der entsprechende Prozentsatz im Einzelhandel mit Fahrzeugen, Maschinen und Büroeinrichtungen (1950: 9,47\% - 1961: 5,73\%) ${ }^{86}$.

Zwischen 1950 und 1961 stieg die Zahl der mithelfenden Familienangehörigen von 204101 auf 270613 an $^{87}$. Der Unternehmensbestand hatte in diesem Zeitraum einen etwas größeren Zuwachs zu verzeichnen ${ }^{88}$. Dies bedeutet, daß im Einzelhandel -anders als im Handwerk - die Verflechtung zwischen mithelfenden Familienangehörigen und Betrieb nicht voranschritt. Vergleicht man dagegen den Anstieg der Inhaberzahlen mit dem der mithelfenden Familienangehörigen, so war der absolute Zuwachs bei letzteren etwas stärker als bei den Betriebsinhabern ${ }^{89}$. Von einer Auflösung der familienbetrieblichen Zusammenhänge kann folglich keine Rede sein ${ }^{90}$. Diese Aussage trifft auch auf der Ebene der Einzelhandelsbranchen zu.

${ }^{82}$ Handwerkszählung 1956, H. 7, S. 21. Vgl. auch Krisam, S. 316, Tab. 27.

${ }^{83}$ Sack, S. 194.

${ }^{84}$ Brodmeier, S. 77. In den 20er Jahren nahm die Buchhaltungstätigkeit der Ehefrauen rapide zu, vgl. Verhandlungen und Berichte, 8. Arbeitsgruppe (Handwerk), Bd. 1, S. 244.

${ }^{85} \mathrm{Im}$ Drechslerhandwerk z. B. arbeiteten die Ehefrauen der Betriebsinhaber auch in der Fertigung mit. Mitte der 50er Jahre verlagerte sich allerdings ihre Tätigkeit auf die immer wichtiger werdende Büroarbeit; vgl. Rodekamp, S. 138.

${ }^{86}$ Errechnet nach Arbeitsstättenzählung 1950, H. 1, S. 98-101; Arbeitsstättenzählung 1961, H. 2, S. 66-71.

${ }^{87}$ Ebenda. Diese Differenz dürfte noch etwas höher ausfallen, wenn man bedenkt, daß in der Erhebung von 1950 zwar West-Berlin, nicht aber das Saarland erfaßt wurde.

${ }^{88}$ Statistisches Jahrbuch 1964, S. 208-211.

${ }^{89}$ Dies hängt damit zusammen, daß der Unternehmensbestand schneller wuchs als die Inhaberzahl. Dies lag vermutlich daran, daß sich der Anteil der Inhaber, die mehrere Unternehmen besaßen, vergrößerte. Zur Entwicklung der Unternehmenszahl vgl. Arbeitsstättenzählung 1950, H. 2, S. 106 ff.; Statistisches Jahrbuch 1964, S. 208-211.

90 Diese These wird von Lutz, S. 221, vertreten. 
Der Anteil der mithelfenden Familienangehörigen korreliert tendenziell negativ mit der durchschnittlichen Betriebsgröße in den einzelnen Einzelhandelsgruppen ${ }^{91}$. Dies ist nicht weiter verwunderlich, da in Betrieben mit hoher Beschäftigtenzahl die begrenzte Zahl mithelfender Familienangehöriger weniger ins Gewicht fällt. Der Betrieb bedurfte allerdings einer gewissen Größe, damit neben dem Ehegatten auch die Kinder mitarbeiten konnten. Hagemanns Ergebnisse zum Lebensmitteleinzelhandel belegen dies. Waren in nur 45,5\% der Betriebe mit einem Jahresumsatz bis 50000 DM Ehepartner mitbeschäftigt, so stieg dieser Prozentsatz in der Umsatzgrößenklasse über 100000 DM auf 85,7\%. Die Beschäftigung der Kinder nahm ebenfalls mit der Umsatzgröße zu (bis 50000 DM: 25,9\% - über 100000 DM 45,5\% $)^{92}$. Wie die Ergebnisse von Greber zeigen, erhöhte sich auch im Schuhmacherhandwerk mit zunehmender Betriebsgröße der Anteil der Betriebe, in denen Familienangehörige mitwirkten ${ }^{93}$.

Wie groß war der Anteil der Betriebe in Handwerk und Einzelhandel, in denen mithelfende Familienangehörige beschäftigt waren? Geht man von Krisams Erhebung aus dem Jahre 1959 aus, so waren lediglich in 37\% der Handwerks- und in 23\% der Einzelhandelsbetriebe keine mithelfenden Familienangehörige beschäftigt ${ }^{94}$. In einigen Handwerksbranchen dürfte der Prozentsatz der Betriebe mit mithelfenden Familienangehörigen an die Verhältnisse im Einzelhandel herangereicht haben (Friseurhandwerk, Nahrungsmittelhandwerk) ${ }^{95}$. Greber weist nach, daß bei der Hälfte der von ihm untersuchten Schuhmacherbetriebe Familienangehörige „mithalfen“. In den umsatzstärkeren Betrieben (über $50000 \mathrm{DM}$ Jahresumsatz) erhöhte sich dieser Wert auf $74 \%{ }^{96}$. Besonders verbreitet war die Mitarbeit von Ehepartnern. Nach den von Krisam ausgewerteten Umfrageergebnissen arbeitete in 49\% der Handwerks- und 59\% der Einzelhandelsbetriebe der Ehepartner des Inhabers im Betrieb mit. Balzer kommt auf der Basis von stichprobenartigen Befragungen aus der ersten Hälfte der 1950er Jahre zu dem Ergebnis, daß etwa in jedem zweiten ländlichen Handwerksbetrieb die Ehefrauen mithalfen"7. Kinder waren - dies zeigt sich in allen Erhebungen - kaum als mithelfende Familienangehörige beschäftigt ${ }^{98}$. Sehr gering war auch der Anteil der mithelfenden Eltern und Schwiegereltern ${ }^{99}$.

${ }^{91}$ Dies trifft auch auf die 20er Jahre zu. 1925 entfielen 83,6\% der mithelfenden Frauen auf Betriebe mit ein bis drei abhängig Beschäftigten; vgl. Haug, S. $16 \mathrm{f}$.

92 Hagemann, S. 100.

${ }^{93}$ Greber, S. 87.

${ }^{94}$ Krisam, S. 318, Tab. 29.

${ }^{95}$ Ebenda, S. 230.

${ }_{96}$ Greber, S. 87.

97 Balzer, S. 238, Tab. 53. In die gleiche Richtung weist das Datenmaterial des Mikrozensus von 1957: Danach waren zwischen $43 \%$ (mit Kindern) bzw. 47\% (ohne Kinder) der Ehefrauen von Selbständigen oder mithelfenden Familienangehörigen (exklusive selbständige Landwirte) erwerbstätig, wobei davon auszugehen ist, daß die außerhäusliche Erwerbstätigkeit in dieser Personengruppe eine Randerscheinung war. Zum Vergleich: Die Erwerbstätigenquote bei den Ehefrauen von abhängig Beschäftigten (gewerblicher Sektor) betrug nur $20 \%$. Zu den statistischen Angaben vgl. Schmucker, S. 45.

${ }^{98}$ Ebenda, S. 240, Tab. 54. Vgl. ferner Krisam, S. 318, Tab. 29. Auch im 19. Jahrhundert spielten Kinder als Arbeitskräfte in Handwerkerhaushalten keine besondere Rolle, was ein zentrales Unterscheidungsmerkmal gegenüber dem bäuerlichen Familientypus darstellt; vgl. hierzu Rosenbaum, S. $163 \mathrm{f}$.

${ }^{99}$ Krisam, S. 318, Tab. 29. 
Im Einzelhandel war - ebenso wie im Handwerk - der Prozentsatz der mithelfenden Familienangehörigen je nach Branche sehr unterschiedlich: im Lebensmitteleinzelhandel z. B. halfen nur knapp 30\% der Ehefrauen bzw. -männer nicht im Geschäft mit. Der überwiegende Teil dieser Ehepartner $(58,8 \%$ ) war mehr als 30 Stunden pro Woche im Geschäft tätig ${ }^{100}$.

Im Einzelhandel waren nur knapp 6\% der Mithelfenden unter 30 Jahren $^{101}$, d. h. daß Kinder von Betriebsinhabern als mithelfende Familienangehörige eine absolute Ausnahme darstellten. Sowohl 1950 als auch 1961 waren die mithelfenden Familienangehörigen in mehr als drei Vierteln der Fälle (78,56\% - 79,34\%) weiblichen Geschlechts ${ }^{102}$. Der Frauenanteil an den mithelfenden Familienangehörigen befand sich damit auf einem ähnlichen Niveau wie im Handwerk. Die Ehefrauen der selbständigen Einzelhändler arbeiteten zu einem wesentlich höheren Prozentsatz, als dies im Handwerk üblich war, als volle Arbeitskraft im Betrieb mit. Bei den Ehemännern weiblicher Betriebsinhaber verhielt es sich ähnlich. Statt im Handwerksbetrieb der Ehefrau mitzuarbeiten, übten viele Ehemänner eine Arbeitnehmertätigkeit, insbesondere einen Arbeiterberuf (rund 50\% der Ehemänner von Meisterinnen), aus ${ }^{103}$. Dies dürfte darauf zurückzuführen sein, daß die weiblichen Betriebsinhaber im Handwerk mehrheitlich in kleinbetrieblich strukturierten Branchen arbeiteten ${ }^{104}$, die keine großen Gewinnspannen aufwiesen (Bekleidungs- und Textilhandwerk, Handwerke für Gesundheits- und Körperpflege) und die darüber hinaus den Mitarbeitern Qualifikationen abverlangten, über die die Ehemänner nicht ohne weiteres verfügten. Dagegen ist wohl im Einzelhandel die Mitarbeit der Ehemänner durch den häufig höheren ökonomischen Anreiz und die geringeren qualifikatorischen Voraussetzungen begünstigt worden. Denkbar ist auch, daß die Berufsstruktur der Ehemänner von Betriebsinhaberinnen in Einzelhandel und Handwerk nicht identisch war und somit einen gewissen Einfluß auf die Bereitschaft und Fähigkeit zur Mitarbeit ausübte.

Um den Stellenwert der Familie im gewerblichen Mittelstand adäquat zu erfassen, ist es notwendig, die Betriebsinhaber zu den mithelfenden Familienangehörigen zu addieren. Der Anteil dieser Beschäftigtengruppen an der Gesamtbeschäftigtenzahl betrug im Handwerk 1939 40, 1949 37,1 und 1956 29,3\%. Bis 1963 ging dieser Anteil auf 24,7\% zurück. Der Grund für diese Abnahme ist insbesondere in dem Rückgang der Einmannbetriebe und dem gleichzeitigen Anstieg der (lohn)abhängig Beschäftigten zu sehen ${ }^{105}$. Im Einzelhandel waren im Jahre 1950 54,72\% und im Jahre 1961 39,1\% aller Beschäftigten familieneigene Arbeitskräfte. Im Einzelhandel mit Nahrungsmitteln lag dieser Anteil überdurchschnittlich hoch (1950: 69,11\% - 1961: 55,93\%) ${ }^{106}$.

${ }^{100}$ Hagemann, S. 97.

101 Berechnet nach dem Handelszensus von 1960, H. 3, S. 63.

${ }^{102}$ Errechnet nach: Arbeitsstättenzählung 1950, H. 1, S. 98-101; Arbeitsstättenzählung 1961, H. 2, S. 66-71.

${ }^{103}$ Krisam, S. $316 \mathrm{f}$.

${ }^{104}$ Handwerkszählung 1963, H. 2, S. 4-37.

${ }^{105}$ Errechnet nach: Handwerkszählung 1949, Bd. 6, S. 8; Handwerkszählung 1956, H. 7, S. 21; Handwerkszählung 1963, H. 4, S. 23.

${ }^{106}$ Arbeitsstättenzählung 1950, H. 1, S. 98-101; Arbeitsstättenzählung 1961, H. 2, S. 66-71. Im ländlichen Einzelhandel waren reine Familienbetriebe, also Betriebe ohne familienfremde Beschäftigte, stark verbreitet, was in bezug auf die familienbetriebliche Struktur der Einzelhandelsunternehmen auf eine beträchtliche Stadt-Land-Differenz hindeutet; vgl. Kappe, S. $155 \mathrm{f}$. 
Ein Teil der Familienmitglieder des Betriebsinhabers hatte nicht den Status der mithelfenden Familienangehörigen, sondern war als Arbeiter, Angestellter oder Lehrling im elterlichen Betrieb beschäftigt. Da die amtliche Statistik keine derartige Kategorie kennt, muß auf die Erhebung von Krisam zurückgegriffen werden. Diese beantwortet allerdings nur die Frage, in wieviel Prozent der Betriebe als Arbeitnehmer beschäftigte Familienangehörige anzutreffen waren: Ende der 50er Jahre bezifferte sich dieser Anteil im Langenberger Handwerk auf $28 \%$ und im Einzelhandel auf $18 \%$. Es dürfte sich hier in der Regel um die Kinder der Betriebsinhaber gehandelt haben. Im Handwerk war der männliche Nachwuchs stärker vertreten als der weibliche, im Einzelhandel verhielt es sich umgekehrt. Mithelfende und beschäftigte Familienangehörige waren insgesamt in $62 \%$ der Handwerksbetriebe und in $78 \%$ der Einzelhandelsbetriebe anzutreffen, d. h. nur in einer Minderheit der mittelständischen Betriebe waren Familienangehörige weder als Arbeitnehmer noch als Mithelfende beschäftigt. Dieses Ergebnis stimmt cum grano salis mit einer Erhebung aus dem Jahre 1964 überein, derzufolge in 38\% der großstädtischen und in 29\% der kleinstädtischen Handwerksbetriebe keine Familienangehörigen als Mithelfende oder als Lohnabhängige beschäftigt waren ${ }^{107}$.

Faßt man die Ergebnisse der statistischen Analyse zusammen, so ist hervorzuheben, $\mathrm{daß}$ die ökonomische Bedeutung der mithelfenden und mitarbeitenden Familienangehörigen in den ersten zwei Nachkriegsjahrzehnten zurückging, was wiederum eine Folge des mit dem durchschnittlichen Betriebsgrößenwachstum einhergehenden Zuwachses an familienfremden Arbeitskräften war. Wählt man indes die einzelnen Haushalte als Bezugsgröße, so ist eine zunehmende Verflechtung von Betrieb und Familie zu konstatieren. Diese Entdifferenzierung zwischen Beruf und Familie war vor allem durch die wachsende Erwerbsbeteiligung weiblicher Familienangehöriger, i.d.R. wohl Ehefrauen, bedingt. Im Einzelhandel war die spezifisch mittelständische Verzahnung zwischen $F_{a}$ milienhaushalt und Arbeitssphäre stärker ausgeprägt als im Handwerk. Im Vergleich zu anderen Berufsgruppen überwogen indes die Gemeinsamkeiten. Als Ursache für die beschriebene Entwicklung kommt insbesondere das Betriebsgrößenwachstum in Betracht, das gerade im administrativen Bereich neue Aufgaben schuf, die vom Betriebsinhaber allein nur schwer zu bewältigen waren. Darüber hinaus mögen die Mitte der 50er Jahre auftretenden Engpässe auf dem Arbeitsmarkt und die daraus resultierende Verteuerung der Arbeitskräfte zusätzlich dazu beigetragen haben, verstärkt auf mithelfende Familienangehörige zurückzugreifen.

\section{Betriebsvererbung}

Weitere Hinweise auf den Grad der Verflechtung zwischen Familie und Betrieb lassen sich aus dem Anteil derjenigen Betriebsinhaber ableiten, die ihren Betrieb nicht selbst gründeten, kauften oder pachteten, sondern von ihren Eltern übernahmen. Die Betriebsvererbung wurde amtlicherseits in der Handwerkszählung von 1963 erfaßt. Demnach waren 61,3\% der zum Zeitpunkt der Erhebung (1.5.1963) bestehenden Betriebe von ihren Inhabern selbst gegründet oder mitgegründet und 38,7\% übernommen worden. Von diesen übernommenen Betrieben wiederum waren $63,6 \%$ vererbt worden oder durch Einheirat an den Inhaber gelangt. Bei $16 \%$ vollzog sich die Betriebsübernahme

${ }^{107}$ Daheim/Kaupen-Haas/Kaupen, Bd. 2, S. 2, Tab. 6. 
im Wege des Kaufs. $15 \%$ der übernommenen Betriebe waren gepachtet worden ${ }^{108}$. Stellt man die Zahl der ererbten und durch Heirat erworbenen Betriebe in Beziehung zu dem gesamten Betriebsbestand, so ergibt sich, daß lediglich jeder vierte Betrieb $(24,6 \%)$ vererbt worden war bzw. auf der Grundlage verwandtschaftlicher Beziehungen den Besitzer gewechselt hatte. Besonders hoch war dieser Anteil im Nahrungsmittel- $(38,1 \%)$ und Holzhandwerk $(35,4 \%)$, besonders niedrig dagegen in den Handwerkgruppen Bekleidung (15,7\%) und Körperpflege $(12,9 \%)^{109}$.

Bevor auf die Ursachen dieser unterschiedlichen Vererbungsquote eingegangen wird, soll zunächst Fleißners Untersuchung, die die differenzierteste dieser Art ist, vorgestellt werden ${ }^{110}$. Auf der Basis von 3463 Handwerkunternehmen, die 1963 im Stadtund Landkreis München bestanden, kommt Fleißner zu dem Ergebnis, daß rund 75\% aller Betriebe Neugründungen darstellten. Die restlichen $25 \%$ hatten einen oder mehrere Vorgänger, wobei diese nicht notwendigerweise Familienmitglieder waren. Der Anteil der Neugründungen schwankte je nach Handwerksgruppe zwischen 31 und 87\%. Im Bekleidungs-, Textil- und Lederhandwerk sowie in den Bau- und Ausbauhandwerken war dieser Prozentsatz am höchsten und im Nahrungsmittelhandwerk am niedrigsten. Diese handwerksinternen Unterschiede hatten mehrere Ursachen. Im Bekleidungshandwerk z. B. wurden alte Betriebe aufgrund ihrer geringen Größe häufig nicht an die nachfolgende Generation bzw. an Handwerkskollegen übergeben, sondern aufgelöst. Im Baugewerbe war die große Zahl der Neugründungen vor allem auf die gute konjunkturelle Situation zurückzuführen. In der Regel hing die Gründungsintensität primär von der Kapitalintensität der jeweiligen Handwerksbranche ab: „Je mehr Kapital zur Errichtung eines Betriebes notwendig ist, desto geringer ist im allgemeinen der Anteil der Neugründungen am Gesamtbestand. " 111 Auf dem Land lag der Anteil der Neugründungen höher als in der Stadt, was Fleißner damit erklärt, daß sich dort im Zuge des Wachstums und der infrastrukturellen Modernisierung der Gemeinden die Handwerkszweige des periodischen Bedarfs (z. B. Friseure, Wäscher, Augenoptiker, Fotografen) erstmals niederließen ${ }^{112}$.

$52 \%$ der im Raum München ansässigen Betriebe, die einen Vorbesitzer hatten, befanden sich seit ihrer Gründung in Familienbesitz. Weitere 38\% wurden nie länger als eine Generation von einer Familie geführt. Die restlichen Betriebe wiesen nur zeitweise eine Familienkontinuität auf. Auf das gesamte Sample übetragen, betrug der Prozentsatz der Betriebe mit ungebrochener Familienkontinuität 13,3\% ${ }^{113}$. Dieser Wert liegt um rund 12 Prozentpunkte niedriger als der aus den amtlichen Erhebungen ermittelte Anteil. Diese Abweichung hängt wahrscheinlich mit der unterschiedlichen Struktur der Erhebungsgebiete zusammen ${ }^{114}$.

\footnotetext{
${ }_{108}$ Handwerkszählung 1963, H. 4, S. 15 f.

${ }^{109}$ Errechnet nach ebenda.

${ }^{110}$ Fleißner, Familienbindung, S. 43-52.

111 Ebenda, S. 46.

112 Ebenda, S. 52.

${ }^{113}$ Ebenda, S. 59.

${ }^{114}$ Genaugenommen ist die Betriebsübergabe an einen Familienangehörigen mit der Vererbung nicht identisch, da der Betrieb auch an einen Familienfremden vererbt werden kann. Quantitativ dürfte dieser Anteil allerdings kaum ins Gewicht fallen.
} 
Der Zusammenhang zwischen Gemeindegröße und Vererbungsquote zeigt sich an Fleißners Daten sehr deutlich: Auf dem Land war der Anteil der Betriebe, die seit ihrer Gründung keinen familienfremden Besitzer hatten, höher als in der Stadt. Zu den Handwerkszweigen, deren Betriebe - soweit sie nicht Neugründungen waren - überwiegend im Familienbesitz verblieben, gehörten das Bau- und Ausbauhandwerk, das metallverarbeitende Handwerk sowie das holzverarbeitende Handwerk. Dagegen wurden im Nahrungsmittelhandwerk, im Gesundheits-und Körperpflegehandwerk sowie im Glas-, Keramik- und Papierhandwerk die Betriebe häufiger von fremden Personen übernommen als von Famlienangehörigen ${ }^{115}$.

Die Familienbetriebe waren im Durchschnitt dreimal so alt wie Betriebe ohne Vorbesitzer und rund 8 Jahre älter als die Betriebe mit familienfremden Vorbesitzern. Hieraus ließe sich schlußfolgern, die ökonomische Stabilität des Unternehmens sei durch die Betriebsvererbung begünstigt worden. Möglicherweise wurden aber auch nur solche $\mathrm{Be}$ triebe den Nachkommen vermacht bzw. von den Erben übernommen, die wirtschaftlich intakt waren und Zunkunftsperspektiven boten ${ }^{116}$.

Einer aus der ersten Hälfte der 50er Jahre stammenden Untersuchung zum ländlichen Handwerk Schleswig-Holsteins ist zu entnehmen, daß die Einheirat in einen Handwerksbetrieb „als Instrument der Betriebsweitergabe von einer Generation in die andere [...] durchaus nicht üblich" war'117. Zu demselben Ergebnis gelangt Kappe in seiner Studie zum ländlichen Einzelhandel118. Wenn die Einheirat auf dem Lande tatsächlich nur von untergeordneter Bedeutung war, ist davon auszugehen, daß diese Form der Betriebsübergabe in der Stadt noch seltener vorkam.

$\mathrm{Daß}$ nicht die Betriebsübergabe an einen zur Familie gehörigen oder familienfremden Nachfolger, sondern die Neugründung von Betrieben die Regel war, zeigt sich auch an einer Regionalstudie über die Veränderung des handwerklichen Betriebsbestandes in den ersten fünf Nachkriegsjahren: demnach betrug im Verwaltungsbezirk Braunschweig der Anteil der Betriebsübernahmen an der Gesamtzahl der Eintragungen in die Handwerksrolle lediglich 26,8\%. Die restlichen 73,2\% entfielen auf Neugründungen $^{119}$. Wie eine Studie zu Südniedersachsen belegt, verringerte sich der Anteil der Neugründungen in der Folgezeit merklich. Dieser Prozeß ging allerdings mit der Abnahme des betrieblichen Fluktuationsvolumens einher, so daß, bezogen auf den gesamten Betriebsbestand, die Veränderungen nicht allzu groß gewesen sein dürften ${ }^{120}$. Inwieweit sich der prozentuale Anstieg der Betriebsübernahmen auf die Betriebsvererbungsquote auswirkte, läßt sich aus diesen Daten nicht ableiten.

Weitere Daten zur Betriebsvererbung im gewerblichen Mittelstand sind einer - allerdings nur bedingt repräsentativen - Erhebung aus dem Jahre $1964 \mathrm{zu}$ entnehmen. 29\%

\footnotetext{
115 Flick, S. 58-65.

${ }_{116}$ Ebenda, S. 70.

117 Balzer, S. 219; im Handwerk der frühen Neuzeit stellte dagegen die Heirat der Meistertochter einen gängigen Weg dar, um in die Zunft aufgenommen zu werden und somit die Selbständigkeit zu erlangen; vgl. Rosenbaum, S. 130.

118 Kappe, S. 217 f. Dieser auf Umfragen aus den Jahren 1956/57 beruhenden Untersuchung zufolge betrug der Prozentsatz der Betriebe, die durch Heirat erworben wurden, nicht mehr als $10 \%$.

119 Wernet/Petersen, S. 26.

120 Flick, S. 39.
} 
der befragten großstädtischen Handwerker hatten ihren Betrieb nicht selbst gegründet, sondern von einem Vorgänger übernommen. 19\% hatten den Betrieb geerbt, $10 \%$ hatten ihn käuflich erworben. In der Kleinstadt bezifferte sich der Anteil der ererbten Betriebe auf 39\%. Diese Form der Betriebsübergabe war hier offenbar verbreiteter als in der Großstadt ${ }^{121}$. Damit wird das von Fleißner konstatierte Stadt-Land-Gefälle bezüglich der Vererbungsquote bestätigt ${ }^{122}$. Im großstädtischen Handel lag der Prozentsatz der ererbten Betriebe mit $24 \%$ nur geringfügig über dem entsprechenden Wert im Handwerk. Im Unterschied zum Handwerk war allerdings die Vererbungsquote der Handelsbetriebe auf dem Lande nicht höher als in der Stadt ${ }^{123}$.

Aufschlußreiche Anhaltspunkte zur Betriebsvererbung im Einzelhandel bietet Hagemanns Untersuchung zum Kölner Lebensmitteleinzelhandel. Die 1959 erfolgte Befragung von 151 Betriebsinhabern dieser Branche ergab, daß jedes vierte Geschäft mindestens in der zweiten (Familien-)Generation betrieben wurde. Umsatzstärkere Betriebe wurden ein wenig häufiger von den Kindern bzw. Schwiegertöchtern und -söhnen übernommen als umsatzschwächere ${ }^{124}$. Im ländlichen Einzelhandel Schleswig-Holsteins betrug Mitte der 50er Jahre der Anteil der Betriebsvererbungen rund ein Drittel ${ }^{125}$, was in etwa dem Kölner Ergebnis und den von Daheim und Mitarbeitern 1964 ermittelten Werten entspricht. Vergleicht man diese lokalen Daten mit der Betriebsvererbungsquote im Handwerk, so fällt auf, daß letztere um mehr als 10\% niedriger lag. Auch Krisams Lokalstudie ergibt, daß die Vererbungsquote im Handwerk etwas geringer war als im Einzelhandel (26 gegenüber $32 \%)^{126}$. Dieser Unterschied fällt allerdings vor dem Hintergrund der Tatsache, daß sowohl im Einzelhandel als auch im Handwerk die Betriebe ohne Familienkontinuität die überwiegende Mehrheit bildeten, kaum ins Gewicht. Wie die festgestellte Quote der Betriebsvererbung in die säkulare Entwicklung einzuordnen ist, läßt sich aufgrund der mangelhaften Datenlage zur ersten Hälfte des 20. Jahrhunderts nur schwer beurteilen ${ }^{127}$. Angesichts der durchschnittlich steigenden Betriebsgröße liegt die Vermutung nahe, daß die Übernahme des elterlichen Betriebes attraktiver wurde. Gleichzeitig wuchsen allerdings auch die Karrierechancen im Angestellten- und Facharbeiterbereich, was wiederum gegen die Weiterführung des elterlichen Betriebs sprach.

\section{Arbeit und Freizeit}

Fragt man nach dem Stellenwert der Arbeit für die Lebensgestaltung, so ist zunächst das quantitative Verhältnis von Arbeitszeit und Freizeit zu rekonstruieren ${ }^{128}$. Im folgen-

121 Daheim/Kaupen-Haas/Kaupen, Bd. 2, S. 2, Tab. 4.

122 Es gibt allerdings auch einen gegenteiligen Befund: Balzer gelangt in seiner Studie zum ländlichen Handwerk in Schleswig-Holstein zu dem Ergebnis, daß nur 17\% der befragten Handwerker ihren Betrieb geerbt hatten; errechnet nach ebenda, S. 217. Dieser vergleichsweise niedrige Wert ist möglicherweise dadurch zu erklären, daß zum Zeitpunkt der Erhebung die Gründungswelle im Handwerk noch anhielt.

${ }^{123}$ Daheim/Kaupen-Haas/Kaupen, Bd. 2, S. 2, Tab. 4.

124 Hagemann, S. 118.

125 Kappe, S. 217 f., Tab. 22 und 23.

126 Krisam, S. 310, Tab. 4.

${ }^{127}$ Bis ins 19. Jahrhundert war die Betriebsvererbung im Handwerk von nachrangiger Bedeutung; vgl. Rosenbaum, S. 163.

${ }_{128}$ Zur Problematik des Begriffs „Freizeit“ vgl. Gerhard Huck, passim. 
den geht es ausschließlich um die tägliche bzw. wöchentliche Arbeitszeit, nicht aber um die Lebensarbeitszeit, die im Zusammenhang mit der Alterssicherung der mittelständischen Selbständigen erörtert werden soll.

Anders als bei der Arbeitnehmerschaft standen sich bei den mittelständischen Gewerbetreibenden Arbeits- und Freizeit nicht in rechtlicher Fixierung separiert gegenüber, sondern waren ineinander verwoben. Eine weitere Besonderheit des gewerblichen Mittelstandes ist in der in zeitlicher Hinsicht außerordentlich hohen Arbeitsbelastung zu sehen. Ende der 50er Jahre arbeiteten - einer lokalen Stichprobe zufolge - $60 \%$ der Handwerker und $66 \%$ der Einzelhändler mehr als 10 Stunden täglich. Bei den Kleinindustriellen betrug der entsprechende Anteil lediglich $42 \%$ und bei den Großhändlern $40 \%$. Ein Arbeitstag unter 8 Stunden stellte für Handwerker und Einzelhändler die absolute Ausnahme dar (rund 5\%). Das gilt auch für die 5-Tage-Woche. Im Unterschied zu den Einzelhändlern, die ihre Arbeitswoche fast vollständig nach den Ladenöffnungszeiten ausrichteten, teilte sich die Mehrzahl der Handwerker (63\%) ihre Arbeitswoche frei ein ${ }^{129}$. Geht man von den Daten aus, die für das Schreinerhandwerk der frühen 60er Jahre vorliegen ${ }^{130}$, so nahm die wöchentliche Arbeitszeit mit der Höhe des Umsatzes zu. Die Gründe hierfür dürften sowohl in der gesteigerten Arbeitsmotivation dieser Handwerker-Unternehmer als auch in der Notwendigkeit zu sehen sein, die in größeren Betrieben verstärkt anfallenden organisatorischen Aufgaben zu bewältigen. Einer Erhebung aus dem Jahre 1967 zufolge hatten nur 6\% der befragten Handwerker eine 40-StundenWoche. $43 \%$ arbeiteten mehr als 60 Stunden pro Woche ${ }^{131}$. Laut einer in Marl 1955 durchgeführten Umfrage machten $73,5 \%$ der selbständigen Handwerker und Geschäftsleute Überstunden. Bei den Angestellten waren es 40,5 und bei den Arbeitern nur knapp $20 \% 132$.

Die tägliche und wöchentliche Freizeit der Handwerker und Einzelhändler war im allgemeinen knapper bemessen als bei Arbeitnehmern ${ }^{133}$. Aus den ausgewerteten Daten läßt sich allerdings nicht ableiten, wie sich die Arbeitsbelastung der Handwerker und Einzelhändler im Untersuchungszeitraum entwickelte, d. h. ob sie im Durchschnitt der Betriebe stieg oder sank. Geht man davon aus, daß sie mit dem Umsatz zunahm, so dürfte sich die Arbeitszeit der selbständigen Mittelständler erhöht haben. Die sich seit Mitte der 50er Jahre langsam, aber stetig reduzierende Arbeitszeit der Arbeitnehmer legt den Schluß nahe ${ }^{134}$, daß das Freizeitbudget immer mehr zu einem Unterscheidungsmerkmal zwischen selbständigen Handwerkern und Einzelhändlern einerseits und Arbeitnehmern andererseits wurde.

Wie wirkte sich die hohe Arbeitsbelastung auf das Urlaubsverhalten der selbständigen Mittelständler aus? Der lokalen Mittelstandserhebung von 1959 ist zu entnehmen,

${ }^{129}$ Krisam, S. 319. Vgl ferner Sack, S. 199. Nach Sacks Erhebungsergebnissen arbeiteten $40 \%$ der befragten Schreiner allein in der Werkstatt mehr als 48 Stunden pro Woche. Hinzu kommt in den meisten Fällen Büroarbeit. Vgl. ferner Daheim/Kaupen-Haas/Kaupen, Bd. 2, S. 9, Tab. 25. ${ }^{130}$ Sack, S. 201.

131 Ellinghaus, S. 170. Die Untersuchungsergebnisse beziehen sich auf folgende Branchen: KfZ-Reparaturhandwerk, Klempnerei, Installation, Heizungsbau.

132 Kieslich, S. 112.

${ }^{133}$ Auf dem Land dürften diese Unterschiede nicht so groß gewesen sein, da dort Mitte der 50er Jahre die wöchentliche Arbeitszeit noch deutlich über 50 Stunden lag; vgl. hierzu Deenen, S. $102 \mathrm{f}$.

${ }^{134}$ Schildt/Sywottek, S. 28. 
daß 40\% der Handwerker und 60\% der Einzelhändler nach eigenen Aussagen nicht beabsichtigten, Urlaub zu machen. Bei den Kleinindustriellen und den Großhändlern betrug diese „Ausfallquote“ rund 30\% ${ }^{135}$. Bei den Arbeitnehmern dürfte dagegen der Urlaubsverzicht die absolute Ausnahme gewesen sein. Das bestätigt auch eine im Jahre 1955 in der westfälischen Industriestadt Marl durchgeführte Umfrage: 12,2\% der Facharbeiter und 17,1\% der Angestellten und Beamten gaben an, im vergangenen Jahr keinen Urlaub gemacht zu haben. Bei den Handwerkern und selbständigen Geschäftsleuten betrug der entsprechende Anteil $77 \%{ }^{136}$.

Auf die Frage, ob sie im letzten Jahr eine große Reise unternommen hätten, antworteten $23 \%$ der Marler Handwerker und Geschäftsleute, 73,5\% der Beamten und Angestellten sowie rund $40 \%$ der Arbeiter mit Ja ${ }^{137}$. Folgt man der 1956 angestellten Erhebung der Gesellschaft für Marktforschung, so lag der Prozentsatz der reisenden Handwerker (35\%) über dem der Arbeiter (25\%) ) $^{138}$. Die Abweichung zwischen den beiden Erhebungen wird man wohl auf die mangelnde Repräsentativität der Marler Stichprobe sowie auf die etwas anders gelagerte Fragestellung zurückführen müssen. Dies legt auch eine repräsentative DIVO-Erhebung aus dem Jahre 1960 nahe. Demnach hatten $70 \%$ der Selbständigen und freien Berufe, 52\% der Angestellten und Beamten sowie $72 \%$ der Facharbeiter keine Urlaubsreise gemacht ${ }^{139}$. Die Angestellten erwiesen sich also am reisefreudigsten, während der Prozentsatz der Reisenden in den Gruppen der Facharbeiter und Selbständigen etwa gleich hoch lag. Die von Krisam ermittelten Daten zur Urlaubsgestaltung beleuchten die Unterschiede im Lager der selbständigen Gewerbetreibenden: der Anteil der mittelständischen Selbständigen, die eine Ferienreise unternahmen, unterschied sich nur geringfügig von dem entsprechenden Anteil der (größeren) Unternehmer.

Geht man nur von denjenigen aus, die sich überhaupt einen Urlaub leisteten, so ist festzustellen, daß die mittelständischen Betriebsinhaber wesentlich seltener daheim blieben als Arbeiter, Angestellte oder Beamte ${ }^{140}$. Der Vergleich mit Freiberuflern und Inhabern mittelständischer Industriebetriebe fällt dagegen negativ aus ${ }^{141}$. Bemerkenswert ist auch, daß die selbständigen Geschäftsleute und Handwerker auf ihren Reisen häufiger Hotels und Pensionen aufsuchten als die Arbeitnehmer, wobei der Unterschied zwi-

135 Krisam, S. 321.

136 Kieslich, S. 116.

137 Ebenda, S. 117.

${ }^{138} \mathrm{Knebel,} \mathrm{S.} \mathrm{76,} \mathrm{Tab.} \mathrm{9.} \mathrm{In} \mathrm{einer} \mathrm{anderen} \mathrm{von} \mathrm{Knebel} \mathrm{zitierten} \mathrm{Erhebung} \mathrm{wurde} \mathrm{der} \mathrm{Anteil} \mathrm{derjeni-}$ gen Personen ermittelt, die 1955 eine mindestens dreitägige Urlaubsreise unternommen hatten. Dabei stellte sich heraus, daß der Anteil der reisenden Arbeiter weit unter dem Bevölkerungsanteil dieser Berufsgruppe lag, während die Selbständigen in Handel und Gewerbe leicht überrepräsentiert waren (ebenda, S. 78). Die Differenz zwischen Arbeitern und Handwerkern ist nur zu einem geringen Teil mit der unterschiedlichen Altersstruktur dieser Berufsgruppen zu erklären. Die jüngeren Altersgruppen waren zwar reisefreudiger als die älteren, doch sind die diesbezüglichen Unterschiede zu gering, um als zentraler Einflußfaktor gelten zu können (ebenda).

139 Der westdeutsche Markt in Zahlen (1962), S. 142. Vgl. auch Jahrbuch für Fremdenverkehr 7 (1959), S. 49. Auch aus dieser Umfrage aus dem Jahre 1958 geht hervor, daß die Reisefreudigkeit der selbständigen Geschäftsleute und Handwerker etwa ebenso gering war wie die der Facharbeiter und unselbständigen Handwerker.

140 Krisam, S. 293.

${ }^{141}$ Leverkus/Wieken, S. 32. 
schen Arbeitern und Selbständigen am größten war (30\% gegenüber $59 \%$ im Jahre 1956) ${ }^{142}$.

Die Vermutung liegt nahe, daß viele Handwerker und Einzelhändler die Entscheidung, in Urlaub zu gehen, zumindest teilweise davon abhängig machten, ob sie sich eine Ferienreise leisten konnten oder nicht. Der Urlaub in den eigenen vier Wänden war offenbar keine erstrebenswerte Alternative. Eine noch wichtigere Rolle dürften freilich wirtschaftliche Überlegungen gespielt haben, war doch eine Urlaubsreise häufig mit einer vorübergehenden Betriebsschließung und damit mit dem Risiko verbunden, Kunden an Konkurrenten zu verlieren ${ }^{143}$.

Die Freizeitgestaltung der Inhaber mittelständischer Betriebe und der Arbeitnehmer wich Ende der 50er Jahre nur in wenigen Punkten voneinander $a^{144}$. Bei der Analyse der Lesestoffe fällt auf, daß die regelmäßige Lektüre von Sportzeitungen sowohl unter weiblichen als auch unter männlichen Betriebsinhabern verbreiteter war als in der Angestellten-, Beamten- und Arbeiterschaft. Dagegen war der Anteil der Arbeitnehmer, die regelmäßig Rundfunksendungen hörten, höher als der entsprechende Prozentsatz der mittelständischen Unternehmer ${ }^{145}$. Rund ein Drittel der mittelständischen Betriebsinhaber hatte kein Hobby. Abgesehen von den Hilfsarbeitern, war dieser Anteil in der Arbeitnehmerschaft um 10 bis $15 \%$ niedriger. Die mittelständischen Betriebsinhaber unternahmen seltener Verwandten-, Bekannten- und Nachbarbesuche als die Arbeitnehmer. Das gleiche gilt für Tanzveranstaltungen ${ }^{146}$. Zum Teil ist dies auf berufsgruppenspezifische Unterschiede in der Altersstruktur zurückzuführen ${ }^{147}$ : Die Betriebsinhaber in Handwerk und Einzelhandel waren im Durchschnitt älter als die Arbeitnehmer, zumal als die Arbeiter, und hatten daher vermutlich auch häufiger eine eigene Familie, was in bezug auf außerhäusliche Freizeitaktivitäten einen Bremsfaktor darstellte.

Der Medienkonsum (Film und Fernsehen) war in den 50er Jahren vor allem in den jüngeren Kohorten (unter 30 Jahren) stark verbreitet ${ }^{148}$. Wie Kieslichs Lokalstudie zu Marl und Reigrotzkis Repräsentativerhebung zeigen, ist auch die Tatsache, daß der Anteil der Kinobesucher unter Handwerkern und Geschäftsleuten geringer war als in der Arbeiterschaft, vor allem mit dem Faktor Alter zu erklären ${ }^{149}$. Als weitere Gründe kom-

${ }^{142}$ Knebel, S. 83, Tab. 16.

${ }^{143}$ Leverkus/Wieken, S. 33. Der Verzicht auf eine Urlaubsreise in den Jahren 1961/62 wurde von dem überwiegenden Teil der befragten Selbständigen damit begründet, geschäftlich unabkömmlich zu sein. Am zweithäufigsten wurden finanzielle Gründe genannt.

${ }_{144} \mathrm{Zu}$ den folgenden Angaben vgl. Krisam, S. 295-300. Unter dem Terminus „mittelständische Betriebsinhaber" werden neben Handwerkern und Einzelhändlern auch Großhändler und Kleinindustrielle subsumiert.

${ }^{145}$ Bei der Interpretation der Daten ist allerdings zu berücksichtigen, daß die mittelständischen $\mathrm{Be}$ triebsinhaber eine andere Altersstruktur aufwiesen als Arbeiter und Angestellte. Dies ist insofern von Bedeutung, als sich die Freizeitgestaltung mit zunehmendem Lebensalter veränderte. Das trifft insbesondere auf den Medienkonsum zu. Vgl. hierzu Hanhardt, S. 86. Vgl. ferner Reigrotzki, Soziale Verflechtungen, S. 199.

${ }^{146}$ Krisam, S. 299; vgl. ferner Reigrotzki, Soziale Verflechtungen, S. 229. Reigrotzkis Ergebnisse zur berufsgruppenspezifischen Häufigkeit des Kinobesuchs beruhen auf einer repräsentativen Stichprobe aus dem Jahre 1953.

${ }^{147}$ Zur Altersabhängigkeit der Freizeitgestaltung vgl. Reigrotzki, Soziale Verflechtungen, S. 199.

148 Reigrotzki, Sozaile Verflechtungen, S. $227 \mathrm{f}$.

${ }^{149}$ Ebenda, S. 229; vgl. Kieslich, S. 12, 50 f. Zur Altersabhängigkeit des Kinobesuchs vgl. ferner Hanhart, S. 147. 
men insbesondere die lange Arbeitsdauer der mittelständischen Betriebsinhaber sowie milieuspezifische Ursachen in Betracht, wobei letztere quellenmäßig nur schwer zu belegen sind.

Vergleicht man die Freizeitgestaltung unserer Untersuchungsgruppen mit der der besserverdienenden Schichten, so fällt auf, daß Handwerker und Einzelhändler nicht durch „demonstrativen Erfahrungskonsum “ gekennzeichnet waren ${ }^{150}, \mathrm{~d}$. h. exklusive, außerhäusliche Freizeitaktivitäten wie Tennis, Segeln, Filmen usw. wurden nur von einer Minderheit der kleinen Selbständigen betrieben.

Alles in allem sind die altersunabhängigen Unterschiede zwischen mittelständischen Betriebsinhabern und abhängig Beschäftigten bezüglich der Freizeitgestaltung nicht groß genug, um sie als Kennzeichen einer unterschiedlichen Soziallage interpretieren zu können. Die hohe zeitliche Arbeitsbelastung kann dagegen durchaus als Charakteristikum des gewerblichen Mittelstandes gelten, wenngleich sich die Schere zwischen dem Freizeitbudget der selbständigen Mittelständler und Arbeitnehmer in unserem Untersuchungszeitraum erst langsam zu öffnen begann. Angesichts der durch die Arbeitszeitverkürzungen der ausgehenden 50er Jahre allmählich in Gang kommenden Ausweitung der Freizeit für die Masse der Arbeitnehmerschaft dürfte sich unter den mittelständischen Selbständigen das Bewußtsein, einen Sonderstatus innezuhaben, verstärkt haben.

\section{Wobnqualität und Konsumgüterausstattung}

Das Niveau der Wohnverhältnisse wird sowohl durch den äußeren Zuschnitt des Wohnraums als auch durch die Wohnausstattung bestimmt. Die Wohnverhältnisse können überall dort - mit Bezug auf den Wohnstandard der Arbeiterschaft - als proletaroid bezeichnet werden, wo eine hohe Wohndichte, eine Wohnküche und kein wohnungseigenes Bad vorhanden sind ${ }^{151}$. Die Besitzverteilung von langlebigen Konsumgütern gibt nicht nur Auskunft über unterschiedliche Wohnbedingungen, sondern indiziert darüber hinaus die berufsspezifischen Unterschiede des materiellen Lebensstandards.

Die Befragung eines repräsentativen Samples der westdeutschen Bevölkerung im Jahre 1959 ergab, daß 46\% der Handwerker und 31\% der Händler maximal ein Wohnraum pro Person zur Verfügung stand. Bei den unteren Beamten und Angestellten betrug der entsprechende Anteil 54\% und bei den Facharbeitern sowie un- und angelernten Arbeitern jeweils $66 \%$. Über ein eigenes Bad verfügten $46 \%$ der Handwerker und $70 \%$ der Händler. Bei den unteren Angestellten belief sich der Anteil der Badbesitzer auf $46 \%$. In der Gruppe der Facharbeiter (34\%) und un- und angelernten Arbeiter war ein eigenes $\mathrm{Bad}$ noch seltener vorhanden ${ }^{152}$.

150 Kätsch, S. 105.

$151 \mathrm{Zu}$ diesen idealtypischen Merkmalen des Arbeiterwohnens vgl. Mooser, S. 147. Vgl. ferner Gransche/Wiegand, S. $442 \mathrm{f}$.

152 Daheim, Vorstellungen, S. 277, Tab. VI. Bei der Berechnung der Wohnräume pro Person wurden als Bezugsgröße nur die Haupternährer und deren Ehefrauen zugrunde gelegt. Die Kategorie "Händler “ umfaßt neben den Einzelhändlern auch andere, ökonomisch bessergestellte kaufmännische Berufe. Vermutlich weichen die präsentierten Anteilswerte dieser Kategorie deshalb so deutlich von denen der Handwerker ab. Weitere Angaben zum Anteil der Badbesitzer in der Arbeiter- und Angestelltenschaft finden sich in: Der westdeutsche Markt (1962), S. 70. Diese Daten, die aus dem Jahre 1961 stammen, stimmen grundsätzlich mit den hier referierten Ergebnissen überein. $\mathrm{Zu}$ den allgemeinen Wohnverhältnissen vgl. Silbermann, passim. 
Die von Krisam zur gleichen Zeit in Langenberg durchgeführte Erhebung bestätigt diese Ergebnisse. Auch hier war der Wohnraum pro Person bei Inhabern mittelständischer Betriebe durchschnittlich größer als bei Arbeitnehmern, wobei der Unterschied zwischen den Betriebsinhabern und den Angestellten und Beamten kleiner war als zwischen letzteren und den Arbeitern ${ }^{153}$. In knapp der Hälfte der Wohnungen mittelständischer Betriebsinhaber gab es weder ein Badezimmer (53\%) bzw. eine Toilette (58\%) noch eine separate Kochküche (52\%). Bei den Angestellten lagen die entprechenden Prozentsätze um rund 10\% und bei den Facharbeitern um rund 20\% höher ${ }^{154}$. Lediglich in bezug auf die wohnungseigene Toilette waren die Unterschiede geringer. Diese Daten zeigen, daß auch noch Ende der 50er Jahre in bezug auf den äußeren Zuschnitt des Wohnraumes z.T. erhebliche berufsspezifische Unterschiede bestanden. Darüber hinaus wird deutlich, wie unterschiedlich die Wohnverhältnisse innerhalb der Handwerkerschaft und der Gruppe der Einzelhändler waren.

Wie Hagemanns Erhebung (1958) zum Lebensmitteleinzelhandel zeigt, hingen die Wohnverhältnisse in starkem Maße vom Einkommen bzw. Umsatz ab. Verfügten in der Umatzgrößenklasse über $100000 \mathrm{DM} 80,6 \%$ der Lebensmittel-Einzelhändler über ein eigenes Bad, so waren es in der Umsatzgrößenklasse bis 50000 DM lediglich $30 \% 155$, d. h. die schlechter verdienenden Einzelhändler befanden sich, was die Ausstattung mit einem Bad betrifft, in einer ähnlichen Lage wie die Facharbeiter.

Die Besitzhäufigkeit langlebiger Gebrauchsgüter war im Handwerk und Einzelhandel in der ersten Hälfte der 1960 er Jahre nahezu identisch. Die Unterschiede zu anderen Selbständigengruppen fielen dagegen deutlicher aus. Die Haushalte von Inhabern mittelständischer Industriebetriebe und Freiberuflern zeichneten sich in ihrer Gesamtheit insbesondere durch einen höheren Standard an Wohnkomfort (Bücherschrank, Fernsehgerät, Zentralheizung, Toaster, Servicewagen) aus. Im Jahre 1963 waren z. B. 69\% der Haushalte von mittelständischen Industriellen und 60\% der Haushalte von Freiberuflern mit einer Zentralheizung ausgestattet. Im Handwerk bezifferte sich der entsprechende Anteil zum gleichen Zeitpunkt lediglich auf 26\% und im Einzelhandel auf $28 \%$. Fast genauso groß waren die Unterschiede beim persönlichen Besitz (PKW, Telefon, private Schreibmaschine, Rasenmäher ${ }^{156}$.

Stellt man in Rechung, daß der Besitz langlebiger Konsumgüter bei Handwerkern und Einzelhändlern im Durchschnitt etwas weniger verbreitet war als bei den Selbständigen insgesamt, so läßt sich mit Hilfe der amtlichen Statistik von 1962 die Konsumgüterausstattung der Haushalte von Handwerkern und Einzelhändlern einerseits und der Arbeitnehmerhaushalte andererseits näherungsweise vergleichen. Dabei zeigt sich, daß bei der Mehrzahl der langlebigen Gebrauchsgüter keine nennenswerten berufsgruppenspezifischen Besitzunterschiede bestanden. Die diesbezügliche Ungleichheit war i.d.R. zwischen Selbständigen- und Angestelltenhaushalten geringer als zwischen letzteren

\footnotetext{
${ }^{153}$ Krisam, S. 158.

154 Ebenda, S. 160. Zur Wohnausstattung der Facharbeiter und Angestellten vgl. auch Osterland, S. 180: demnach verfügten im Jahre 1958 45\% der Angestellten und $23 \%$ der Facharbeiter über eine Wohnung mit Bad.

${ }^{155}$ Hagemann, S. 274.

${ }^{156} \mathrm{Zu}$ den Zahlenangaben vgl. Leverkus/Wieken, S. 47.
} 
und Arbeiterhaushalten ${ }^{157}$. Auf die berufsgruppenspezifische Verteilung von PKWs und Telefonen treffen diese Aussagen allerdings nicht zu. In Selbständigenhaushalten waren diese beiden Güter wesentlich häufiger anzutreffen als in Haushalten von Arbeitnehmern ${ }^{158}$. Die Ergebnisse der bundesweit durchgeführten DIVO-Erhebung von 1959 weichen in nur einem Punkt von diesem Befund ab: demnach besaßen zu diesem Zeitpunkt 13\% der un- und angelernten Arbeiter sowie 21\% der Facharbeiter einen Kühlschrank. Bei den Handwerkern (39\%) und Händlern (59\%) lag der Anteil der Kühlschrankbesitzer signifikant höher ${ }^{159}$. Diese Daten zeigen, daß in bezug auf den Kühlschrankbesitz die Nivellierung zwischen Arbeitern und selbständigen Mittelständlern Ende der 50er Jahre noch nicht abgeschlossen war. Einer DIVO-Umfrage aus dem Jahre 1958 ist zu entnehmen, daß der Fernseherbesitz bei Selbständigen und Freiberuflern zwar am weitesten verbreitet war (20\%), daß jedoch die entsprechende Quote der Angestellten und Beamten (jeweils 13\%) sowie der Arbeiter (12\%) nur unwesentlich niedriger lag ${ }^{160}$. Wie die amtliche Konsumgütererhebung von 1962 zeigt, wurden in den folgenden Jahren die diesbezüglichen Ungleichheiten zwischen den Berufsgruppen fast völlig eingeebnet ${ }^{161}$.

Verringerten sich im Untersuchungszeitraum die zwischen selbständigen Mittelständlern bestehenden Unterschiede in der PKW-Besitzquote? Wählt man die absolute Differenz zwischen den PKW-Besitzanteilen der Handwerker und Einzelhändler einerseits und der Arbeiter und Angestellten andererseits als Maßstab, so ist festzustellen, daß die Ungleichheit der PKW-Besitzverteilung in den Jahren 1960 bis 1962 ihren Höhepunkt erreichte. Sieht man von der Möglichkeit des Mehrfachbesitzes ab, ergibt sich im Handwerk im Jahre 1951 eine PKW-Eigentümerquote von rund 9\%. Im Einzelhandel war der Anteil der Besitzer um rund 10 bis $20 \%$ höher. Bei den Angestellten und Arbeitern lag der entsprechende Wert zur selben Zeit unter einem Prozent. In der frühen Bundesrepublik war also sowohl im gewerblichen Mittelstand als auch in der Arbeitnehmerschaft der Autobesitz eine Randerscheinung. Bei den Kleingewerbetreibenden begann sich dies in der zweiten Hälfte der 1950er Jahre zu ändern. Im Jahre 1958 verfügten rund $40 \%$ und im Jahre 1961 rund $52 \%$ aller Handwerker über einen PKW. Im Einzelhandel dürfte dieser Stand jeweils zwei bis drei Jahre früher erreicht worden sein. Im Jahre 1965 besaß die überwiegende Mehrheit der Handwerker (rund 60\%) und der Einzelhändler (rund 70\%) ein eigenes Auto. Demgegenüber besaß 1958 jeder fünfundzwanzigste, 1961 jeder zehnte und 1965 jeder fünfte Arbeiter ein Auto. Bei den Angestellten lagen die entsprechenden Prozentsätze zu den jeweiligen Zeitpunkten rund 5\% hö-

\footnotetext{
157 Statistisches Jahrbuch 1964, S. 530; vgl. ferner Der westdeutsche Markt (1962), S. 88. Auch im Kaiserreich bestanden zwischen den Wohnungsausstattungen von selbständigen Handwerkern und Facharbeitern allenfalls quantitative, nicht aber die Art der Einrichtung betreffende, qualitative Unterschiede; vgl. Schomerus, S. 211-232.

158 Statistisches Jahrbuch 1964, S. 530.

${ }^{159}$ Daheim, Vorstellungen, S. 276, Tab. V.

160 Der westdeutsche Markt (1958), S. 112.

161 Statistisches Jahrbuch 1964, S. 530.
} 
her. ${ }^{162}$ Bezüglich des PKW-Eigentums läßt sich folglich erst seit Mitte der 60er Jahre von einer spürbaren Nivellierung des Unterschiedes zwischen selbständigen Mittelständlern und Unternehmern sprechen. Die DIVO-Erhebung von 1959 weist den Autobesitz von Facharbeitern sowie un- und angelernten Arbeitern separat aus. Die Besitzquote dieser beiden Arbeitergruppen wies nur geringe Unterschiede auf. Sie betrug bei den un- und angelernten sechs und bei den Facharbeitern acht Prozent ${ }^{163}$. An dem Gesamtbefund ändert sich folglich nichts.

Ein ähnliches Muster der Ungleichheitsentwicklung scheint auch bei der Verbreitung des Telefonbesitzes vorgelegen zu haben. Laut der DIVO-Erhebung verfügten Ende der 50er Jahre lediglich 3\% der Arbeiter sowie 12\% der unteren Angestellten und Beamten über ein Telefon. Bei den Händlern belief sich dieser Anteil auf 53 und bei den Handwerkern auf 34\% ${ }^{164}$. Bis zum Frühjahr 1960 stagnierte in der Arbeiterschaft der Prozentsatz der Telefonbesitzer, während er bei den Selbständigen (ohne Landwirte) offenbar stieg ${ }^{165}$.

Berufsgruppenspezifische Unterschiede manifestierten sich nicht nur im Besitz oder Nichtbesitz eines Konsumgutes, sondern auch in dessen Qualität. Am PKW-Eigentum läßt sich dies exemplarisch untersuchen. Der Anteil der Kleinstwagenbesitzer (bis 499 ccm Hubraum) war im gesamten Untersuchungzeitraum in der Arbeiterschaft signifikant höher als bei Angestellten, Handwerkern und Einzelhändlern. In der zweiten Hälfte der 50er Jahre nivellierten sich die Unterschiede allerdings spürbar: Waren im Juli 1957 noch 31,42\% aller Arbeiter, die ein Auto besaßen, Eigentümer eines Kleinstwagens, so verringerte sich dieser Anteil bis Juli 1961 auf 21,19\%. Im Handwerk ging der Anteil der Kleinstwagenbesitzer im selben Zeitraum von 7,8 auf 5,35\% und im Einzelhandel von 4,85 auf $2,77 \%$ zurück ${ }^{166}$.

Innerhalb der mittelständischen Berufsgruppen hing der PKW-Besitz stark von der Betriebsgröße ab. Im Einzelhandel des Jahres 1949 z. B. besaßen nur 3,61\% der Inhaber von Alleinbetrieben ein Auto. In der Betriebsgrößenklasse von zwei bis neun Beschäftigten

162 Errechnet nach: Statistisches Jahrbuch 1952, S. 300; Statistisches Jahrbuch 1956, S. 327; Statistisches Jahrbuch 1959, S. 308; Statistisches Jahrbuch 1960, S. 354; Statistisches Jahrbuch 1961, S. 359; Statistisches Jahrbuch 1962, S. 361; Statistisches Jahrbuch 1963, S. 351; Statistisches Jahrbuch 1966, S. 365. Die Schätzung der Gesamtzahl der Arbeiter und Angestellten zu den jeweiligen Zeitpunkten beruht auf den Volkzählungen von 1951, 1961 und 1970; vgl. Ritter, Wahlen, S. 36. Zum Handwerk vgl. Handwerkszählung 1949, Bd. 6, S. 9; Handwerkszählung 1956, H. 7, S. 24; Handwerkszählung 1963, H. 4, S. 25 . Zum Einzelhandel vgl. Arbeitsstättenzählung 1950, H. 1, S. 98 f.; Arbeitsstättenzählung 1961, H. 2, S. 66 f. Den Schätzungen liegt die Annahme zugrunde, daß sich die Zahl der tätigen Inhaber zwischen den Zählungsjahren kontinuierlich entwickelte. Zur allgemeinen Entwicklung des PKW-Bestandes vgl. Wirtschaft und Statistik, H. 1, S. 52-54.

${ }^{163}$ Daheim, Vorstellungen, S. 276, Tab. V. In der von Krisam 1959 untersuchten Kleinstadt lagen die entsprechenden Werte etwas höher: demnach verfügten $20 \%$ der männlichen Facharbeiter mittelständischer Betriebe und $11 \%$ der in mittelständischen Betrieben beschäftigten männlichen Hilfsarbeiter über PKW-Eigentum. Bei den Frauen betrugen die entsprechenden Anteile 15 bzw. 9\%; vgl. Krisam, S. 144.

164 Daheim, Vorstellungen, S. 276, Tab. V.

${ }^{165}$ Statistisches Jahrbuch 1964, S. 530. Die vorsichtige Formulierung rührt daher, daß die Kategorien der beiden Erhebungen nur bedingt übereinstimmen.

${ }^{166}$ Errechnet nach: Kraftfahrt-Bundesamt, Bestand 1. Juli 1957, S. 39; Dass., Bestand 1. Juli 1961, S. 61. Vgl. auch Siebke, S. 76 . 
betrug die Eigentümerquote $13,39 \%$. Erst in dem Interverall von 10 bis 49 Beschäftigten stieg sie auf $67,34 \%{ }^{167}$. Diese Ergebnisse verdeutlichen zum einen die Einkommensabhängigkeit des PKW-Besitzes innerhalb der mittelständischen Berufsgruppen. Zum anderen fällt auf, daß selbst unter den Inhabern von Einmannbetrieben der Anteil der Autobesitzer höher war als in der einkommensmäßig nicht bessergestellten Arbeiterschaft. Darauf deutet auch eine Verbraucherstatistik aus dem Jahre 1959 hin, derzufolge in der Einkommensklasse bis 500 DM (Familieneinkommen) 22\% der Selbständigen und Freiberufler, jedoch nur 5\% der Arbeiter, Angestellten und Beamten ein Auto besaßen ${ }^{168}$. Dieser Befund ist in erster Linie damit zu erklären, daß die Selbständigen das Auto auch zu geschäftlichen Zwecken benötigten, während es die abhängig Beschäftigten vor allem als Transportmittel für den Weg zur Arbeit nutzten ${ }^{169}$. Eine weiterer Erklärungsfaktor ist nach Auffassung von Beckermann in dem „Prestigebewußtsein der Handwerker" zu sehen, das sich „wohl am deutlichsten in der Wagenhaltung “ zeige $^{170}$.

Die PKW-Besitzquoten der einzelnen Handwerks- und Einzelhandelsbranchen wichen z.T. deutlich voneinander ab. Folgt man den lokalen Umfrageergebnissen von Krisam, so waren im Jahre $195981 \%$ der Bau-, Holz-, Metall- und Elektrohandwerker Eigentümer eines PKW oder Kombiwagen, während die entsprechenden Anteile im Friseur- $(40 \%)$ sowie im Textil- und Lederhandwerk (18\%) signifikant niedriger lagen. Im Einzelhandel waren die branchenspezifischen Unterschiede etwas geringer: Die Lebensmitteleinzelhändler lagen hier mit einem Anteil von $76 \%$ an der Spitze, während die Textil- und Ledereinzelhändler mit $54 \%$ das Schlußlicht bildeten ${ }^{171}$. Trotz dieser recht großen handwerks- und einzelhandelsinternen Differenzen bleibt festzuhalten, daß im überwiegenden Teil der Branchen die PKW-Eigentumsquote wesentlich höher lag als in der Facharbeiterschaft und in der Gruppe der Angestellten und Beamten ${ }^{172}$.

Welche Rolle spielte das Einkommen für den Erwerb langlebiger Konsumgüter im allgemeinen? Nach den Ergebnissen der Einkommens- und Verbrauchsstichprobe von 1962/63 ergaben sich bei Haushalten von Selbständigen und Arbeitnehmern innerhalb gleicher Einkommensgruppen „sowohl hinsichtlich der Höhe als auch der Verteilung der Verbrauchsausgaben keine allzu großen Unterschiede“ ${ }^{173}$. 1962 lagen die Ausgaben der Arbeitnehmer für Verkehr und Nachrichtenübermittlung in Relation zum Einkommensniveau sogar über denen der Selbständigen, was vermutlich auf den Nachholbedarf der Arbeitnehmer zurückzuführen ist ${ }^{174}$.

\section{Soziale Beziehungen der selbständigen Handwerker und Einzelbändler}

Die Untersuchung der Lebensbedingungen läßt nur begrenzt Rückschlüsse darauf zu, inwieweit Handwerker und Einzelhändler Eigenschaften sozialer Gruppen aufwiesen.

\footnotetext{
167 Arbeitsstättenzählung 1950 (Bd. 45), H. 1, S. 113.

168 Tensi, S. 203-213.

${ }^{169}$ Siebke, S. 71. Die Daten, die diese Aussage belegen, stammen aus der zweiten Hälfte des Jahres 1960. Zur Art der PKW-Nutzung vgl. auch Der westdeutsche Markt (1962), S. 141.

170 Beckermann, Auslese, S. 50.

171 Krisam, S. 144.

172 Ebenda, S. 142 (vgl. Anm. 130).

173 Wirtschaft und Statistik 1965, H. 8, S. 492.

174 Ebenda.
} 
Um dies festzustellen, bedarf es einer Analyse der innerhalb der mittelständischen Berufsgruppen bestehenden sozialen Kontakte. Dabei ist grundsätzlich zwischen zweckrationalen, geschäftsmäßigen Beziehungen und affektiven Bindungen zu unterscheiden. Es geht also um die Frage, ob die Berufsgruppen des alten Mittelstandes in der Nachkriegszeit vornehmlich Gemeinschaften oder Zweckverbände waren und inwieweit sich diese berufsgruppeninternen Beziehungsmuster im Zeitverlauf veränderten ${ }^{175}$.

Als Indikatoren für die berufsgruppenspezifische Selektivität der Sozialbeziehungen kommt neben dem Heirats- und Freundschaftsverhalten die Teilnahme an gesellschaftlichen Organisationen in Betracht ${ }^{176}$. Hierunter sind Freizeitvereine, kirchliche Institutionen, politische Organisationen und Berufsverbände zu verstehen. Die folgende Darstellung läßt sowohl die quellenmäßig nur schwer faßbaren Heiratsbeziehungen als auch die Beteiligung an politischen Organisationen, die in einem anderen Kontext erörtert werden soll, unberücksichtigt. Die Berufsorganisationen werden auf ihre soziale Funktion hin untersucht, wobei es insbesondere um die Frage geht, inwiefern die lokalen Berufsverbände über die sozialen und wirtschaftlichen Unterschiede ihrer Mitgliederschaft hinweg zur Entstehung bzw. zur Erhaltung eines wie auch immer gearteten Gemeinschaftsbewußtseins beitrugen. Die Analyse der außerberuflichen sozialen Beziehungen zielt darauf $a b$, das Ausmaß der gesellschaftlichen Integration von Handwerkern und Kleinhändlern zu bestimmen.

\section{Zur gemeinschaftsbildenden Funktion der Berufverbände}

Die Innungen hatten als örtliche Zusammenschlüsse selbständiger Handwerker gleicher Fachrichtung eine zentrale Stellung in der Handwerksorganisation inne. Sie lösten sich Mitte des 19. Jahrhundert in zunehmendem Maße von der zünftischen Tradition und nahmen immer mehr den Charakter ökonomischer Interessenvertretungen an ${ }^{177}$. Es ist nicht zuletzt den sozialpolitischen Funktionen der Innungen zuzuschreiben ${ }^{178}$, $\mathrm{da} ß$ unter den Bedingungen der Gewerbefreiheit das soziale Zusammengehörigkeitsbewußtsein in der von großen ökonomischen und soziokulturellen Unterschieden geprägten Handwerkerschaft nicht vollkommen erodierte. In erster Linie sind hier zu nennen soziale Hilfeleistungen wie Krankenunterstützung, Pensionskassen und Sterbegeld sowie die den Innungen obliegende Regelung der Lehrlingsausbildung. Gewiß, die sozialen Unterschiede zwischen reichen und armen Handwerkern führten dazu, daß letztere den Innungen häufig fernblieben ${ }^{179}$. Doch spätestens seit der Einführung des Instituts der fakultativen $Z$ wangsinnung im Jahre 1897 und dem Beginn der mittelständischen Sammlungspolitik befand sich die Innungsbewegung im Aufschwung. Durch die Einführung der Pflichtinnung im Dritten Reich wurden schließlich alle selbständigen Handwerker zwangsweise Mitglieder der weitgehend gleichgeschalteten Innungen ${ }^{180}$.

175 Anm. 2.

176 Zum theoretischen Hintergrund vgl. Bolte/Hradil, S 306f. Vgl. ferner Mohr, S. 157-176.

177 Lenger, Sozialgeschichte, S. 104.

${ }^{178}$ Kocka, Arbeitsverhältnisse, S. 323.

179 Lenger, Sozialgeschichte, S. 156.

180 Zur beherrschenden Stellung der Innungen und Handwerkskammen im Dritten Reich vgl. Saldern, S. 127-131. 
Nach 1945 wurde mit Ausnahme der französischen Zone die Zwangsmitgliedschaft in den Westzonen abgeschafft ${ }^{181}$. In der Handwerksordnung von 1953 wurde die Pflichtmitgliedschaft schließlich endgültig beseitigt. Trotz der freiwilligen Mitgliedschaft ging der Anteil der in den Innungen organisierten Handwerker nur unwesentlich zurück. Im Jahre 1949 gehörten in den Westzonen 91,1\% aller selbständigen Handwerker einer Innung an. Das waren rund $20 \%$ mehr als $1926(70,9 \%)^{182}$. Den höchsten Organisationsgrad hatten die Nahrungsmittelhandwerke $(95,15 \%)$ und den niedrigsten die papierverarbeitenden, keramischen und sonstigen Handwerke $(83,61 \%)$ zu verzeichnen ${ }^{183}$. In der amerikanischen Zone war der Anteil der Innungsmitglieder deutlich geringer als in der britischen. Bereits in der Weimarer Republik wiesen die süddeutschen Landesteile gegenüber den Regionen nördlich des Mains eine erheblich schwächere Innungsbesetzung auf, was vor allem daran lag, daß in den norddeutschen Ländern die Zwangsinnungen wesentlich verbreiteter waren ${ }^{184}$. Weshalb die süddeutschen Zwangsinnungen keinen ähnlichen Aufschwung nahmen wie im Norden, ist allerdings eine offene Frage. In der Nachkriegszeit prägte sich das Nord-Süd-Gefälle bezüglich des Innungsorganisationsgrades vorübergehend noch stärker aus. Die entscheidende Ursache hierfür ist in der 1948 in der amerikanischen Zone eingeführten Gewerbefreiheit zu sehen, die zu einem Zustrom von „handwerksfremden Kräften“ führte, worunter Personen zu verstehen sind, die aufgrund ihrer Ausbildung und ihrer Herkunft keine Beziehung zur Handwerksorganisation hatten. Die Handwerksorganisation versuchte ihrerseits, wie oben dargestellt, alle diejenigen vom Markt fernzuhalten, die ohne entsprechende Qualifikation in die Selbständigkeit drängten.

Bis 1956 ging der Innungsorganisationsgrad bundesweit um fast $10 \%$ auf $81,3 \% \mathrm{zu}-$ rück ${ }^{185}$. Gleichzeitig verringerte sich die Differenz zwischen den ehemaligen „amerikanischen" Ländern und den restlichen Bundesländern merklich. Die Nivellierung des Nord-Süd-Gefälles läßt sich dadurch erklären, daß ein Großteil der im Zuge der Gewerbefreiheit entstandenen und dem Handwerk distanziert gegenüberstehenden Betriebe inzwischen wieder vom Markt verschwunden war ${ }^{186}$.

Wie aus einer 1948 in Bayern durchgeführten Erhebung hervorgeht, war die Reichweite der einzelnen Innungen unterschiedlich. Sie hing von der Betriebsdichte der einzelnen Berufszweige ab. 38,7\% der Innungen erstreckten sich über einen Stadt- und Landkreis, 41,8\% über zwei bis vier Stadt- oder Landkreise. Die übrigen Innungen wiesen einen noch größeren Einzugsbereich auf ${ }^{187}$, was natürlich die Teilnahme der Handwerker an den Innungsversammlungen erschwerte.

${ }^{181}$ Chesi, S. 136f., 160. In der amerikanischen Zone wurde die erste „Verordnung über den vorläufigen Aufbau des deutschen Handwerks vom 16.6.1934“ bis 1948 zwar nicht ausdrücklich außer Kraft gesetzt, doch war die ablehnende Haltung der amerikanischen Besatzungsmacht in dieser Frage hinlänglich bekannt; vgl. ebenda, S. 162, 165; vgl. ferner Bericht der Handwerkskammer Bremen über die Jahre 1945 bis 1949, S. 66-68.

182 Wernet, Statistik S. 82.

${ }^{183}$ Errechnet nach Handwerkszählung 1949, Bd. 5, S. 173.

${ }^{184}$ Wernet, Statistik S. 86-88. Der Organisationsgrad der Zwangsinnungen betrug $192679,5 \%$, der Organisationsgrad der freien Innungen dagegen nur 20,5\% (ebenda, S. 82).

${ }^{185}$ Errechnet nach: Handwerkszählung 1956, H. 5, S. 129.

${ }^{186}$ Chesi, S. $171 \mathrm{f}$.

${ }^{187}$ Deutsches Handwerksinstitut (Hg.), Wirtschaftslehre des Handwerks, München 1964, S. 336. 
In den Handwerkskammerberichten der 50er Jahre wird immer wieder betont, die Zahl der Innungsaustritte falle kaum ins Gewicht ${ }^{188}$. Die überwiegende Mehrzahl der Austritte sei vielmehr durch Betriebsaufgabe bedingt ${ }^{189}$. Ging der Austritt eines Innungsmitgliedes mit der Löschung seines Betriebes in der Handwerksrolle einher, veränderte sich der Organisationsgrad nicht. Im Falle einer Betriebsaufgabe geschah dies nur, wenn der Betrieb den Besitzer wechselte und der neue Betriebsinhaber nicht der Innung beitrat. Relative Mitgliedereinbußen stellten sich auch ein, wenn ein selbständiger Handwerker nach seinem Austritt aus der Innung seinen Betrieb weiterführte. In diesem Fall wurde die Abkehr von der Innung bewußt vollzogen, wobei sich die Frage stellt, welche Motive einem solchen Schritt zugrunde lagen. Nach Einschätzung der Handwerkskammer Flensburg waren - zumindest in den frühen 50er Jahren - „Austritte aus den Innungen etwa aus Interesselosigkeit oder Gegnerschaft [...] verschwindend gering" ${ }^{190}$. „Eine Aufgabe der Innungsmitgliedschaft aus wirtschaftlichen Gründen, in erster Linie, um den Beitrag einzusparen, “ sei dagegen häufiger zu verzeichnen gewesen ${ }^{191}$.

Mindestens ebenso erklärungsbedürftig wie die Innungsabgänge ist der im gesamten Untersuchungszeitraum sehr hohe Anteil der Innungsmitglieder an der Handwerkerschaft. Es stellt sich die Frage, welche ökonomischen und sozialpolitischen Vorteile mit der Innungsmitgliedschaft verbunden waren.

In der unmittelbaren Nachkriegszeit besaßen die Innungen maßgeblichen Einfluß auf die Gewerbezulassung. Unter dem Aspekt der Konkurrenzabwehr war es daher für die bereits selbständigen Handwerker durchaus rational, die Innungsmitgliedschaft und damit auch das Mitspracherecht zu erwerben bzw. zu erhalten. Ein noch wichtigerer Anreiz für die Innungsmitgliedschaft bestand in der zentralen Stellung, die die Innungen im System der Rohstoffbewirtschaftung innehatten ${ }^{192}$. Von der Zuteilungspolitik der Innung hing nicht selten das Überleben eines Betriebes ab. Mit dem Abbau des Bewirtschaftungssystems verloren die Innungen ihre ökonomische Schlüsselstellung. Wirtschaftliche Bedeutung kam ihnen, wie bereits geschildert, in den 50er Jahren vor allem auf dem Gebiet der Preisbildung zu, wobei allerdings Preisabsprachen je nach Handwerkszweig einen unterschiedlichen Stellenwert einnahmen.

${ }^{188}$ Im Handwerkskammerbezirk Oldenburg traten vom 1.4.1951 bis zum 31.3.1952 5,8\% der Innungsmitglieder aus; vgl. Handwerkskammer Oldenburg, Tätigkeitsbericht für die Zeit vom 1. April 1951 bis zum 31. März 1952, S. 11. Im pfälzischen Handwerkskammerbezirk schieden 1959 6,1\% der Innungsmitglieder aus; vgl. Geschäftsbericht der Handwerkskammer der Pfalz 1959/60, S. 20; vgl. Jahresbericht der Handwerkskammer Arnsberg 1950/51, S. 66.

${ }^{189}$ Geschäftsbericht der Handwerkskammer der Pfalz 1959/60, S. 20: Im Jahre 1959 erfolgten 75,1\% der Austritte aus pfälzischen Innungen infolge einer Betriebsaufgabe.

190 'Tätigkeitsbericht der Handwerkskammer Flensburg, 1.4.1949-31.3.1952, S. 33.

191 Ebenda, S. 34. Mit dieser Feststellung stimmt auch die ein Jahr zuvor im selben Kammerbezirk gemachte Beobachtung überein, daß ein hoher Anteil der Austritte, die nicht auf Betriebsaufgaben beruhten, auf wirtschaftlich schwache Betriebe entfiel; vgl. Tätigkeitsbericht der Handwerkskammer Flensburg, 1.4.1952 bis 31.3.1954, S. 112. Im Handwerkskammerbezirk Oldenburg betrug der durchschnittliche Innungsbeitrag pro Jahr 34,80 DM; vgl. Handwerkskammer Oldenburg, Tätigkeitsbericht für die Zeit vom 1. April 1951 bis zum 31. März 1952, S. 11.

192 Alfred Schön, Die Innung als Grundstein und Instrument der Handwerkspolitik. Aktivierung des Innungslebens als Aufgabe, in: Handwerkskammer Münster 1900-1950. 50 Jahre berufsständische Selbstverwaltung des Handwerks, S. 172-178, hier 175. 
Vor dem Hintergrund dieses ökonomischen Funktionsverlustes nimmt es nicht wunder, daß gerade in den frühen 50er Jahren immer wieder die Versammlungsmüdigkeit der Innungsmitglieder moniert wurde ${ }^{193}$. Andererseits ist zu betonen, daß der Innungsorganisationsgrad im Laufe der 50er Jahre keineswegs dramatisch sank. Die Erklärung hierfür ist nicht zuletzt im hohen Rationalisierungsbedarf der Handwerksbetriebe zu suchen. Die Innungen verstärkten ihre Funktion als Vermittler betriebswirtschaftlicher und technischer Kenntnisse und nahmen somit immer mehr den Charakter von Dienstleistungsorganisationen an ${ }^{194}$. Dieser Funktionswandel wurde seitens der Kammerorganisation, dem Aufsichtsorgan der Innungen, bewußt angestrebt. So wies z. B. der schleswig-holsteinische Landeshandwerksrat in seinen 1953 verabschiedeten Richtlinien zur Aktivierung des Innungslebens den Innungen die Aufgabe zu, in verstärktem Maße Gewerbeförderung zu betreiben ${ }^{195}$.

Welche sozialen Leistungen erbrachten die Innungen für ihre Mitglieder? Abgesehen von den nur in einem Teil der Innungen bestehenden Pensionskassen, bei denen es sich zumeist um Zwerggebilde mit beschränktem Personenkreis handelte ${ }^{196}$, war im Kaisereich die Vorsorge für das Alter noch weitgehend Sache des einzelnen Handwerkers ${ }^{197}$. Eine etwas günstigere Entwicklung nahm die Errichtung von Unterstützungskassen für den Krankheitsfall. Allerdings wurde dieser Kassentyp in zunehmendem Maße von der Innungsebene auf die Ebene der Handwerkskammern verlagert. Nach 1918 schritt die Zentralisierung, die die Leistungsfähigkeit der Kassen erhöhte, weiter voran ${ }^{198}$. Eine ähnliche Entwicklung vollzog sich im Bereich der Alterssicherung. Die Handwerkskammern, die das wachsende Sicherungsbedürfnis ihrer Mitglieder erkannt hatten, wirkten nunmehr an der Errichtung von berufsständischen Alters- und Lebensversicherungen mit ${ }^{199}$. Obgleich sich ihr Klientenkreis in der Regel auf Handwerker beschränkte, waren diese Privatversicherungen nicht Teil der Handwerksorganisation. Die Handwerkskammern selbst wurden in den 20er Jahren, zumal nach der Inflation, in verstärktem Maßefürsorgerisch tätig, wobei sie sich insbesondere dem immer dringlicher werdenden Problem der Altersar-

${ }^{193}$ DHBl 1950, H. 8 (25.4.1950), S. 119 f.; DHBl 1950, H. 13 (15.7.1950), S. 197 f.; vgl. ferner Schön, in: Handwerkskammer Münster 1900-1950, S. 172-178, hier 175.

${ }^{194}$ Im Handwerkskammerbezirk Flensburg konnte im Zeitraum von 1949 bis 1952 beobachtet werden, "daß die Innungen in steigendem Maße bemüht sind, ihre Aufgabe einer fachlichen und wirtschaftlichen Förderung der Mitglieder gerecht zu werden “. Vgl. Tätigkeitsbericht der Handwerkskammer Flensburg 1.4.49 bis 31.3.1952, S. 34. V.gl. auch Wirtschaftslehre des Handwerks, München 1964, S. 338. Es wird festgestellt, „daß der Behandlung ökonomischer Fragen von seiten der Fachorganisationen immer mehr Bedeutung beigemessen wird“. Vgl. auch Jahresbericht der Handwerkskammer Arnsberg 1950-51, S. 65: Im Tätigkeitsbericht heißt es, „daß den Innungsmitgliedern am meisten damit gedient ist, wenn die Behandlung fachlicher Fragen in den Vordergrund gestellt wird“. Die Innungsversammlung im Bauhauptgewerbe war immer dann gut besucht, „wenn die Bildung von Arbeits- oder Interessengemeinschaften auf der Tagesordnung stand". Hinweise dafür, daß die beruflichen Vereinigungen des Handwerks die Aufgeschlossenheit ihrer Mitglieder gegenüber technischen Innovationen förderten, finden sich bei Ellinghaus, S. $142 \mathrm{f}$.

195 Tätigkeitsbericht der Handwerkskammer Flensburg, 1.4.1952 bis 31.3. 1954, S. 113; vgl. auch Alfred Schön (Anm. 192), S. 175f. Vgl. auch Boyer, Gewerbezulassung, S. 307.

196 Zöllner, S. 26.

197 Guderjahn, S. 66.

198 Zöllner, S. $28 \mathrm{f}$.

${ }^{199}$ Es handelte sich dabei um private Krankenversicherungen, die ihren Aufgabenbereich ausdehnten, vgl. Deierling, S. 41-44; vgl. Büsch, S. 34 f. 
mut und der Erwerbwerbsunfähigkeit zuwandten. Der Umfang und die Höhe der Unterstützungsleistungen waren jedoch denkbar gering ${ }^{200}$. Durch die 1. Handwerksverordnung von 1934 erfolgte die sozialpolitische „Entmachtung “ der Innungen und Kammern. Die Errichtung oder Aufrechterhaltung von Unterstützungkassen für Krankheit, Alter oder Invalidität war ihnen von nun ab untersagt. Von diesem Verbot ausgenommen waren die Unterstützungfonds der Kammern, sofern diese nicht auf dem Versicherungsprinzip beruhten, sondern sich auf die Funktion der Armenfürsorge beschränkten ${ }^{201}$.

Nach Einführung der Handwerkeraltersversorgung im Jahre 1938 konzentrierten sich die Kammern darauf, die Altersarmut derjenigen Handwerker zu lindern, die zum Zeitpunkt der Einführung der Versicherungspflicht zu alt waren, um Ansprüche auf eine Alterversorgung zu erwerben. Die sogenannte „Altershilfe“ war als Fürsorgeleistung mit Zuschußcharakter konzipiert, auf die kein Rechtsanspruch bestand und deren Vergabe in Absprache mit den Kreishandwerkerschaften und Innungen erfolgte. Die Altershilfe konnte also de facto nur von den in der Innung organisierten Handwerkern mit Aussicht auf Erfolg beantragt werden. Die Altershilfezahlungen wurden im Wege einer im Handwerkskammerbeitrag enthaltenen Umlage finanziert. Im Jahre 1940 betrug die Empfängerzahl rund $12000^{202}$. In den 50er Jahren blieb die Zahl der Beihilfeleistungen auf einem gleichbleibend niedrigen Niveau ${ }^{203}$. Die Altershilfe, so läßt sich resümierend festhalten, stärkte zwar prinzipiell die Stellung der Innungen, doch war sie zu knapp bemessen und ihre potentielle Klientel zu klein ${ }^{204}$, als daß sie einen nachhaltigen Effekt auf die Mitgliederentwicklung in den Innungen hätte ausüben können 205 .

${ }^{200}$ Festschrift der Handwerkskammer Saarbrücken. Zur Weihe des Hauses am 10. Dezember 1929, Saarbrücken o.J., S. 28-30; Geschäfts-Bericht der Handwerkskammer Reutlingen. Vom 1. Januar 1914 bis 31. Dezember 1924, Reutlingen 1925, S. $174 \mathrm{f}$.

201 Zöllner, S. 31, 36.

202 Büsch, S. 51.

${ }^{203}$ Dies läßt sich exemplarisch an den von der Passauer Handwerkskammer in den Jahren 1950/51 und 1959/60 erbrachten Beihilfeleistungen zeigen; vgl. Handwerkskammer für Niederbayern, Jahresbericht 1950/51, o.O./o.J., S. 102; Handwerkskammer für Niederbayern, Jahresbericht 1959/60, o.OJo.J., S. 37. Vgl. ferner Handwerkskammer Aachen, Grenzlandhandwerk in der Belastungsprobe. Geschäftsbericht der Handwerkskammer für den Reg.-Bez. Aachen, o.O./o.J., S. 49.

${ }^{204} \mathrm{Im}$ Handwerkskammerbezirk Arnsberg kamen im Zeitraum vom 1.10 .1950 bis zum 31.12.1961 272 Handwerkerinnen und Handwerker in den Genuß der Altershilfe-Unterstützung. Addiert man die in diesen 11 Jahren geleisteten Auszahlungen und dividiert diese durch die Empfängerzahl, so ergibt sich, daß der durchschnittliche Unterstützungsbetrag pro Empfänger 1431,- DM betrug; hierbei ist allerdings zu berücksichtigen, daß nicht jeder der Empfänger über den ganzen Zeitraum hinweg Altershilfezahlungen erhielt; vgl. Handwerkskammer Arnsberg, Jahresbericht 1961, S. 16. Die monatliche Unterstützung betrug im selben Handwerkskammerbezirk 25,- DM; vgl. Handwerkskammer Arnsberg, Jahresbericht 1959, S. 22.

${ }^{205}$ Das gleiche gilt für die an die Adresse bedürftiger Handwerker gerichtete "Weihnachtsspende“. Diese wurde $z$ war von den Innungen mitfinanziert, die Zuteilung erfolgte jedoch über die Kreishandwerkerschaften: vgl. Handwerkskammer für Niederbayern, Jahresbericht 1959/60, S. 40. Die Sterbekassen waren ebenfalls Kammerinstitutionen und somit dem Einflußbereich der Innungen weitgehend entzogen. Ihr Mitgliederbestand war gering. Im Handwerkskammerbezirk Arnsberg waren z. B. waren nur 12,8\% der in der Handwerksrolle eingetragenen Betriebsinhaber Mitglied der Sterbekasse. Die ausgezahlten Sterbegelder schwankten je nach Höhe des Mitgliedsbeitrags zwischen 360 und 500 DM; vgl. Handwerkskammer Arnsberg, Jahresbericht 1959, S. 16, 121. 
Die Innungszugehörigkeit war Voraussetzung für die freiwillige Mitgliedschaft der selbständigen Handwerker und ihrer Arbeitnehmer in den Innungskrankenkassen. Obschon sich in den 50er Jahren der Anteil der selbständigen Handwerker an der Mitgliederschaft der Innungskrankenkassen erhöhte, waren im Jahre 1961 laut einer in Göttingen und Umgebung durchgeführten Umfrage nur $9 \%$ der befragten Handwerker Mitglied einer solchen Kasse. 32\% hatten sich der Ortskrankenkasse, 3\% einer Ersatzkasse und 1\% der Landeskrankenkasse angeschlossen ${ }^{206}$. Rund 10\% der Handwerker gehörten weder einer sozialen noch einer privaten Krankenversicherung an ${ }^{207}$. Der geringe Prozentsatz der in den Innungskrankenkassen versicherten Handwerker hing zum einen mit $\$ 176$ RVO zusammen, demzufolge die selbständigen Meister nur dann einer Innungskrankenkasse beitreten durften, „wenn sie regelmäßig keine oder höchstens zwei Versicherungspflichtige beschäftigten und wenn das jährliche Gesamteinkommen 7200,- DM nicht übersteigt “208. Die Innungskrankenkassen waren also vornehmlich als Gesellenkassen konzipiert. Ein weiterer Grund für die geringe Beteiligungsrate der selbständigen Handwerker ist darin zu sehen, daß lediglich rund 20\% der Innungen Träger einer solchen Einrichtung waren ${ }^{209}$. Die Mehrzahl der Innungen hatte von ihrem Recht, Unterstützungskassen zu errichten, keinen Gebrauch gemacht und konnte somit die Krankenversicherung auch nicht als Instrument für die Mitgliederwerbung einsetzen $^{210}$. Für die Trägerinnungen waren die Innungskrankenkassen ein durchaus werbewirksames Zugpferd, da in den 50er Jahre ihr durchschnittlicher Beitragssatz rund 5 Prozentpunkte unter dem der Ortskrankenkassen lag'211. Dieses Beitragsgefälle dürfte die Attraktivität der Innungsmitgliedschaft vor allem für Inhaber größerer Betriebe erhöht haben ${ }^{212}$.

Die skizzierte Entwicklung vollzog sich vor dem Hintergrund der Umgestaltung der Innungskrankenkassen zu branchenübergreifenden und überörtlichen Großorganisationen $^{213}$. Die 50er Jahre waren durch einen beispiellosen Mitgliederzuwachs gekennzeichnet: Entfielen 19492149 Versicherte auf eine Innung, so waren es $19585497^{214}$. Der einstmals in den einzelnen Innungen stattfindende Risikoausgleich wurde somit auf leistungsfähigere Füße gestellt.

${ }^{206}$ Hausmann, Das Handwerk im Haushalt, S. 23, Anm. 2, S. 26. Zu ähnlichen Ergebnissen kommt Balzer, S. 244.

${ }^{207}$ Diese Angabe bezieht sich auf das Jahr 1956, ebenda, S. 25.

208 Estenfeld, S. 11.

2091959 gab es im Bundesgebiet 2149 Trägerinnungen; vgl. Handwerkammer Oldenburg, Tätigkeitsbericht für die Zeit vom 1.1.1958 bis zum 31.12.1959, S. $21 \mathrm{f}$.

${ }^{210}$ Guderjahn, S. 66. Auch im Kaiserreich verfügten bei weitem nicht alle Innungen über eine eigene Krankenkasse. Dies war der Grund, warum bereits vor dem Ersten Weltkrieg sogenannte Kranken-Unterstützungskassen auf berufsständischer Basis entstanden. Der Beitritt zu diesen Privatversicherungen war nicht an die Mitgliedschaft in der Handwerksorganisation gekoppelt; vgl. Deierling, S. $18 \mathrm{f}$.

211 Statistisches Jahrbuch 1952, S. 342 f.; Statistisches Jahrbuch 1961, S. 406 f.: 1949 betrug das Beitragsgefälle $4,33 \%$ und $19585,53 \%$.

${ }^{212}$ Handwerkskammer Hamburg, Jahresbericht 1958, S. 72.

${ }^{213}$ Estenfeld, S. 15-17. Vgl. Guderjahn, S. 118. Zur Zusammenlegung lokaler und regionaler Kassen vgl. 50 Jahre Handwerkskammer für Oberbayern. Eine Jubiläumsschrift, hrsg. von der Handwerkskammer für Oberbayern, München 1950, S. 100; vgl. Tätigkeitsbericht der Handwerkskammer Flensburg, 1.4.1949 bis 31.5.1952, S. 126.

${ }^{214}$ Statistisches Jahrbuch 1952, S. 340 f.; Statistisches Jahrbuch 1961, S. $406 \mathrm{f}$. 
Die an die Innungsmitgliedschaft gekoppelten sozialen Leistungen, so läßt sich zusammenfassend konstatieren, waren im Untersuchungszeitraum zu unbedeutend, um die Mitgliederentwicklung der Innungen nachhaltig zu beeinflussen. Dieser Befund trifft grundsätzlich auch auf die Weimarer Republik zu, obgleich zu diesem Zeitpunkt das sozialpolitische Aufgabengebiet der Innungen größer war.

Unter dem Aspekt der sozialen Beziehungen ist es von Belang, wie häufig und in welcher Form sich die selbständigen Handwerker an den Veranstaltungen der Innungen beteiligten. Den Umfrageergebnissen von Sack zu den Kölner Schreinern aus dem Jahre 1959 zufolge nahmen nur 25\% der selbständigen Handwerker regelmäßig an Innungsversammlungen teil, 19,2\% besuchten diese Veranstaltungen überhaupt nicht, 40,8\% nur hin und wieder oder selten, und 14,4\% gehörten der Innung gar nicht an. Die Schreiner aus den mittleren Umsatzgrößenklassen (20000-250000 DM Umsatz/Jahr) beteiligten sich am häufigsten an der Innungsarbeit ${ }^{215}$. Dieses Ergebnis stimmt grosso modo mit den 1962 von Greber erhobenen Daten zum Schuhmacherhandwerk überein ${ }^{216}$. Der Kreis der an Innungsversammlungen teilnehmenden Handwerker war mithin in sozioökonomischer Hinsicht homogener als die Mitgliederschaft insgesamt. Dieser Befund trifft auch auf andere Bereiche des Innungslebens zu. So besuchten z. B. diejenigen von Greber befragten Schuhmacher, die sich am unteren und oberen Ende der Umsatzskala befanden, seltener die geselligen Veranstaltungen der Innungen als ihre Kollegen in den mittleren Umsatzgrößenklassen, wobei hervorzuheben ist, daß das Interesse an dieser Form organisierter Geselligkeit insgesamt sehr gering war. Die befragten Handwerker waren offenbar stärker an einem fachlichen Austausch interessiert als an geselligen Kontakten mit ihren Berufskollegen. Diese Festellung deckt sich mit dem von Sack ermittelten Ergebnis, demzufolge nur 14,5\% der befragten Schreiner der Meinung waren, daß die Innung die berufsständische Solidarität festigen solle. Die Mehrheit der übrigen Schreiner sah die Aufgabe der Innung primär darin, Funktionen wahrzunehmen, die der Einzelbetrieb nicht erfüllen könne (Lehrlingsausbildung, juristische Beratung, Vertretung nach außen, Preisfestsetzung, Schutz vor Konkurrenz) ${ }^{217}$.

Nach den Beitrittsgründen ihrer Mitglieder befragt, gaben die handwerklichen Fachverbände im Jahre 1961 am häufigsten das wirtschaftspolitische Informationsbedürfnis der Handwerker sowie den Bedarf an individueller Hilfe in technischen, betriebswirtschaftlichen, arbeits- und steuerrechtlichen Fragen an. Soziale Kontakte wurden als Beitrittsgrund erst an letzter Stelle genannt ${ }^{218}$. Die referierten Umfrageergebnisse belegen, $\mathrm{da} ß$ die Innungen in erster Linie eine ökonomische Interessenorganisation und weniger eine ständische Vereinigung waren. Es ist daher anzunehmen, daß die in den 50er Jahren nachweisbaren Bemühungen, die Attraktivität der Innungen durch die „Pflege der Geselligkeit" zu erhöhen, im Hinblick auf ihren Wirkungsgrad von zweitrangiger Bedeutung waren ${ }^{219}$. Die Untersuchung von Greber deutet darauf hin, daß die soziale Zusam-

\footnotetext{
215 Sack, S. 249.

216 Der Anteil regelmäßig an Innungsversammlungen teilnehmender Mitglieder lag allerdings im Schuhmacherhandwerk höher (bei 48\%); vgl. Greber, S. 201.

${ }^{217}$ Sack, S. 251.

${ }^{218}$ Schmölders, S. 187. Vgl. ferner den gegenwartsbezogenen Befund von Kosel, S. 134.

219 Tätigkeitsbericht der Handwerkskammer Flensburg, 1.4.1949-31.3.1952, S. 3; Handwerkskammer Oldenburg, Tätigkeitsbericht für die Zeit vom 1. April 1951 bis zum 31. März 1952, S. 10 .
} 
mensetzung der Innungsführung von der Mitgliederstruktur deutlich abwich. Der Anteil der Amtsinhaber war in der obersten Umsatzgrößenklasse am höchsten. Der Grund ist vor allem darin zu sehen, daß die besserverdienenden Handwerker im Gegensatz zu ihren weniger erfolgreichen Kollegen über die für die Führung der Innung erforderlichen Kenntnisse verfügten. Außerdem war es für die Inhaber größerer, stärker arbeitsteilig organisierter Betriebe leichter, sich die für die Innungsarbeit nötige Zeit zu nehmen $^{220}$. Einem Bericht aus dem Jahre 1952 ist zu entnehmen, daß die Bereitschaft zur ehrenamtlichen Mitarbeit abnahm. Als Ursache wurde zum einen „die starke Inanspruchnahme der handwerklichen Betriebsinhaber genannt, zum anderen aber auch die bedauerliche Zeiterscheinung, daß vor allem die junge Generation wenig geneigt ist, Aufgaben im Dienste der Öffentlichkeit zu übernehmen" ${ }^{221}$.

Zieht man ein Zwischenresümee, so ist zu betonen, daß die Innungen in den 50 er Jahren immer mehr den Charakter wirtschaftlicher Interessenverbände annahmen. Die Versachlichung der Sozialbeziehungen schritt auch in diesem Rahmen voran. Daß unter den Teilnehmern an Innungsversammlungen die Inhaber von Kleinstbetrieben und überdurchschnittlich großen Betrieben leicht unterrepräsentiert waren, ist in erster Linie auf abweichende wirtschaftliche Interessenlagen zurückzuführen. Einen gewissen Einfluß dürfte darüber hinaus der Umstand gehabt haben, daß sich diese beiden Handwerkergruppen auch in sozialer Hinsicht tendenziell in einer Außenseiterposition befanden.

Die Beziehungen zwischen Gewerbetreibenden und örtlichen Berufsorganisationen waren im Einzelhandel weniger eng als im Handwerk. Um die Wechselwirkung zwischen Verband und Basis besser zu verstehen, ist es notwendig, kurz auf die Organisationsstruktur des Einzelhandels einzugehen. Es fällt auf, daß es in unserem Untersuchungszeitraum bis auf wenige Ausnahmen unterhalb der Landesebene keine selbständigen Fachverbände gab ${ }^{222}$. Anders als in der Weimarer Zeit waren die branchenspezifischen Fachvertretungen in der Regel Teil der regionalen Einzelhandelsverbände, die für die Belange aller Einzelhändler eines bestimmten Gebietes zuständig waren. Die Einzelhändler konnten nur in die Bezirks- bzw. Landesverbände eintreten; die Mitgliedschaft in den Fachorganisationen war korporativ ${ }^{223}$. Aufs Ganze gesehen, befanden sich die Fachgemeinschaften gegenüber den überfachlichen Verbandsorganen in einer subalternen Stellung, was sich nicht zuletzt in ihrer finanziellen Abhängigkeit von den Bezirksund Landesverbänden äußerte. Die Einzelhandelsverbände verfügten weder über organisationseigene soziale Selbsthilfecinrichtungen, noch waren sie mit der Überwachung der Lehrlingsausbildung betraut. Das Schwergewicht ihrer Arbeit lag auf wirtschafts-, sozial- und fachpolitischem Gebiet ${ }^{224}$.

Der Organisationsgrad der Einzelhändler lag traditionell sehr niedrig. 1925 betrug er 28,6\%. Bis 1934 stieg er - offenbar in Erwartung einer baldigen Zwangsmitgliedschaft auf $40,5 \%{ }^{225}$. Für die unmittelbare Nachkriegszeit liegen nur Zahlen aus der britischen

\footnotetext{
220 Greber, S. 200.

221 Die Lage des Handwerks im 1. Quartal 1952, S. 6 f.

222 Hauptgemeinschaft des Einzelhandels, 4. Arbeitsbericht (1951), S. 41. Vgl. ferner Wein, S. 293.

${ }^{223}$ Vgl. z. B. die Satzung des Landesverbandes des bayerischen Einzelhandels, in: Bayerischer Einzelhandel 2 (1948), Nr. 12.

${ }^{224}$ Hauptgemeinschaft des Deutschen Einzelhandels, 5. Arbeitsbericht (1953), S. 43.

225 Brüggemann, S. 38.
} 
Zone vor. Geht man von dem Gesamtbestand der Einzelhandelsarbeitsstätten im Jahre 1950 aus, so betrug der Anteil der verbandlich organisierten Einzelhändler in SchleswigHolstein 30\%, in Niedersachsen $36 \%$, in Bremen $55 \%$ und in Hamburg $57 \%{ }^{226}$. Sieht man von der höheren Organisationsbereitschaft der städtischen Einzelhändler $\mathrm{ab}^{227}$, muß der Mitgliederanteil der Einzelhandelsverbände in der umittelbaren Nachkriegszeit als sehr niedrig eingestuft werden. Ein überraschender Befund, wenn man bedenkt, daß die regionalen Einzelhandelsverbände eine wichtige Rolle im staatlichen Bewirtschaftungssystem spielten. Sie schlugen den zuständigen Behörden vor, nach welchen Gesichtspunkten die Waren am zweckmäßigsten zu verteilen seien, und hatten außerdem die Funktion, Bezugsrechte an die Einzelhandelsbetriebe weiterzuleiten ${ }^{228}$. Die Fachgemeinschaften waren an diesem Verfahren offenbar nicht zentral beteiligt. Dies macht es zumindest verständlicher, warum z. B. in Bayern die Bildung von Fachgemeinschaften im Frühjahr 1949 selbst auf Bezirksebene noch nicht abgeschlossen war ${ }^{229}$.

In den 50er Jahren hatten die Einzelhandelsverbände allem Anschein nach einen Mitgliederzuwachs zu verzeichnen, denn Anfang der 60er Jahre bezifferte sich der Anteil der organisierten Einzelhändler auf ca. 50\%. Betriebe mit einem Jahresumsatz unter 100000 DM gehörten nur zu ca. 20\% einem Verband an. Bei Betrieben mit einem Jahresumsatz zwischen 100000 bis $300000 \mathrm{DM}$ steigerte sich dieser Anteil auf $60 \%$. In der Umsatzgrößenklasse von 300000 bis 1000000 gehörten $80 \%$ der Betriebsinhaber einem Einzelhandelsverband an ${ }^{230}$. Auch Hagemann kommt in seiner 1959 durchgeführten Untersuchung des Kölner Lebensmitteleinzelhandels zu dem Ergebnis, daß der Organisationsgrad mit dem Umsatz zunahm. Insgesamt waren 58,9\% der befragten Lebensmitteleinzelhändler Mitglieder des Einzelhandelsverbandes. Aufschlußreich sind die Motive für die Mitgliedschaft: 50,6\% der Verbandsangehörigen waren auf die Wahrung ihrer Interessen bedacht, während 26,9\% Traditionsverbundenheit und Kollegialität als Gründe für ihre Mitgliedschaft anführten. Der Nichteintritt in den Verband wurde - ähnlich wie im Handwerk - am häufigsten damit begründet, daß die Mitgliedsbeiträge zu hoch seien ${ }^{231}$.

Die Klagen über den schlechten Besuch der Fachgemeinschaften rissen in den 50er Jahren nicht ab. Den Bundesfachverbänden, so ein Funktionär des Schuheinzelhandels, fehle es an Geld, „und in den Unterverbänden sei auf Grund der meistenteils überfachlichen Organisation die fachliche Betreuung nicht intensiv genug“232. Im Vergleich zu den Handwerkern nahmen die Händler seltener am Verbandsleben teil233.

Die Schwierigkeit der Einzelhandelsverbände, ihre Basis zu mobilisieren, ist im Kontext der Expansion der freiwilligen Ketten zu sehen. Im Kölner Lebensmitteleinzelhandel z. B. betrug der Anteil derjenigen, die weder dem Einzelhandelsverband noch einer

${ }^{226}$ HDE-Kellerbestand, Aufstellung über Mitgliederzahlen, undatiert (vermutlich aus dem Jahre 1947).

${ }_{227}$ Daheim/Kaupen-Haas/Kaupen, S. 21, Tab. 51.

228 Bayerischer Einzelhandel 1 (1947), Nr. 8, S. 29

229 Bayerischer Einzelhandel 3 (1949), Nr. 7/8, S. 50.

${ }^{230}$ Wein, S. 271; diese Angaben werden bestätigt durch das Datenmaterial von Daheim/KaupenHaas/Kaupen, Bd. 2, S. 21, Tab. 51.

${ }^{231}$ Hagemann, S. $210 f$.

232 Protokoll über die ordentliche Delegiertenversammlung des Bundesverbandes des Deutschen Schuheinzelhandels e.V. vom 2. bis 4.7.1957 in Hamburg, S. 13.

${ }^{233}$ Daheim/Kaupen-Haas/Kaupen, Bd. 2, S. 22, Tab. 52. 
freiwilligen Gruppe angehörten, lediglich 25,8 \% 234 . Geht man von Hagemanns Feststellung aus, „daß die freiwilligen Zusammenschlüsse weitgehend die Funktion der Berufsorganisation übernommen haben "235, so muß das Urteil von der mangelnden Organisierbarkeit der Einzelhändler relativiert werden. Am wenigsten trifft dies allerdings auf die Kleinstbetriebe $\mathrm{zu}$, da diese in den freiwilligen Gruppen ebenso unterrepräsentiert waren wie in den Verbänden.

Abschließend ist festzuhalten, daß die Einzelhandelsverbände noch weniger als die Innungen imstande waren, solidarische Beziehungen zwischen ihren Mitgliedern zu stiften. Dies hing nicht zuletzt mit der im Vergleich zum Handwerk weniger stark ausgeprägten berufsständischen Tradition zusammen. Die Tatsache allerdings, daß Einzelhändler unterschiedlichster Provenienz in den örtlichen Verbänden zusammenkamen, läßt vermuten, daß trotz des Vorherrschens zweckrationaler Beziehungsmuster ein Minimum an Zusammengehörigkeitsgefühl vorhanden war bzw. erzeugt wurde. So stuften sich z. B. diejenigen Lebensmitteleinzelhändler, die Mitglieder eines Einzelhandelsverbandes waren, etwas häufiger im „Mittelstand“ ein als die Nichtmitglieder ${ }^{236}$. Auch wenn nicht ersichtlich ist, ob dies primär auf den Einfluß der verbandspolitischen Mittelstandsrhetorik oder auf die größere Organisationsbereitschaft der sich zum Mittelstand zählenden Einzelhändler zurückzuführen ist, wird man der verbandlichen Organisation im Hinblick auf das Gemeinschaftsbewußtein eine stabilisierende Wirkung nicht absprechen können.

\section{Soziale Kontakte in Freizeitvereinen}

Will man etwas über die sozialen Kontakte erfahren, die die selbständigen Mittelständler in Freizeitvereinen knüpften, so ist die Berufsstruktur der Vereine zu analysieren. Entsprechende Erhebungen wurden im Untersuchungszeitraum nur in der rheinischen Industriegemeinde Euskirchen sowie in einer ebenfalls im Rheinland gelegenen ländlichen Gemeinde durchgeführt ${ }^{237}$. Vergleichbare Daten zu großstädtischen Vereinen liegen nicht vor.

Aus der von Renate Mayntz im Jahre 1955 vorgenommenen Erhebung zur berufsstrukturellen Zusammensetzung von 18 Euskirchener Vereinen ist ersichtlich ${ }^{238}$, daß die Selbständigen aus Handel, Handwerk und Gewerbe im Vergleich zu den übrigen Be-

234 Hagemann, S. 212.

235 Ebenda.

236 Ebenda, S. 295.

237 Mayntz, Schichtung, S. 229-232; vgl. Wurzbacher. Ein Großteil der in den 50er Jahren durchgeführten soziologischen Erhebungen zum Vereinswesen unterscheidet nicht zwischen Freizeitvereinen, Berufsverbänden und politischen Organisationen und ist daher für unsere Zwecke nur eingeschränkt verwendbar; vgl. z. B. Reigrotzki, Soziale Verflechtung, S. 175, und Kieslich, S. $87 \mathrm{f}$.

238 Mayntz, Schichtung, S. 230 (Tab. 51). Mayntz geht es um den Anteil der verschiedenen Berufsgruppen in den einzelnen Vereinen. Um die Verteilung der Selbständigen auf die Vereine zu ermitteln, war eine Umrechnung notwendig. Die jeweiligen Besetzungshäufigkeiten mußten auf die Gesamtheit der selbständigen Mittelständler bezogen werden. 
rufsgruppen über die heterogensten Sozialbeziehungen verfügten ${ }^{239}$. Bei keiner anderen Berufsgruppe war die Vereinszugehörigkeit so breit über die verschiedenen Vereinstypen gestreut wie bei den selbständigen Mittelständlern. So besaßen 4,0\% der Kleingewerbetreibenden die Mitgliedschaft in Arbeitervereinen und 5,39\% in exklusiven Vereinen wie dem Tennisklub oder dem Reiterverein, denen ansonsten fast ausschließlich Unternehmer sowie höhere Beamte und Angestellte angehörten. Die sich in der Vereinsmitgliedschaft manifestierende soziale Nähe zur Arbeiterschaft bzw. zur gesellschaftlichen Elite verweist erneut auf die großen sozialen Unterschiede innerhalb der Selbständigenschicht. Am häufigsten waren die Selbständigen aus Handel, Handwerk und Gewerbe in der Sebastianus-Bruderschaft $(29,83 \%)$, der Allgemeinen Schützengesellschaft $(16.7 \%)$, dem Euskirchener Sportverein (12,51\%) sowie dem Eifelverein vertreten $(11,42 \%)$. Die Allgemeine Schützengesellschaft kann als Mittelstandsverein gelten, da die Selbständigen fast drei Viertel aller Mitglieder stellten. Interessant ist, daß die Bürgerliche Schützengesellschaft nur von knapp 4\% der selbständigen Mittelständler frequentiert wurde. Dies lag wohl in erster Linie daran, daß in diesem Schützenverein in erheblichem Umfange auch Facharbeiter bzw. Handwerksgesellen (30\%) organisiert waren. Die Mehrheit der Gewerbetreibenden zog offenbar den Kontakt mit beruflich Gleichgestellten vor.

Die sich in diesen Befunden ausdrückende Ambivalenz von relativer Offenheit und sozialer Abgeschlossenheit gegenüber anderen Berufsgruppen spiegelt die innere Fragmentierung der Selbständigengruppe wider. Sie ist aber auch Ausdruck der Sozialverfassung des untersuchten Ortes. Welch große Unterschiede zwischen einer Industriegemeinde und einer ländlichen Gemeinde bestanden, zeigt sich an Wurzbachers Untersuchung: auf der Ebene des Dorfes gab es weder elitäre noch Unterschichtenvereine. Die Berufsgliederung der nichtkirchlichen Freizeitgruppen zeichnete sich durch ihre Heterogenität aus. Kleingewerbetreibende, Akademiker und Arbeiter gehörten häufig denselben Vereinen an. Handwerker und Gewerbetreibende waren in Relation zu ihrem Anteil an der Erwerbsbevölkerung überproportional vertreten. Noch höher war ihr Anteil an den aktiven Mitgliedern ${ }^{240}$. Dies ist damit zu erklären, daß die Kleingewerbetreibenden „durch ihren Beruf wesentlich stärker auf ihren Wohn- und Heimatort orientiert (waren) als die großenteils auspendelnden Arbeiter, Angestellten und Beamten" ${ }^{241}$. Ein weiterer Grund für die hohe Vereinsbeteiligung der Kleingewerbetreibenden ist in dem gerade in kleinräumigen Lebenszusammenhängen besonders ausgeprägten Doppelcharakter von sozialen und geschäftlichen Beziehungen $\mathrm{zu} \operatorname{sehen}^{242}$.

${ }^{239}$ Ebenda, S. 20. Mayntz unterscheidet zwischen Selbständigen und Unternehmern. Letztere werden nicht durch Beschäftigtenzahl oder Umsatzhöhe definiert. In dieser Kategorie werden vielmehr jene Selbständigen zusammengefaßt, "die uns entweder namentlich oder persönlich als Besitzer großer Euskirchener Handelsfirmen, Baufirmen oder Fabriken etc. bekannt waren, oder die sich, wo es sich um Quellenmaterial aus der Vergangenheit handelte, selbst als, Fabrikant ${ }^{\prime}$ bezeichneten“. Angesichts dieser kategorialen Unterscheidung und der Tatsache, daß Euskirchen überwiegend kleingewerblich geprägt war, erscheint es gerechtfertigt, die übrigen Selbständigen dem Mittelstand zuzuordnen.

240 Wurzbacher, S. 66-69. Vgl. ferner Beckhoff, S. 40, der in seiner Untersuchung aus den Jahren 1961/62 zu zwei kleinbäuerlichen Taunusgemeinden feststellte, daß Handwerker im Gegensatz $\mathrm{zu}$ Landwirten auch in Arbeitervereinen vertreten waren.

${ }^{241}$ Ebenda, S. 161.

242 Vgl. auch Beckhoff, S. 40. 
Als Fazit bleibt festzuhalten: Je kleiner der Ort, desto unwesentlicher war die berufliche und finanzielle Stellung für die Teilnahme an Freizeitvereinen, und desto wahrscheinlicher wurden schichtübergreifende Kontakte ${ }^{243}$. Zeitgenössischen Erhebungen zur Vereinszugehörigkeit von großstädtischen Handwerkern ist zu entnehmen, daß die Bereitschaft, sich in Vereinen zu organisieren, mit zunehmendem Umsatz linear anstieg. So betrug z. B. im Kölner Schuhmacherhandwerk im Jahre 1962 der Mitgliederanteil in der Umsatzgrößenklasse von 15000 bis 50000 DM 32\%, während er bei den Schuhmachern, die jährlich über 50000 DM umsetzten, bei $52 \%$ lag $^{244}$. Wenngleich der Organisationsgrad bei den von Mayntz untersuchten Selbständigen in Handel, Handwerk und Gewerbe vergleichsweise hoch ausfiel245, ist davon auszugehen, daß ein beachtlicher Teil der Handwerker und Einzelhändler überhaupt keinem Verein angehörte ${ }^{246}$. Die Abhängigkeit der Vereinsmitgliedschaft vom ökonomischen Erfolg war kein Charakteristikum des Mittelstandes, sondern entsprach einem gesamtgesellschaftlichen Muster, das Mayntz wie folgt beschreibt: „Je höher der soziale Status, um so häufiger ist die Mitgliedschaft in überhaupt einer der erfaßten Organisationen, und um so häufiger findet man auch mehrere Mitgliedschaften.“247

Betrachtet man die von Greber am Beispiel der Kölner Schuhmacher untersuchten persönlichen, also nicht in organisierter Form stattfindenden Kontakte zwischen Berufskollegen, so wird wiederum die hohe Bedeutung der Betriebsgröße bzw. des Umsatzes für die Sozialbeziehungen deutlich: Die in der mittleren Umsatzklasse angesiedelten Schuhmacher verkehrten häufiger mit ihren Berufskollegen als die übrigen Schuhmacher $^{248}$.

Die Stadt-Land-Differenz wirkte sich nicht nur auf Art und Umfang der Vereinsbeteiligung aus, sie beeinflußte auch die sozialen Beziehungen und die Lebensführung in einem umfassenden Sinne. Balzers Untersuchung über die verschiedenen Lebensformen im ländlichen Handwerk Schleswig-Holsteins zeigt dies in exemplarischer Weise. Der Verfasser unterscheidet drei Gruppen von Betriebsinhabern: Während sich die erste, ökonomisch am schlechtesten gestellte Gruppe vornehmlich an dem Kleidungsverhalten und den Umgangsformen der unterbäuerlichen Schichten orientierte, ähnelten die wirtschaftlich erfolgreicheren Handwerker in ihrer Lebensweise den selbständigen Landwirten. Eine dritte Gruppe, die vornehmlich aus der Stadt stammende Handwerker umfaßte und deren Angehörige häufig in den „modernen“ technischen Handwerken tätig waren, sei durch einen bürgerlichen Lebensstil gekennzeichnet, was sich beispielsweise in der scharfen Trennung zwischen Arbeits- und Freizeitkleidung, in einer ausgeprägten Neigung zu Reisen und Ausflügen sowie in städtischen Akzenten bei der Wohnungsaustattung manifestiere. Darüber hinaus meint Balzer feststellen zu können, daß dieser „, bürgerliche“ Handwerkertyp, der auf dem Land in der Minderheit war, be-

\footnotetext{
${ }^{243}$ Vgl. hierzu auch Roth, S. 208.

${ }^{244}$ Greber, S. 231 f.; vgl. auch Sack, S. 261. Unter Vereinsmitgliedschaft subsumiert Sack allerdings neben der Mitgliedschaft in Geselligkeits- und Sportvereinen auch die Parteizugehörigkeit.

${ }^{245}$ Der Organisationsgrad der Selbständigen läßt sich anhand der von Mayntz gemachten statistischen Angaben grob abschätzen. Er betrug demnach mindestens 70\%, wahrscheinlich aber über $80 \%$.

${ }^{246}$ Daheim/Kaupen-Haas/Kaupen, Bd. 2, S. 11, Tab. 29.

${ }^{247}$ Mayntz, Schichtung, S. 242.

248 Greber, S. 204.
} 
sonders hohen Wert auf die berufliche Ausbildung der Kinder legte ${ }^{249}$. Die Milieuabhängigkeit der beobachteten Lebensformen veranlaßt Balzer zu der Schlußfolgerung, das ländliche Handwerk zeichne sich „durch eine besonders stark ausgeprägte Assoziationsfähigkeit" aus ${ }^{250}$.

Eine wichtige Ursache für die abweichenden Verhaltensweisen ist darin zu sehen, $\mathrm{daß}$ Kleingewerbetreibende allein aufgrund des ausgeprägten Kundenkontaktes einem hohen sozialen Anpassungsdruck unterlagen. In der dörflichen Lebenswelt war die soziale Kontrolle besonders intensiv. Auf diesen Umstand machte auch das „Magazin des Lebensmitteleinzelhändlers" aufmerksam: Anders als in Großstädten müsse in kleinen Orten "neben entsprechender Kundenbehandlung auch das eigene persönliche Verhalten genau ausgerichtet sein. Das Privatleben unterliegt sozusagen der öffentlichen Kontrolle" 251 . Auch mit Empfehlungen wurde nicht zurückgehalten: „Der eigene Lebenswandel sollte untadelig sein, um den Mitbürgern keinen Anlaß zum Gerede zu geben. Keinesfalls sollte man durch große Geldausgaben auffallen [...] Der Neid ist eine böse Eigenschaft. "252 Eine Form des sozialen Zwangs war zweifellos auch die stillschweigende Anwesenheitspflicht der Selbständigen bei dörflichen Festivitäten. Der Einzelhändler mußte, wie eine Mitte der 50er Jahre in einer stadtfernen Gemeinde durchgeführte Umfrage erkennen läßt, bei solchen Gelegenheiten „unter den kritischen Augen sämtlicher Einwohner seine unterschiedslose Geneigtheit jedermann durch spendable Gesten und andere persönliche Aufmerksamkeiten dartun und ,büßt' $[\mathrm{e}]$ auf diese strapazierende Weise seine dem privaten Bereich vorbehaltene selektive Lebensform“253.

Der wirtschaftliche und soziale Strukturwandel des ländlichen Einzelhandels wurde im Untersuchungszeitraum insbesondere durch die infrastrukturelle Erschließung der ländlichen Gemeinden vorangetrieben. Die durch die Konkurrenz mit dem städtischen Handel bedingte Orientierung an überörtlichen Marktstrukturen hatte auch soziale Konsequenzen, zumal im Verhältnis zwischen Betriebsinhabern und Kunden. Kappe stellt in seiner Untersuchung aus den Jahren 1956/57 eine Versachlichung der Kundenbeziehungen fest, wobei in stadtnahen Gemeinden dieser Trend wesentlich stärker war als in stadtfernen ${ }^{254}$. In der Umbruchssituation der 1950er Jahre fand, um mit Erker zu sprechen, eine „Entprovinzialisierung dörflichen Lebens“ statt ${ }^{255}$, die zu einer Schwächung dörflicher Gruppenabhängigkeiten führte und die auch den kleinen Selbständigen einen Zuwachs an sozialer Autonomie bescherte. Dieser Prozeß war freilich Anfang der 1960er Jahre keinesfalls abgeschlossen, sondern hält bis zur Gegenwart an ${ }^{256}$.

\footnotetext{
249 Balzer, S. 250-253.

250 Ebenda, S. 255.

251 Der Einzelhandel in Dorf und Kleinstadt, in: Magazin des Lebensmitteleinzelhändlers, April 1951, Nr. 24, S. 6.

${ }^{252}$ Ebenda.

${ }^{253}$ Kappe, S. 237.

${ }^{254}$ Kappe, S. 114. Für die in stadtnahen Gemeinden wohnenden Einzelhändler war der Zwang zur Anpassung nicht ganz so kraß.

255 Erker, Revolution, S. 425.

${ }^{256}$ Zur sozialen Funktion des Einzelhandels in einer Arbeitergemeinde der 1970er Jahre vgl. Lehmann, S. 109-111.
} 


\section{Kirchgangshäufigkeit}

Schicht- und berufsübergreifende soziale Kontakte fanden in organisierter Form nicht nur in Vereinen, sondern auch in der Kirche statt. Der sonntägliche Kirchenbesuch stellte ein Minimum an sozialer Teilhabe im Rahmen der Gemeinde dar. Wie hoch war der Anteil derjenigen Handwerker und Einzelhändler, die regelmäßig den Gottesdienst besuchten? In den Kirchenstatistiken der 50er Jahre, insbesondere in denen der evangelischen Kirche, finden sich keine berufsgruppenspezifischen Daten zur Kirchgangshäufigkeit. Die wenigen zeitgenössischen Repräsentativerhebungen, die es gibt, haben den Nachteil, daß sie, wenn überhaupt, nur die selbständigen Handwerker, nicht aber die selbständigen Einzelhändler gesondert ausweisen.

Einer 1955 in der Stadt Marl durchgeführten Umfrage ist zu entnehmen ${ }^{257}$, daß die Kirchgangshäufigkeit bei den Katholiken $51,3 \%$ betrug und damit mehr als dreimal so hoch lag wie bei den Protestanten ${ }^{258}$. Von den selbständigen protestantischen Handwerkern nahm nur eine kleine Minderheit von 12,5\% regelmäßig am Gottesdienst teil. Die katholischen Berufskollegen wiesen mit einer Besuchsquote von $66,1 \%$ eine wesentlich stärkere Kirchenbindung auf. Dieser Prozentsatz entsprach in etwa dem der Beamten und Angestellten. Bei den katholischen Gesellen betrug der Anteil der Kirchgänger $46,9 \%$ und bei den Bergarbeitern gar nur 30,7\%. In Reutlingen hatten die katholischen Handwerker in Relation zu ihrem Anteil am Kirchenvolk in den Jahren 1955/56 die höchste Beteiligung an Gottesdienst und Abendmahl aufzuweisen ${ }^{259}$. Auch Weyands Untersuchung zum Dekanat Marl, die auf Daten aus den Jahren 1955 und 1957 beruht, kommt zu dem Ergebnis, daß die selbständigen katholischen Handwerker in Relation zu ihrem Anteil an der Erwerbsbevölkerung unter den Gottesdienstbesuchern leicht überrepräsentiert waren. Das gleiche gilt für die Kategorie der Geschäftsleute, zu der allerdings neben den Kaufleuten auch die freien Berufe gezählt wurden ${ }^{260}$.

Berücksichtigt man, daß in der Altersgruppe der Erwachsenen die älteren Jahrgänge häufiger unter den Kirchgängern vertreten waren als die jüngeren, so liegt die Vermutung nahe, die überdurchschnittliche Beteiligungsquote der Handwerker hänge zumindest teilweise mit ihrem vergleichsweise hohen Durchschnittsalter zusammen. Die Differenz zwischen der Kirchgangshäufigkeit der Arbeiter und der selbständigen Handwerker ist indes zu groß, als daß sie vornehmlich auf die unterschiedliche Altersschichtung dieser beiden Berufgruppen zurückgeführt werden könnte261.

Ein wesentlich wichtigerer Einflußfaktor ist in dem jeweiligen sozialkulturellen Milieu zu sehen, dem die Kirchgänger angehörten. So war z. B. in der Industriepfarrei des Marler Dekanats die Kirchgangshäufigkeit in allen Berufsgruppen deutlich geringer als in den ländlichen Pfarreien. Auf dem Land betrug der Anteil der Kirchgänger unter den männlichen Handwerkern 79,7\%. Zusammen mit den Landwirten standen sie hier in bezug auf den Anteil der Kirchgänger an der Spitze der Berufsgruppen; in der Industrie-

257 Kieslich, S. 100.

${ }^{258}$ Dieses Ergebnis scheint durchaus repräsentativ für die Bundesrepublik zu sein, da auch Reigrotzki auf der Basis einer überregional angelegten Erhebung aus dem Jahre 1953 zu einem ähnlichen Resultat kommt; vgl. Reigrotzki, Soziale Verflechtungen, S. $38 \mathrm{f}$.

${ }^{259}$ Tenbruck, S. 127.

260 Weyand, S. $122 \mathrm{f}$.

${ }^{261}$ Ebenda, S. 114; zum allgemeinen Zusammenhang zwischen Altersschichtung und Kirchgang vgl. Tenbruck, S. 126; Köster, S. 90. 
pfarrei nahmen sie dagegen mit einer Quote von $32,4 \%$ einen mittleren Platz ein ${ }^{262}$. Diese Diskrepanz dürfte vor allem mit der im Vergleich zur Stadt höheren und damit exponierteren sozialen Stellung der Handwerker in der dörflichen Gesellschaft zu erklären sein. In bezug auf die selbständigen Handwerkerinnen greift dieser Erklärungsansatz allerdings nicht, da diese sowohl auf dem Land als auch im industriell-städtischen Milieu im Vergleich zu den übrigen "weiblichen“ Berufsgruppen die höchste Kirchgangshäufigkeit aufwiesen ${ }^{263}$.

Wie entwickelte sich nun die Kirchenbindung der gewerblichen Mittelständler im Zeitverlauf? Diese Frage läßt sich zumindest ansatzweise anhand der Daten beantworten, die von Köster 1956 in einer evangelischen Gemeinde einer norddeutschen Industriegroßstadt erhoben wurden. Demnach waren zum Zeitpunkt der Erhebung die Selbständigen in der Gruppe der "Kirchentreuen" entsprechend ihrem Bevölkerungsanteil vertreten ${ }^{264}$. Als kirchentreu wurde eingestuft, wer mindestens einmal im Monat den Gottesdienst besuchte. In der Vätergeneration der Befragten waren die Selbständigen unter den regelmäßigen Kirchgängern deutlich überrepräsentiert ${ }^{265}$. Nach Auffassung von Köster läßt sich diese Differenz zwischen den Generationen nicht primär auf die quantitative Abnahme der selbständigen Berufspositionen zurückführen. Hierin schlage sich vielmehr „eine seit etwa dreißig Jahren in Gang befindliche Entwicklung nieder, im Verlauf derer die Selbständigen aus der Kirche bzw. aus dem Kreis der Kirchentreuen auswanderten. Es ist ganz deutlich, daß das bei den Einzelhändlern und selbständigen Handwerkern mit der Anpassung an die Wirtschaftsmentalität der modernen

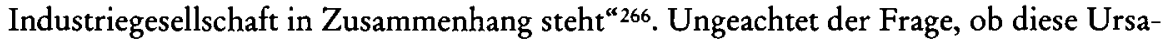
chenbestimmung zureichend ist, gibt es für die frühe Bundesrepublik in der Tat Hinweise auf eine verstärkte Abkehr der genannten Berufsgruppen von der Kirche. Anfang der 50er Jahre waren z. B. in Hannover und Hamburg rund 20\% derjenigen, die aus der evangelischen Kirche austraten, Handwerker. Gemessen an ihrem Anteil an der Gesamtbevölkerung, waren die Handwerker unter den Austretenden extrem überrepräsentiert. Keine andere Berufsgruppe hatte eine solch hohe Austrittsquote zu verzeichnen ${ }^{267}$.

Versucht man aus dem hier präsentierten, insgesamt recht disparaten Quellenmaterial allgemeine Schlüsse zu ziehen, so ist vor allem darauf hinzuweisen, daß die Konfessionszugehörigkeit und der Wohnort bzw. das soziale Milieu einen wesentlich stärkeren Einfluß auf die Kirchgangshäufigkeit hatten als die Variable „Beruf“ “ Zumindest für die protestantischen Handwerker läßt sich mit einiger Sicherheit sagen, daß die Kirche als Ort, an dem sozialer Austausch stattfindet, nur von marginaler Bedeutung war. Auf die Gruppe der katholischen Handwerker, die einen wesentlich höheren Anteil an Kirchgängern aufwies, ist diese Aussage nicht ohne weiteres zu übertragen.

Die untersuchte Kirchenbindung sagt natürlich nicht nur etwas über Sozialbeziehungen, sondern auch über die Religiosität der Mittelständler und damit über verhaltensrelevante Normen aus. Versucht man indes aufgrund quantitativer Angaben zum Kirchenbesuch, der ja „nur eine der möglichen Formen kirchengebundener Religiosität" dar-

\footnotetext{
262 Weyand, S. $113 \mathrm{f}$.

${ }^{263}$ Ebenda.

${ }^{264}$ Köster, S. 97 f., Tab. 40.

${ }^{265}$ Ebenda, S. 99.

266 Ebenda.

${ }^{267}$ Reich, S. 384.
} 
stellt ${ }^{268}$, auf den Einfluß religiöser Verhaltensregeln im Alltag zu schließen, läuft man Gefahr, sich in das Reich der Spekulation zu begeben ${ }^{269}$. Methodisch unbedenklicher ist die Frage nach dem Stellenwert der Religiosität für die soziale Identität der Mittelständler. Die hierzu vorliegenden Umfrageergebnisse lassen erkennen, daß nur ein äußerst geringer Teil der befragten Handwerker und Einzelhändler den regelmäßigen Gottesdienstbesuch als Mittelstandsmerkmal betrachtete ${ }^{270}$.

\section{Intergenerationelle berufliche Mobilität}

\section{Soziale Herkunft}

Die soziale Herkunft von Bevölkerungsgruppen gehört zu den Grundfragen der Mobilitätsforschung. Herkunftsstudien beschäftigen sich mit einem Teilaspekt intergenerationeller Mobiltät. Sie zeigen auf, aus welchen gesellschaftlichen Schichten sich soziale Gruppen rekrutieren, wobei die Berufe der Väter i.d.R. den Bezugspunkt darstellen. Auf den gewerblichen Mittelstand übertragen, stellt sich die Frage, welchen Stellenwert die Selbstrekrutierung einnahm, d. h. es soll der Anteil derjenigen Handwerker und Einzelhändler ermittelt werden, deren Väter sich in einer vergleichbaren beruflichen Position befanden. Ein besonderes Augenmerk gilt der Frage, wie hoch der Prozentsatz der Arbeitnehmerkinder in den Reihen der Kleingewerbetreibenden war. Grundsätzlich wird von folgender Beziehung ausgegangen: Je verbreiteter die Fremdrekrutierung, desto geringer die soziale Homogenität und desto größer die soziale Distanz zwischen den Berufskollegen. Diese Hypothese beruht auf der Annahme, daß die Sozialisation innerhalb einer Handwerkerfamilie bzw. einer Einzelhändlerfamilie die Bildung eines berufsständischen Gemeinschaftsbewußtseins und mittelständischer Lebensformen in besonderer Weise begünstigte.

Das grundlegende Problem des gewählten methodischen Ansatzes besteht darin, daß sich im Rahmen einer Rekrutierungsanalyse keine Aussagen über Zugangschancen z. B. von Arbeitern zum selbständigen Handwerk - treffen lassen ${ }^{271}$. Auch die Wahrscheinlichkeit der „Berufsvererbung “ im gewerblichen Mittelstand läßt sich auf diese Weise nicht bestimmen. Hierzu müßten Daten zur Berufswahl aller Kinder der Vätergeneration vorliegen. Da im Rahmen dieser Globalanalyse darauf verzichtet wurde, derartige Datensätze herzustellen, liegt der Schwerpunkt der folgenden Analyse auf Her-

\footnotetext{
268 Boos-Nünning/Golomb, S. 24.

${ }^{269}$ Zum Zusammenhang zwischen Konfession und ökonomischer Werthaltung vgl. Ellinghaus, S. 83-85. Der Autor kommt zu dem Schluß, daß der Einfluß der Konfession auf die Wirtschaftsorientierung der Handwerker gering zu veranschlagen ist. Inwieweit dieser Befund auch für den sozialen Bereich zutrifft, geht aus dieser Untersuchung allerdings nicht hervor. In einem gewissen Widerspruch zu Ellinghaus' Ergebnissen steht die Tatsache, daß mit steigender Betriebsgröße der Anteil der katholischen Selbständigen sank. Aus den Volkszählungsdaten von 1961 ist allerdings ersichtlich, daß sich dieser Trend, der in Industrie und Handel stärker war als im überwiegend kleinbetrieblich strukturierten Handwerk, erst ab einer Betriebsgröße von 50 und mehr Beschäftigten nennenswert auswirkte; vgl. Nellessen-Schumacher, S. 48-54. Die Erörterung dieses interessanten Phänomens würde den in diesem Kapitel verfolgten Erkenntnisrahmen sprengen.

${ }^{270}$ Hagemann, S. 316, Tab. 147; Sack, S. 96, Tab. 39.
}

${ }^{271}$ Bolte/Recker, S. $48 \mathrm{f}$. 
kunftsdaten, wie sie z. B. von den Handwerkskammern erhoben wurden. Die Einzelhandelsorganisationen haben derartige Erhebungen im Untersuchungszeitraum nicht angestellt. Die im folgenden präsentierten Daten erlauben nur begrenzte Einblicke in die intergenerationelle berufliche Mobilität, greifen aber über den gerade in bezug auf das Kleinunternehmertum sehr dürftigen Forschungsstand hinaus ${ }^{272}$.

Die Sozialstatistiken der Handwerksorganisation enthalten Angaben zur sozialen Herkunft von Meisterprüflingen. Bei der Auswertung dieser Daten ist zu berücksichtigen, daß sich nur ein Teil der Gesellen, die sich der Meisterprüfung unterzogen, selbständig machte. Schon allein aufgrund der Möglichkeit der Betriebsvererbung ist davon auszugehen, daß die Selbstrekrutierungsquote in der Gruppe der selbständigen Handwerker höher lag als bei den Meisterprüflingen. Ein Teil der herangezogenen Statistiken bezieht sich auf Meisteranwärter und nicht auf die erfolgreichen Absolventen der Meisterprüfung. Im Zeitraum von 1951 bis 1955 betrug die Durchfallquote $13,6 \%{ }^{273}$, d. h. die hieraus möglicherweise resultierenden Verzerrungen verfälschen den Gesamttrend nur unwesentlich.

Bundesweite Ergebnisse zur sozialen Herkunft der Meisterprüflinge liegen für das Jahr 1953 vor $^{274}$. Demnach betrug der Anteil der Meisterprüflinge, deren Väter selbständige Handwerker waren, 38,8\%. 9,2\% der Väter waren in der Land- und Forstwirtschaft und $4,1 \%$ als Selbständige im Sektor Handel und Verkehr tätig. Insgesamt entstammten etwas mehr als die Hälfte $(54,9 \%)$ aller Meisterprüflinge einem Selbständigenhaushalt. Auffällig ist der geringe Prozentsatz an Gesellen mit kaufmännischer Herkunft. Der Anteil derjenigen Prüflinge, die Beamten- und Angestelltenfamilien angehörten, war demgegenüber weitaus höher (15\%). 29,1\% der Gesellen, die sich zur Prüfung anmeldeten, kamen aus einer Arbeiterfamilie. Interessant ist, daß in der Vätergeneration Industriefacharbeiter, ungelernte Arbeiter und Handwerksgesellen anteilsmäßig fast gleichermaßen vertreten waren (jeweils rund $9 \%$ ). Wenn man davon ausgeht, daß letztere innerhalb der Arbeiterschaft die kleinste Gruppe bildeten, so liegt der Schluß nahe, daß die Töchter und Söhne von Handwerksgesellen im Vergleich zu den Kindern von Industriefacharbeitern und Ungelernten unter den Meisteranwärtern überproportional vertreten waren. Addiert man die Meisterprüflinge, deren Väter Handwerksgesellen waren, zu den aus dem selbständigen Handwerk stammenden Meisteranwärtern hinzu, so wird ersichtlich, daß fast jeder zweite Geselle, der die Meisterprüfung ablegte, einer Familie angehörte, die dem Handwerk beruflich verbunden war. Sieht man von den Selbständigenkindern ab, so verfügte nur ein knappes Drittel der Meisteranwärter über eine "handwerksfremde" Herkunft.

Auf der Grundlage einzelner Handwerkskammerstatistiken läßt sich abschätzen, wie sich die Herkunftsanteile im Untersuchungszeitraum verschoben. Entsprechende Daten liegen z. B. für den Handwerkskammerbezirk Bielefeld vor. Die Bielefelder Meister-

\footnotetext{
272 Zum Forschungsstand vgl. Kaelble, S. 326.

${ }^{273}$ Watrin, S. 154.

${ }^{274}$ DHBI 6, H. 5 (10.3.1954), S. 66. Die Daten aus den Ländern Schleswig-Holstein, Hamburg, Niedersachsen, Nordrhein-Westfalen, Rheinland-Pfalz und Bayern wurden zu einem gewogenen Bundesdurchschnitt zusammengefaßt. Ähnliche Herkunftsstrukturen läßt die Statistik über die soziale Herkunft von 2490 Meisterprüflingen des niedersächsischen Handwerks im Zeitraum vom 31.5.1951 bis 31.12.1951 erkennen; vgl. Nordwestdeutsches Handwerk 52, Nr. 4 (23.2.1952), S. 49.
} 
prüfungsstatistik zeichnet sich durch zwei Besonderheiten aus. Es wurde lediglich die soziale Herkunft der männlichen Meisterprüflinge ausgewiesen. Außerdem wurden nur diejenigen Gesellen erfaßt, die die Meisterprüfung bestanden hatten. Im Jahre 1952 bezifferte sich die Selbstrekrutierungsquote der männlichen Meisterprüflinge auf $35 \%$, was etwa dem ein Jahr später erhobenen Bundesdurchschnitt entsprach. In den folgenden Jahren schwankte dieser Anteil nur geringfügig. Im Jahre 1960 betrug er 38\%. Nennenswerte Veränderungen waren nur bei den aus der Landwirtschaft stammenden Meisterprüflingen zu verzeichnen. In dieser Kategorie ging der Herkunftsanteil von 10\% im Jahre 1952 auf 3\% im Jahre 1960 zurück. Eine leichte Zunahme von 9 auf $13 \%$ ist bei den Prüflingen festzustellen, deren Väter Handwerksgesellen waren. Das gleiche gilt für die kaufmännische Herkunftsschicht (Steigerung von 4 auf $9 \%)^{275}$. Die Daten zum Handwerkskammerbezirk Braunschweig deuten ebenfalls darauf hin, daß der Anteil der Söhne von selbständigen Landwirten rückläufig war ${ }^{276}$. Daß sich die Selbstrekrutierungsquote des Handwerks bis Anfang der 70er Jahre nicht entscheidend veränderte, läßt eine zu diesem Zeitpunkt vorgenommene Rekrutierungsanalyse erkennen. Demnach hatten $42 \%$ der selbständigen Handwerker Väter, die ebenfalls selbständige Handwerker gewesen waren 277 . Diese Zahlen sollten allerdings nicht überinterpretiert werden, da sie nur bedingt mit den Meisterprüfungsstatistiken vergleichbar sind.

Auf der Ebene der einzelnen Handwerksgruppen und -zweige ist das Herkunftsprofil der Meisterprüflinge quellenmäßig schwer faßbar. Entsprechende Daten finden sich in Lamprechts Studie über die Handwerkskammerbezirke Dortmund und Münster ${ }^{278}$. Diese Untersuchung, die sich auf 2012 Erhebungsbogen aus den Jahren 1949 und 1950 stützt, ist allerdings methodisch insofern problematisch, als sie den Vaterberuf nicht nach selbständiger und unselbständiger Berufsstellung disaggregiert. Aus den präsentierten Daten geht also nicht hervor, ob die untersuchten männlichen Meisteranwärter Söhne von Handwerksgesellen oder selbständigen Handwerkern waren ${ }^{279}$. Besonders verbreitet war die „,erweiterte“, auf selbständige und unselbständige Handwerker bezogene Selbstrekrutierung in den Nahrungsmittel- und Holzhandwerken sowie in der Gruppe der sonstigen Handwerke. Das Bauhandwerk wies im Handwerkskammerbezirk Dortmund eine sehr niedrige und im Bezirk Münster eine sehr hohe Selbstrekrutierungsquote auf, ein klarer Trend läßt sich also nicht ausmachen. Im Bekleidungs- und Metallhandwerk war die Berufsvererbung am geringsten. Im Bekleidungsgewerbe hing dies vor allem damit zusammen, daß hier aufgrund des geringeren Technisierungs- und

${ }^{275}$ Tätigkeitsbericht der Handwerkskammer Bielefeld für die Zeit vom 1. April 1948 bis zum 31. Dezember 1953, S. 95; Die Handwerkskammer Bielefeld 1954-1957, Situations- und Tätigkeitsbericht, S. 108; Handwerkskammer Bielefeld, Tätigkeitsbericht 1958-1960, S. 99.

${ }^{276}$ Handwerkskammer Braunschweig, Tätigkeitsbericht für die Zeit vom 1. Januar bis 31. Dezember 1953, S. 31; Handwerkskammer Braunschweig, Tätigkeitsbericht für die Zeit vom 1. Januar bis 31. Dezember 1954, S. 38.

277 Hofbauer/Kraft, S. 214.

${ }^{278}$ Lamprecht, Lebensbild, S. 30-36.

${ }^{279}$ In der Absicht, die Herkunftsbestimmung zu spezifizieren, führt Karl Heinz Lampert bei seiner Darstellung der Ergebnisse zum Handwerkskammerbezirk Dortmund die Kategorie "Handwerksmeister" ein; ebenda, S. 31. Da nicht davon ausgegangen werden kann, daß alle Handwerksmeister selbständig waren, finden diese Ergebnisse im folgenden keine Berücksichtigung. 
Kapitalbedarfs „für Arbeitersöhne eine größere Chance einer Werkstatteröffnung besteht ${ }^{\text {“280. }}$.

Betrachtet man die Herkunftsstruktur einzelner Handwerkszweige im Kammerbezirk Dortmund, so sind bezüglich der Selbstrekrutierungsquote und des Anteils der aus der Berg- und Industriearbeiterschaft stammenden Meisteranwärter noch größere Schwankungen zu konstatieren als auf der Ebene der Handwerksgruppen. Sehr hoch war die Berufsvererbung bei den Schornsteinfegern, Stellmachern, Fleischern und Schmieden. Im Schlosser-, Rundfunkmechaniker- und Klempnerhandwerk sowie bei den Polsterern und Maurern war der Anteil der Handwerkersöhne am geringsten ${ }^{281}$. Die hierfür in Frage kommenden Ursachen sind vielfältig. So ist z. B. beim Bauhandwerk zu vermuten, daß der Rückgang der Selbstrekrutierungsquote vor allem durch die Expansion dieser Branche und den damit verbundenen Anstieg des Bedarfs an Führungskräften bedingt war. Bei den modernen Handwerken wiederum war der Zustrom von handwerksfremden Kräften nicht zuletzt auf die fehlende handwerkliche Berufstradition zurückzuführen.

Das Datenmaterial zur sozialen Herkunft derjenigen Meisterprüflinge, die sich tatsächlich selbständig machten, ist eng begrenzt. Laut einer Untersuchung aus dem Jahre 1964, die in einer Kleinstadt und einer Großstadt durchgeführt wurde, betrug der Anteil derjenigen großstädtischen Handwerker, deren Väter ebenfalls selbständige Handwerker waren, $57 \%$. Jeweils $14 \%$ waren Kinder selbständiger Händler und selbständiger Landwirte. Aus der Arbeiterschaft stammten lediglich 5\%. In der Gruppe der befragten kleinstädtischen Handwerker war die Selbstrekrutierungsquote sogar noch höher (73\%). In der Vätergeneration waren die Arbeiter mit $10 \%$ etwas stärker vertreten. Die selbständigen Händler und Landwirte spielten hier als Rekrutierungsbasis mit einem Anteil von jeweils 3\% nur eine marginale Rolle ${ }^{282}$. Obgleich diese Daten aufgrund ihrer eingeschränkten Repräsentativität vorsichtig zu interpretieren sind, läßt sich ihnen immerhin entnehmen, daß die Selbstrekrutierungsquote der selbständigen Handwerker deutlich über der der Meisterprüflinge lag. Das entsprechende Datenmaterial zum ländlichen Handwerk in Schleswig-Holstein bestätigt diese Schlußfolgerung: dort hatten $47,3 \%$ die Berufsposition ihrer Väter übernommen. 26\% kamen aus Bauernfamilien ${ }^{283}$. Die berufliche Laufbahn nach der Meisterprüfung führte also vor allem Selbständigenkinder ins Handwerk. Arbeiterkinder schafften auch mit Meistertitel nur selten den Sprung in die Selbständigkeit ${ }^{284}$. Diese Asymmetrie der Herkunftsstrukturen wird man kaum auf die quantitativ eher marginale Betriebsvererbung zurückführen können. Es scheint vielmehr, als habe bei den Kindern von selbständigen Handwerkern eine Ver-

280 Ebenda, S. 31.

281 Ebenda, S. 107-111 (Tab. 11-14). Auf Zahlenangaben wird hier bewußt verzichtet, da davon auszugehen ist, daß die Fremdrekrutierung in der Industrieregion Dortmund, die durch einen überdurchschnittlich hohen Arbeiteranteil gekennzeichnet war, nur sehr bedingt die Verhältnisse im gesamten Bundesgebiet widerspiegelt.

${ }_{282}$ Daheim/Kaupen-Haas/Kaupen, Bd. 2, S. 7, Tab. 20.

283 Balzer, S. 225, Tab. 47.

284 Beckermann, Auslese, S. 26, schreibt hierzu: „Fast drei Zehntel der Jungmeister kommen allein aus der Arbeiterschaft. In diesen Kreisen ist die Spartätigkeit seit jeher gering und es fehlt daher oft die Voraussetzung, einen Handwerksbetrieb zu gründen oder zu übernehmen." (S. 26) 
haltensdisposition vorgeherrscht, bei der die Selbständigkeit als erstrebenswertes Ziel einen relativ hohen Stellenwert einnahm.

Daten zur sozialen Herkunft einzelner Handwerksbranchen sind z.B. im Rahmen der im Jahre 1959 bzw. 1962 vorgenommenen Erhebungen zum Kölner Schreiner- und Schuhmacherhandwerk entstanden. 45,6\% der befragten Schreiner gaben an, ihre Väter seien im gleichen Gewerbe tätig gewesen. Die Väter von weiteren $16 \%$ gehörten anderen Handwerksbranchen an. Der Arbeiteranteil in der Vätergeneration bezifferte sich auf $10,4 \% 285$. Im Schuhmacherhandwerk betrug die auf die eigene Branche bezogene Selbstrekrutierungsquote $41 \% .10 \%$ der befragten Schuhmacher waren Söhne bzw. Töchter von sonstigen Handwerkern. $12 \%$ stammten von Facharbeitern und $14 \%$ von un- und angelernten Arbeitern ab286. Wenn auch davon auszugehen ist, daß ein Teil der Befragten nicht zwischen unselbständiger und selbständiger Berufsstellung ihrer Väter unterschied, ist der relativ geringe Prozentsatz der Schuhmacher und Schreiner, die aus einer Arbeiterfamilie kamen, bemerkenswert. Es drängt sich der Eindruck auf, als seien diese beiden ökonomisch keineswegs prosperierenden Handwerke als Aufstiegsposition für Arbeiterkinder zunehmend unattraktiver geworden. Hierbei handelt es sich freilich nur um eine Hypothese. Eindeutiger sind dagegen die Ergebnisse zur Selbstrekrutierung: Diese fand vornehmlich in der eigenen Handwerksbranche statt. Die Schuhmacher beispielsweise rekrutierten sich häufiger aus der Facharbeiterschaft als aus den übrigen Handwerksberufen. Die Repräsentativität dieses Befundes vorausgesetzt, läßt sich die These formulieren, daß der durch intergenerationelle Mobilitätsvorgänge gestiftete soziale Zusammenhalt im Gesamthandwerk geringer war, als die Berufsstandsideologen wahrhaben wollten. Jürgens kommt in seiner im Jahre 1959 fertiggestellten Studie über das Kieler Handwerk ebenfalls zu dem Ergebnis, daß die einzelnen Branchen als Bezugspunkt der beruflichen Mobilität von zentraler Bedeutung waren: $68 \%$ der befragten Handwerksmeister gaben an, daß ihre Väter Handwerker waren, wobei unklar ist, ob in selbständiger oder abhängiger Stellung. Rund die Hälfte der Handwerkersöhne war in der gleichen Branche tätig wie der Vater ${ }^{287}$.

Zur sozialen Herkunft der Einzelhändler liegt kaum Quellenmaterial vor ${ }^{288}$. Eine Ausnahme bildet eine 1964 unter selbständigen Händlern durchgeführte Umfrage, wobei allerdings neben den Einzelhändlern auch die Großhändler erfaßt wurden. In der Gruppe der befragten großstädtischen Händler betrug die Selbstrekrutierungsquote $51 \%$, also etwa so viel wie im Handwerk ${ }^{289}$. Die Tatsache, daß $28 \%$ der Händler dem

\footnotetext{
${ }^{285}$ Sack, S. 150.

${ }^{286}$ Greber, S. 98.

287 Jürgens, S. $55 \mathrm{f}$.

${ }^{288}$ Bedauerlicherweise wurde in der DIVO-Untersuchung von 1959 (Der westdeutsche Markt, 1962) nur die soziale Herkunft der Händler erhoben. Da diese Kategorie neben den Einzelhändlern auch Großhändler und sonstige Kaufleute umfaßt, wurde auf eine Präsentation dieser Daten verzichtet. Darüber hinaus bestehen Bedenken bezüglich der Repräsentativität dieses Datensatzes, demzufolge nur 27\% der Handwerker Kinder von Selbständigen waren. Dieser Prozentsatz weicht von sämtlichen oben präsentierten Daten deutlich ab und ist daher in Frage zu stellen; vgl. Daheim, Vorstellungen, S. 273, Tab. II.

${ }^{289}$ Daheim/Kaupen-Haas/Kaupen, Bd. 2, S. 7, Tab. 20. Eine Infratest-Erhebung aus dem Jahre 1968 ermittelt ähnliche Werte. Die Selbstrekrutierungsquote der "kleinen Selbständigen“ lag bei etwas über $50 \%$. Ein statistisch signifikanter Stadt-Land-Unterschied ist nicht nachweisbar; vgl. Walter Müller, Familie, S. 87, Tab. 17.
} 
Handwerk entstammten, ist ein Indiz für die soziale Nähe der mittelständischen Berufsgruppen. Die Angestellten und Arbeiter waren in der Vätergeneration der Befragten jeweils mit $5 \%$ vertreten. Der entsprechende Anteil der Landwirte lag bei $3 \%$. In der untersuchten Kleinstadt bezifferte sich der Anteil derjenigen, die ebenso wie ihre Väter selbständige Händler waren, lediglich auf $20 \%$. Um so höher war dafür der Anteil der selbständigen Händler, die aus Handwerker- (34\%) und Bauernfamilien (17\%) kamen $^{290}$. Aufs Ganze gesehen, war also auch hier die Selbständigenquote in der Vätergeneration außerordentlich hoch. Die Ursachen dürften die gleichen sein wie im Handwerk. Hervorzuheben ist die zwischen Handwerk und Handel bestehende Verflechtung der Herkunftsströme, wobei allerdings die Händler häufiger aus Handwerkerfamilien stammten als umgekehrt ${ }^{291}$. Die von Kappe zum ländlichen Einzelhandel erhobenen Daten stimmen im großen und ganzen mit den Untersuchungsergebnissen von $\mathrm{Da}$ heim und Mitarbeitern überein: Die Selbstrekutierungsquote lag in den untersuchten Gemeinden bei 29 (stadtfern) bzw. 19\% (stadtnah). Durchschnittlich entstammte also etwa jeder vierte Einzelhändler dem selbständigen Einzelhandel. Der Anteil der Selbständigen insgesamt lag dagegen in der Vätergeneration wesentlich höher (83\% in stadtfernen und $50 \%$ in stadtnahen Gemeinden) ${ }^{292}$.

Branchenspezifische Daten finden sich in der im Jahre 1959 durchgeführten Fallstudie zum Kölner Lebensmitteleinzelhandel. Bei 20,4\% der befragten Lebensmitteleinzelhändler war bereits der Vater als selbständiger Händler tätig. 12,8\% waren Söhne und Töchter von selbständigen Landwirten und $11,3 \%$ Kinder von selbständigen Handwerkern. 32\% der Lebensmitteleinzelhändler kamen aus einer Arbeiterfamilie und 14,7\% aus einer Angestellten- oder Beamtenfamilie ${ }^{293}$. Vergleicht man diese Zahlen mit der Herkunftsstruktur der von Daheim und Mitarbeitern befragten großstädtischen Händler, so fällt vor allem die niedrige Selbstrekrutierungsquote der Lebensmitteleinzelhändler auf. Auch der Selbständigenanteil insgesamt war in der Vätergeneration der Lebensmitteleinzelhändler vergleichsweise klein. Bemerkenswert ist zudem, daß die Arbeiterschaft die mit Abstand größte Herkunftsgruppe darstellte. Offenbar gehörte der Lebensmitteleinzelhandel zu jenen Einzelhandelszweigen, die von der Unterschicht aus relativ gut erreichbar waren.

Eine weitere Rekrutierungsanalyse zu einem Teilbereich des Einzelhandels stammt von Hans Gerd Schütte, der am Beispiel der Schüler der Braunschweiger DrogistenAkademie den Wandel der Herkunftsstruktur untersuchte. Im Unterschied zu den Lebensmitteleinzelhändlern rekrutierte sich der Drogisten-Nachwuchs kaum aus der Arbeiterschaft ${ }^{294}$. Wenngleich die Drogisten sowohl quantitativ als auch von der Art ihrer Tätigkeit her im Einzelhandel lediglich eine Randstellung einnahmen, so zeigt doch dieses Beispiel die zwischen den Einzelhandelsberufen bestehenden Unterschiede.

Ein interessantes Faktum zum intragenerationellen Mobilitätsverhalten fördert Krisams 1959 durchgeführte Mittelstandserhebung zutage. Demnach hatten 59\% der männlichen Einzelhändler, aber nur 10\% der männlichen Handwerker einen Erstberuf, der mit

290 Daheim/Kaupen-Haas/Kaupen, Bd. 2, S. 7, Tab. 20.

291 Ebenda.

${ }^{292}$ Kappe, S. 204-207, Tab. 18 und 19. Die Erhebung wurde 1956/57 durchgeführt.

${ }^{293}$ Hagemann, S. 106-109.

294 Schütte, S. $63 \mathrm{f}$. 
ihrer späteren Tätigkeit als Selbständige in keinem Zusammenhang stand ${ }^{295}$. Daheims Erhebung von 1964 läßt erkennen, daß die Handwerker häufiger als die Einzelhändler den Betrieb direkt nach ihrer Ausbildung übernahmen. Der Anteil derjenigen Selbständigen, die während ihrer beruflichen Laufbahn in einem fremden Großbetrieb gearbeitet hatten, war im Handwerk geringer als im Einzelhandel ${ }^{296}$. Wenn man davon ausgeht, daß eine geringe Berufsstetigkeit im Karriereverlauf i.d.R. mit einer schwächeren Bindung an den Beruf einherging, so hätte man zumindest eine Teilerklärung dafür, warum die Selbstrekrutierung im Einzelhandel tendenziell niedriger ausfiel als im Handwerk.

\section{Intergenerationelle berufliche Auf-und Abstiegsmobilität}

Versucht man trotz der eingangs geschilderten Quellenproblematik Aussagen über die im Kontext unserer Fragestellung relevanten intergenerationellen Abstromquoten zu machen ${ }^{297}$, so ist man auf Schürens Untersuchung und Datensammlung zur beruflichen Mobilität im 19. und 20. Jahrhundert angewiesen. Vier der im Rahmen dieser Studie verwendeten Datensätze reichen bis ins Jahr 1956. Es handelt sich dabei um Stichproben zu Berlin, Bielefeld, Oberhausen sowie zu dem in der Nähe von Münster gelegenen Industriedorf Borghorst. Die Berufsangaben der jeweiligen Kindergeneration werden den Heiratsregistern entnommen. Da seit 1920 die Berufe der Eltern in den standesamtlichen Listen nicht aufgeführt werden, ermittelt Schüren diese anhand der Kirchenbücher - ein nicht unproblematisches Verfahren, da der Vaterberuf nicht, wie üblich, zum Zeitpunkt der Heirat, sondern bei der Geburt der (späteren) Eheleute erfaßt wird ${ }^{298}$. Geht man davon aus, daß viele Handwerker und Einzelhändler zu einem Zeitpunkt heirateten, als sie noch Arbeitnehmer waren, so ergeben sich aus dem gewählten methodischen Ansatz Verzerrungen, die tendenziell zu einer quantitativen Unterbewertung der Selbständigenposition führen ${ }^{299}$. Dieser methodische Vorbehalt gilt insbesondere für das erste Nachkriegsjahrzehnt, in dem das Durchschnittsalter der Meisterprüflinge, insbesondere der männlichen Gesellen, besonders hoch lag ${ }^{300}$. Es gibt in der Tat Indizien

${ }^{295}$ Krisam, S. 112. Von den Kölner Schuhmachern waren $24 \%$ früher in anderen Berufen tätig gewesen; vgl. Greber, S. 105.

${ }^{296}$ Daheim/Kaupen-Haas/Kaupen, Bd. 2, S. 8, Tab. 24; S. 9, Tab. 24.

${ }^{297}$ Abstromquoten lassen erkennen, in welche Berufsgruppen die Söhne und Töchter einer bestimmten väterlichen Statusgruppe abwandern.

${ }^{298}$ Schüren, S. $37 \mathrm{f}$.

${ }^{299}$ Vgl. hierzu die methodologischen Bemerkungen von Lenger, Kleinbürgertum, S. 96.

${ }^{300}$ Lamprecht, Lebensbild, S. 108-111; das nach diesen Angaben errechnete Durchschnittsalter der männlichen Meisterprüflinge in den Jahren 1949/50 betrug in der Mehrzahl der Handwerksgruppen rund 35 Jahre. Diese Überalterung ist vor allem auf den Krieg zurückzuführen. Dies zeigt sich auch darin, daß im Verlaufe der 50 er Jahre das durchschnittliche Lebensalter der Prüflinge sank. Derlei Tendenzen sind z. B. erkennbar im Handwerkskammerbezirk Bielefeld; vgl. Tätigkeitsbericht der Handwerkskammer Bielefeld für die Zeit vom 1. April 1948 bis zum 31. Dezember 1953, S. 94; die Handwerkskammer Bielefeld 1954-1957, S. 106; Handwerkskammer Bielefeld, Tätigkeitsbericht 1958-1960, S. 98. In einer aus den 30er Jahren stammenden Studie über das Frankfurter Herrenschneiderhandwerk wurde festgestellt, daß seit den 1920er Jahren mehr als die Hälfte aller selbständigen Handwerker zu Beginn ihrer Karriere älter als 30 Jahre alt waren; vgl. Badow, S. 42. Daß auch im Einzelhandel die Selbständigkeit häufig erst nach Ausübung einer unselbständigen Tätigkeit erlangt wurde, belegt eine Fallstudie zum Lebensmitteleinzelhandel; vgl. Hagemann, S. $110 \mathrm{f}$. 
dafür, daß der Anteil derjenigen Handwerker, die erst nach der bestandenen Meisterprüfung bzw. nach der Errichtung oder Übernahme eines eigenen Betriebes heirateten, vergleichsweise niedrig lag ${ }^{301}$. Ein weiteres Problem von Schürens Berufsklassifikation besteht darin, daß die Kategorie "Handwerker" sowohl Handwerksgesellen als auch proletaroide Selbständige umfaßt. Die Kategorie „Meister, Wirte“ setzt sich zu 50\% aus Handwerksmeistern und zu jeweils $20 \%$ aus Gastwirten und Krämern zusammen. Fraglich ist zudem, ob tatsächlich alle Handwerksmeister selbständig waren.

Schürens Datenmaterial ist zu entnehmen, daß die Handwerksgesellen, die zahlenmäßig den größten Teil der Kategorie „Handwerker“ ausmachten, ein anderes intergenerationelles Mobilitätsverhalten an den Tag legten als die übrigen Gruppen der Arbeiterschaft. So gelang ihren Kindern der Aufstieg in die Mittel- und Oberschicht häufiger als beispielsweise den Nachkommen von ungelernten und gelernten Arbeitern. Die Berufsvererbung und die Endogamie waren im unselbständigen Handwerk besonders ausgeprägt ${ }^{302}$, die Bindung zum Handwerk also dementsprechend groß. Interessant ist jedoch, daß die Kinder von Handwerksgesellen und Inhabern handwerklicher Minderbetriebe nur sehr selten in Berufspositionen des gewerblichen Mittelstandes aufstiegen. Die Aufstiegsmobilität in dieser Richtung nahm nach dem Zweiten Weltkrieg sogar $\mathrm{ab}^{303}$, was vornehmlich mit dem berufsstrukturellen Wandel zusammenhängen dürfte, insbesondere mit der Expansion der Dienstleistungsberufe und dem zahlenmäßigen Rückgang der Selbständigenpositionen im gewerblichen Mittelstand. Des weiteren dürfte diese Entwicklung durch die zunehmenden Kapitalanforderungen bei Eröffnung bzw. Übernahme eines Betriebes begründet sein.

Im gewerblichen Mittelstand bestand Schürens Datenmaterial zufolge keine überdurchschnittliche Berufstradition. Nur 11,1\% der Söhne von gewerblichen Mittelständlern waren im Berlin des Jahres 1956 selbständige Mittelständler, in Borghorst waren es sogar nur 4,8\% ${ }^{304}$. Aufgrund der oben erläuterten Validitätsproblematik wird man diese Anteile wesentlich höher ansetzen müssen. Darauf lassen auch die 1971 ermittelten Abstromquoten von Männern der Geburtsjahrgänge 1920 bis 1936 schließen. Danach waren 30,5 \% der Söhne von Selbständigen mit maximal 10 Mitarbeitern Inhaber von gewerblichen Kleinbetrieben ( bis 10 Mitarbeiter). 3,1\% besaßen größere Betriebe. Von einer Berufsvererbung läßt sich bei den kleinen Selbständigen also etwa in einem Drittel der Fälle sprechen. Der Anteil derjenigen Selbständigensöhne, die in die Arbeiterschaft abwanderten, war fast ebenso hoch. Sehr verbreitet war zudem die Abwande-

301 Balzer, S. 232. Das durchschnittliche Heiratsalter der ländlichen Handwerker, die Balzer in Schleswig-Holstein befragte, betrug 28 Jahre und lag somit unter dem Durchschnittsalter der Meisterprüflinge. Eine in Kiel durchgeführte Erhebung ergab, daß $77 \%$ der Handwerker vor Vollendung des dreißigsten Lebensjahres heirateten. $30 \%$ waren sogar jünger als 25; vgl. Jürgens, S. 59.

302 Schüren, S. 215 f., 268-273, Tab. 5.5.1.

${ }^{303}$ Dieses Ergebnis deckt sich mit einer Mobilitätserhebung zur Stadt Köln; vgl. Daheim, Intergenerationen-Mobilität, S. 102.

${ }^{304}$ Schüren, S. 292-295, Tab. 6.3.1. Der säkulare Trend ist nicht eindeutig auszumachen: Die Borghorster Daten deuten auf eine signifikante Abnahme der Berufsvererbungsquote im Vergleich zur Zwischenkriegszeit hin. In Berlin lagen offenbar keine größeren Niveausprünge vor. 
rung in mittlere und gehobene Angestelltenpositionen (20,9\% ${ }^{305}$. Ungeachtet der Frage, wie repräsentativ diese Daten im Hinblick auf die hier interessierenden Berufsgruppen tatsächlich sind, läßt sich als Zwischenergebnis festhalten, daß mindestens zwei Drittel der Nachkommen von gewerblichen Mittelständlern die berufliche Position der Väter nicht übernahmen.

Wohin strömten nun die Söhne und Töchter von selbständigen Handwerkern, Einzelhändlern und Gastwirten? In Berlin wanderten im ersten Nachkriegsjahrzehnt rund die Hälfte in das unselbständige bzw. proletaroide selbständige Handwerk ab, was auf eine enge Berufsverbundenheit hindeutet, zumal nicht ausgeschlossen ist, daß sich ein Teil dieser Personen im weiteren Lebensverlauf selbständig machte. In Borghorst betrug der entsprechende Anteil bei den Männern 14 und bei den Frauen 25\%. Die entscheidende berufliche Anlaufstation war hier die nichthandwerkliche Arbeiterschaft. Im Gegensatz zu Berlin war in Borghorst auch der Anteil derjenigen Mittelstandskinder, die Angestelltenberufe ergriffen, äußerst gering. An diesen, von den Berliner Ergebnissen abweichenden Befunden läßt sich der Einfluß ermessen, den regionalspezifische Bedingungen auf das Mobilitätsverhalten ausübten. Bemerkenswert ist - und dies gilt für beide Orte -, daß nur ein geringer Anteil der aus dem gewerblichen Mittelstand stammenden Kinder in die verwandten Selbständigenberufe der Kaufleute und Kleinunternehmer abwanderte. Auch untere Angestelltenpositionen wurden kaum frequentiert ${ }^{306}$. Der tertiäre Sektor wurde von den Mittelstandskindern selbst in den 50er Jahren verhältnismäßig selten angesteuert (von den Töchtern allerdings häufiger als von den Söhnen), die Verbindung zur Arbeiterschaft war demgegenüber wesentlich stärker.

Geht man von den Abstromraten aus, so war der gewerbliche Mittelstand weder für die Arbeiterschaft noch für den neuen Mittelstand eine nennenswerte Anlaufstation. Die Vorstellung, die Berufsgruppen des alten Mittelstandes seien eine Drehscheibe des sozialen Aufstieges gewesen, ist daher zu verwerfen ${ }^{307}$.

\section{Das soziale Prestige der Mittelständler - Fremdwahrnehmung und Selbsteinschätzung}

Die soziale Wertschätzung von Berufspositionen und die sich hierin ausdrückenden Vorstellungen über den vertikalen Aufbau der Sozialstruktur werden üblicherweise mit Hilfe von Prestigeskalen gemessen. Auf diese Weise läßt sich die Rangordung und damit auch die Prestigeabstufung der zu beurteilenden Berufspositionen ermitteln. Dieses in der schichtungssoziologischen Forschung der 50er und frühen 60er Jahre häufig ange-

305 Mayer/Müller, S. 116, Tab. 2. Die Daten stammen aus der Mikrozensus-Zusatzerhebung von 1971. Sie stimmen weitgehend mit den Ergebnissen einer hier nicht referierten Infratest-Erhebung aus dem Jahre 1968 überein; vgl. Walter Müller, Familie, S. 56 (Tab. 8). Beide Erhebungen sind allerdings im Hinblick auf die 50er Jahre nur bedingt aussagekräftig, da die befragten Jahrgänge nur teilweise mit den uns interessierenden Kohorten übereinstimmen. Problematisch ist auch, daß die Selbständigenkategorie neben Handwerkern und Kleinhändlern auch andere Berufsgruppen umfaßt.

306 Kaelble stellt auf der Grundlage von Herkunftsstudien ebenfalls fest, daß im 20. Jahrhundert Angestellte aus Familien von Handwerkern, Kleinhändlern und Landwirten seltener wurden; vgl. Kaelble, S. $309 \mathrm{f}$.

${ }^{307}$ Schüren, S. 231. 
wandte Verfahren ist methodisch nicht unproblematisch. Zum einen handelt es sich bei den Berufen, die von den Befragten miteinander in Beziehung gesetzt wurden, lediglich um eine kleine, nur bedingt repräsentative Auswahl. Zum anderen läßt sich die soziale Schichtstruktur nicht ohne weiteres aus der Prestigeordnung ableiten. Eine weitere Unsicherheit ergibt sich aus der sozialen Stellung derjenigen Personen, die die prestigemäßige Einstufung vornahmen ${ }^{308}$. Im Falle der Selbsteinstufung ist die Gefahr einseitiger Beurteilungen besonders groß, aber auch bei der Fremdeinschätzung können derartige Verzerrungen auftreten. Diese grundsätzlichen methodischen Vorbehalte gilt es mitzubedenken, wenn im folgenden das ausnahmslos zeitgenössischen soziologischen Studien entnommene Datenmaterial zur sozialen Wertschätzung der gewerblichen Mittelständler ausgewertet wird.

Repräsentative Daten zur Prestigedifferenzierung sind 1953/54 im Rahmen von Boltes Schleswig-Holstein-Studie erhoben worden ${ }^{309}$. Den Befragten wurden 38 Berufspositionen vorgelegt, die nach dem sozialen Ansehen geordnet werden sollten. Städtische und ländliche Bevölkerungsgruppen wurden getrennt befragt. Ebenso wurde mit den Gruppen der Jungarbeiter, Studierenden und Berufsschüler verfahren. Als wesentliches Ergebnis ist festzuhalten, daß sich die städtische Prestigeordnung von der ländlichen nicht prinzipiell unterschied ${ }^{310}$. Größere Abweichungen sind lediglich bei den landwirtschaftlichen Berufen zu konstatieren, die von den befragten Landbewohnern vergleichsweise hoch bewertet wurden. Die im Sample enthaltenen Berufe des selbständigen Mittelstandes (Textilkaufmann, Kolonialwarenhändler, Friseurmeister, Schneidermeister, Autoschlosser) wurden sowohl in der Stadt als auch auf dem Land im mittleren Bereich der Prestigeskala plaziert. Die Vermutung, daß die Einzelhandelsberufe generell höher oder niedriger eingestuft wurden als die Handwerksberufe, bestätigt sich nicht ${ }^{311}$. Sowohl in der Stadt als auch auf dem Land führte der Textilkaufmann, gefolgt vom selbständigen Autoschlosser, das Berufsfeld des gewerblichen Mittelstandes an. Ein kleiner, gemeindegrößenklassenabhängiger Unterschied bestand bei der Einordnung der Kolonialwarenhändler und Friseure. Die städtischen Befragten stuften letztere i.d.R. höher ein als die Kolonialwarenhändler. Auf dem Land, wo derartige „Luxushandwerke“ ohnehin seltener waren und auch kulturell eine geringere Bedeutung hatten, verhielt es sich umgekehrt. Der Friseur rangierte hier hinter dem selbständigen Schneidermeister, der nach der städtischen Erhebung das Schlußlicht der Selbständigen darstellte.

Abgesehen von zwei Ausnahmen schätzten sämtliche Befragtengruppen das soziale Ansehen der Industrie-Facharbeiter geringer ein als das von mittelständischen Selbständigen. Dies ist insofern bemerkenwert, als Schneider und Friseure in der Regel nicht mehr, sondern eher weniger verdienten als Facharbeiter in der Industrie. Die mittleren Angestellten wiederum nahmen in der Rangordnung in etwa den gleichen Platz ein wie die Handwerker und Einzelhändler. Angesichts dieser Bewertungsrelationen läßt sich die These vertreten, daß das soziale Ansehen nicht bloß durch das berufstypische Einkommensniveau, sondern darüber hinaus durch Berufsstellung und Ausbildungsstand wesentlich beeinflußt wurde. Einschränkend ist allerdings hinzuzufügen, daß die hö-

\footnotetext{
${ }^{308}$ Zur methodischen Problematik vgl. Bolte/Hradil, S. 213.

309 Bolte, Aufstieg, S. 31-67.

310 Ebenda, S. $54 \mathrm{f}$.

311 Ebenda, S. 38 f. (Tab. 4), S. 55 (Tab. 9).
} 
here Wertschätzung der Selbständigkeit zum Teil wohl auch auf der Unkenntnis der tatsächlichen Einkommensverhältnisse der selbständigen Mittelständler beruhte.

Wurzbachers Untersuchung der dörflichen Prestigeordnung, die im Grundsatz die gleichen Ergebnisse zutage förderte wie Boltes Erhebung, deutet ebenfalls darauf hin, daß die Verdienstsituation der selbständigen Mittelständler überschätzt wurde. Die Selbständigkeit war in den Augen der Dorfbewohner nicht nur Mittel zum Zweck, sondern auch Wert an sich. Das gilt ebenso für die berufliche Leistung: Der Handwerker war nicht zuletzt deshalb so angesehen, weil „er ,etwas gelernt' und mit der Meisterprüfung den Nachweis besonderer fachlicher Fähigkeiten erbracht habe“312. Das „Können“ des Ladeninhabers wurde demgegenüber gering geschätzt. Diese Sichtweise teilten auch die Handwerker selbst. Einer Umfrage aus dem Jahre 1959 zufolge ordneten sie - seltener als die befragten Händler - die Berufsposition des Lebensmitteleinzelhändlers in die gesellschaftliche Mitte ein. Die Händler hingegen hatten hohen Respekt vor dem Handwerk. So wurde z. B. der Schneidermeister von ihnen häufiger zur gesellschaftlichen Mitte gezählt als von den Handwerkern selbst ${ }^{313}$.

Mayntz' Untersuchungsergebnisse zur Prestigestruktur der Industriegemeinde Euskirchen stimmen weitgehend mit den bereits referierten Befunden überein. Auf der Grundlage der von den Befragten vorgenommenen Einstufungen der Berufspositionen könne man, so die Autorin, „die Selbständigen (außer jenen sehr großen, die hier als Unternehmer gerechnet werden), die mittlere Angestellten- und Beamtenschaft und ausschnittweise auch die einfachen Angestellten und Beamten als die eigentlichen Mittelstandsgruppen in der Wahrnehmung der Bevölkerung ansprechen “314. Eine von Daheim ausgewertete repräsentative Umfrage aus dem Jahre 1959 legt gleichfalls den Schluß nahe, daß in der Vorstellung der Befragten die kleinen und mittleren Selbständigen, die qualifizierten technischen und kaufmännischen Angestellten sowie die mittleren Beamten, nicht aber die Arbeiter zu den Mittelschichten zu zählen seien ${ }^{315}$. Im Unterschied zu Mayntz' Studie wird in Daheims Befragung begrifflich zwischen gesellschaftlicher Mitte bzw. Mittelschichten einerseits und Mittelstand andererseits differenziert. Die Umfrage ergab, daß sich im Urteil der Bevölkerung der Mittelstand in erster Linie aus den Selbständigen in Handwerk, Handel und Gewerbe zusammensetzte ${ }^{316}$. Der Terminus Mittelstand stellte mithin eine Spezifizierung des Mittelschichtenbegriffs dar.

Die auf der Methode der sozialen Selbsteinschätzung beruhenden Untersuchungsergebnisse von Kleining/Moore, die auf Bevölkerungsumfragen der Jahre 1958/59 basieren, stimmen mit diesem Befund nicht ganz überein ${ }^{317}$ : die obersten Gruppen der Arbeiterschaft wie z. B. Maschinenmeister, Montageführer und Facharbeiter mit besonderer Ausbildung und Überwachungsfunktion wurden zur unteren, „industriellen“ Mittel-

\footnotetext{
312 Wurzbacher, S. 47.

313 Daheim, Vorstellungen, S. 263.

314 Mayntz, Schichtung, S. 112.

315 Daheim, Vorstellungen, S. 251.

316 Ebenda, S. 244.

317 Kleining/Moore, S. 237-277. Bei der Methode der sozialen Selbsteinstufung ordnet jeder Befragte seinen Beruf einer vorher definierten Gruppe von Berufen zu, die ihm ähnlich bzw. gleichwertig erscheinen. Mit Hilfe der ermittelten Prestigeskala wird eine Hierarchie der einzelnen Berufsgruppen erstellt; S. 87-89.
} 
schicht gezählt. Sie standen somit auf der gleichen Stufe wie die kleinen Selbständigen und die Masse der Angestellten und unteren Beamten, die von den Autoren dem „nichtindustriellen " Mittelstand zugeordnet wurden. Mit dieser Zweiteilung der unteren Mittelschicht wird die Trennungslinie zwischen Arbeiterelite und Kleingewerbetreibenden gewissermaßen auf eine horizontale Ebene verlagert, wobei das Zusammengehörigkeitsgefühl das entscheidende Abgrenzungskriterium darstellt. Das Schichtungsmodell von Kleining/Moore ist insofern differenzierter als die vorgestellten Prestigeskalen, als es die selbständigen Mittelständler mehreren Schichten zuordnet ${ }^{318}$, d. h. es wird auch innerhalb der Berufspositionen des gewerblichen Mittelstandes zwischen „kleinen“ und "großen" Selbständigen unterschieden. Auch wenn die Grenzziehung zwischen den Prestigeschichten teilweise recht willkürlich erscheint, werden auf diese Weise die innerhalb der einzelnen Handwerks- und Einzelhandelsbranchen bestehenden sozioökonomischen Unterschiede vergleichsweise gut erfaßt.

Wie sahen die Kleingewerbetreibenden selbst die soziale Prestigestruktur, und wie ordneten sie sich in diese ein? Die von den Kölner Schuhmachern und Schreinern sowie den Münchener Lebensmitteleinzelhändlern angegebenen Prestigeabstufungen stimmten im großen und ganzen mit den Vorstellungen der Gesamtbevölkerung überein ${ }^{319}$. Zum Teil ist sogar eine etwas geringere Bewertung der mittelständischen Berufspositionen festzustellen. Die von Sack befragten Schreiner stuften das soziale Ansehen von Buchhaltern und Werkmeistern höher ein als das von Lebensmitteleinzelhändlern und selbständigen Schneidern ${ }^{320}$. Nach dem Urteil der von Greber interviewten Schuhmacher waren die Schneider sogar in der oberen Unterschicht einzuordnen. Die Schuhmacher selbst stuften sich nur eine Position höher ein. Sie rangierten somit hinter dem „Kassierer bei der Sparkasse“, einer Position aus der unteren Angestelltenschaft ${ }^{321}$. Demgegenüber tendierte - nach den Untersuchungsergebnissen von Bolte und Mayntz - die Bevölkerung zu einer Höherbewertung der genannten Selbständigenberufe. Dabei ist allerdings zu berücksichtigen, daß diese Bewertung Mitte der 50er Jahre erfolgte, die Daten zur Selbsteinschätzung der Schreiner und Tischler aber aus den späten 50er und frühen 60er Jahren stammen. In diesem Zeitraum hatte sich die wirtschaftliche Lage dieser Handwerkszweige im Vergleich zum Einkommensniveau der Arbeitnehmer verschlechtert.

Innerhalb der einzelnen Handwerkszweige läßt sich ein signifikanter Zusammenhang zwischen der Höhe des wirtschaftlichen Erfolges und der Selbsteinstufung nachweisen: So ordneten sich z. B. 29,4\% der Schreiner, die weniger als 20000 DM im Jahr umsetzten, in die untersten drei Stufen der Prestigeskala ein. Bei den Schreinern mit einem Jahresumsatz zwischen 100000 und 250000 DM betrug dieser Anteil nur 4,5\%. Die Tatsache allerdings, daß sich rund $60 \%$ der Inhaber von Minderbetrieben in den mittleren und etwas mehr als $10 \%$ in den oberen Bereich der Prestigehierarchie einordneten, zeigt, daß nach Auffassung der meisten Schreiner der Selbständigenstatus an sich bereits ausreichte, um ein hohes gesellschaftliches Prestige zu reklamieren ${ }^{322}$.

\footnotetext{
318 Ebenda, S. 92.

${ }^{319}$ Hagemann, S. 304; Sack, S. 82; Greber, S. 218.

320 Sack, S. 82.

321 Greber, S. 218.

322 Sack, S. 89.
} 
Was die Verwendung des Mittelstandsbegriffs betrifft, so läßt sich anhand der Untersuchung von Daheim nachweisen, daß im Selbstverständnis der Selbständigen nicht nur die Arbeiter, sondern auch „die Angestellten und Beamten vom ,Mittelstand' unterschiedene Schichten“ darstellten ${ }^{323}$. Die überwiegende Mehrheit der von Greber befragten Kölner Schuhmacher zählte diese Berufsgruppen ebenfalls nicht zum Mittelstand $^{324}$. Die Befragung der Kölner Schreiner führte in bezug auf die Beamten und Angestellten zu einem ähnlichen Ergebnis. Irritierend ist allerdings, daß die Berufsgruppe der Handwerker lediglich von rund einem Viertel und die der Geschäftsleute von einem Drittel der befragten Schreiner in den Mittelstand eingeordnet wurden ${ }^{325}$. Diesen Tatbestand deutet Sack als „das kaum verhüllte Eingeständnis einer gesellschaftlichen Unsicherheit " ${ }^{326}$. Es fragt sich indes, warum diese Unsicherheit bei den Schuhmachern nicht bestand, obwohl diese wirtschaftlich eher schlechter gestellt waren als die Schreiner. Bei den Kölner Lebensmitteleinzelhändlern betrug der Anteil derjenigen, die sich dem Mittelstand zugehörig fühlten, 65,7\%. 8,6\% waren der Auffassung, es gebe keinen Mittelstand, und 25,7\% hatten zu dieser Frage keine Meinung ${ }^{327}$. Wenngleich der Anteil der Lebensmitteleinzelhändler, die einen indifferenten Standpunkt einnahmen, als relativ hoch anzusehen ist, werden Sacks Ergebnisse hierdurch nicht bestätigt. Man wird also davon ausgehen können, daß sich der Großteil der Handwerker und Einzelhändler auch am Ende unseres Untersuchungszeitraumes noch zum Mittelstand zählte.

Bemerkenswert ist, daß sich die Inhaber kleiner Lebensmittelgeschäfte fast ebenso häufig als Angehörige des Mittelstandes fühlten wie die Inhaber von mittleren und großen Betrieben ${ }^{328}$. Dies läßt vermuten, daß - ab einem gewissen Einkommens- und Umsatzniveau - der ökonomische Erfolg keineswegs das Hauptkriterium für die Zuordnung zum Mittelstand darstellte. Nach dem typischen Kennzeichen des Mittelstands befragt, nannten die Lebensmitteleinzelhändler etwa gleich häufig die Merkmale „Fleiß und Sparsamkeit" sowie "mittleres Einkommen“, wobei die Spannweite der mittleren Einkommensklasse nicht näher definiert wurde. Am dritthäufigsten wurde die Selbständigkeit genannt. Eine gewisse Rolle spielte auch das Merkmal „bürgerliche Gesinnung“ ${ }^{329}$. Die von Sack befragten Kölner Schreiner betrachteten ebenfalls „Fleiß und Sparsamkeit" als die Hauptkennzeichen des Mittelstandes. Dahinter rangierten die Merkmale „gute Bildung“, „wirtschaftliche Selbständigkeit“ sowie „mittleres Einkommen “330. Da die abhängig Beschäftigten von den Einzelhändlern und Handwerkern in der Regel nicht zum Mittelstand gezählt wurden, stellt sich die Frage, warum die Selbständigkeit nicht an der Spitze der genannten Mittelstandsmerkmale stand. Sack vermutet, daß „der Begriff ,Mittelstand' keine Schichtbezeichnung, sondern ein Verhaltensmerkmal“ darstellte ${ }^{331}$. Eine andere Erklärung wäre, daß die Kleingewerbetreibenden

\footnotetext{
323 Daheim, Vorstellungen, S. 245.

324 Greber, S. 218, Tab. 139.

325 Sack, S. 95, Tab. 38.

326 Ebenda.

327 Hagemann, S. 291.

328 Ebenda, S. 295.

329 Ebenda, S. 316, Tab. 147.

330 Sack, S. 96.

331 Ebenda, S. 95. Nach dieser Argumentation wäre die Selbständigkeit kein Verhaltensmerkmal, sondern ein Zustand, auf dessen Basis sich gewisse Verhaltensweisen entwickeln.
} 
dazu tendierten, die aus ihrer Sicht positiven Mittelstandsmerkmale in den Vordergrund zu stellen. Nach dieser Interpretation wäre die Selbständigkeit nicht eindeutig positiv besetzt gewesen. Diese Hypothese stimmt mit einigen Umfrageergebnissen aus den späten 50er und frühen 60er Jahren überein. Der Erhebung von Reichardt ist zu entnehmen, daß die selbständige Tätigkeit nur von einer Minderheit der Inhaber kleinerer Betriebe (bis zu fünf Beschäftigten) als uneingeschränkt vorteilhaft angesehen wurde. Mit steigender Betriebsgröße nahm der Anteil der positiven Stellungnahmen $z^{332}$. Die Mittelstandserhebung in Langenberg ergab, daß $45 \%$ der Handwerker und $40 \%$ der Einzelhändler mit ihrer Arbeit keine besonderen Vorteile verbanden. Allerdings betrachteten etwa 4 von 10 Mittelständlern die Selbständigkeit an sich bereits als vorteilhaft. Nur 22\% der Handwerker und 24\% der Einzelhändler waren der Ansicht, daß ihnen aus ihrer Berufsstellung keine besonderen Nachteile erwuchsen. Die übrigen Befragten waren offenbar gegenteiliger Auffassung. Relativ häufig genannte Nachteile waren der Freizeitmangel (Handwerker: 20\% - Einzelhändler: 10\%) sowie das unternehmerische Risiko (Handwerker: 20\% - Einzelhändler: 10\%) ${ }^{333}$.

\section{Selbständige Vertriebene und SBZ-Flüchtlinge in Handwerk und Einzelhandel}

Die Vertriebenen waren unter den Betriebsinhabern des gewerblichen Mittelstands unterrepräsentiert. Der Vertriebenenanteil an der Gesamtbevölkerung belief sich 1950 auf 16,1 und 1961 auf 15,9\% ${ }^{334}$. Im selbständigen Handwerk lag der entsprechende Wert wesentlich niedriger ${ }^{335}$. Dieser Wert stieg zwar bis 1963 auf 7,67\% ${ }^{336}$, doch ändert dies nichts daran, daß die Vertriebenen im selbständigen Mittelstand schwächer vertreten waren, als es ihrem Anteil an der Wohnbevölkerung entsprochen hätte. Dies gilt ebenso für den Einzelhandel, wo die Vertriebenen bis Mitte der 50er Jahre lediglich rund 6\% der Betriebsinhaber stellten ${ }^{337}$.

In den Sektoren Bekleidung und Gesundheits- und Körperpflege lag der Vertriebenenanteil sowohl im Handwerk als auch im Einzelhandel zwei bis drei Prozentpunkte über dem Durchschnittswert. Diese Abweichung ist in erster Linie damit zu erklären, daß der für die Betriebseröffnung notwendige Kapitalbedarf in diesen Handwerks- und Einzelhandelsgruppen verhältnismäßig niedrig lag338.

Auf der Ebene der Handwerkszweige gab es überdurchschnittlich viele Vertriebenenbetriebe vor allem auf dem Gebiet des Musik- und Glasinstrumentenbaus, im Glas- und Porzellanmalerhandwerk, im Weberhandwerk, im Handschuhmacherhandwerk sowie im Gürtler- und Metalldrückerhandwerk. Die meisten dieser Handwerke waren in der

332 Reichardt, S. 41, Tab. 3.

${ }^{333}$ Krisam, S. 321, Tab. 38.

${ }^{334}$ Ritter/Niehuss, Wahlen, S. 31, Tab. 1.8.

335 Handwerkszählung 1956, H. 7, S. 39, Tab. 53.

336 Berechnet nach Handwerkszählung 1963, H. 4, S. 44-47, und H. 3, S. 28-32. Zur unmittelbaren Nachkriegszeit vgl. auch Waldmann, S. 182.

${ }^{337}$ Vertriebenenbetriebe im westdeutschen Handel, S. 5, Tab. 1 a.

${ }^{338}$ Albrecht, S. 174. Zum Einzelhandel vgl. Die Vertriebenenbetriebe im westdeutschen Handel, S. 5, Tab. 1a. Zum gesamten gewerblichen Bereich vgl. Jolles, S. 239. 
Heimat der Vertriebenen besonders verbreitet ${ }^{339}$. Im Einzelhandel, in dem derartige Spezialisierungen keine Rolle spielten, waren die branchenspezifischen Schwankungen wesentlich geringer.

Die Daten zu den mittelständischen SBZ-Flüchtlingen sind noch spärlicher als zu den Vertriebenen. Im Handwerk betrug der Anteil der aus der SBZ zugewanderten Selbständigen an der Gesamtzahl der Betriebsinhaber im Jahre 1956 nur 0,5\%. 1963 waren es knapp 3\% ${ }^{340}$. Gemessen an ihrem Bevölkerungsanteil, waren die Flüchtlinge im selbständigen Mittelstand unterrepräsentiert.

Dieser kurze statistische Überblick zeigt, daß sich die Vertriebenen und SBZ-Flüchtlinge rein quantitativ in der Masse der selbständigen Mittelständler verloren. Ein besonderes Merkmal der selbständigen Vertriebenen ist in den ersten Nachkriegsjahren in der geringen Größe ihrer Betriebe zu sehen. Sie gehörten mithin zu den ökonomisch und damit einkommensmäßig schlechter gestellten Mittelständlern. Bis Mitte der 50er Jahre glich sich die Betriebsgröße dem allgemeinen Standard an ${ }^{341}$. Die durchschnitcliche Größe der SBZ-Flüchtlingsbetriebe lag zum gleichen Zeitpunkt deutlich höher als der entsprechende Wert für das Gesamthandwerk (6,4 gegenüber 4,8 Beschäftigten je Betrieb). Diese Abweichung deutet auf eine positive Auslese unter den Flüchtlingshandwerkern hin. Die Handwerker, die sich in den 50er Jahren zum Verlassen der SBZ entschlossen, konnten ihre berufliche Zukunft in Westdeutschland zweifellos besser einschätzen und vorbereiten als die Heimatvertriebenen. Einem Teil der zuwandernden Handwerker gelang es sogar, Kapital oder Produktionsmittel aus der SBZ nach Westdeutschland zu bringen ${ }^{342}$. Die Leistungsstärke der Flüchtlingsbetriebe aus den ehemaligen Ostgebieten und der SBZ dürfte auch etwas mit der Altersstruktur ihrer Inhaber zu tun gehabt haben. Das Durchschnittsalter der selbständigen Handwerker war bei den Vertriebenen und Zugewanderten wesentlich geringer als bei den Einheimischen. Bei letzteren lag im Jahre 1956 insbesondere der Prozentsatz der über 65jährigen signifikant über dem entsprechenden Wert bei den Flüchtlingen ${ }^{343}$. Die selbständigen Handwerker aus der SBZ wiederum waren jünger als ihre Kollegen aus den Vertreibungsgebieten $^{344}$.

Angesichts des Umstandes, daß die zwischen vertriebenen und einheimischen Selbständigen bestehende ökonomische Ungleichheit im Verlauf der 50er Jahre abgebaut wurde, stellt sich die Frage, ob es auch in sozialer Hinsicht zu einer Nivellierung kam. Für den Einzelhandel ist belegt, daß der Anteil der Vertriebenen an der Kundschaft der

339 Handwerkszählung 1956, H. 7, S. 39; Handwerkszählung 1963, H. 4, S. 44, und H. 3, S. 28.

${ }^{340}$ Handwerkszählung 1956, H. 7, S. 39, Tab. 51.

3411949 betrug die durchschnittliche Betriebsgröße im Gesamthandwerk 3,56 Beschäftigte pro Betrieb und im Vertriebenenhandwerk 2,83 Beschäftigte pro Betrieb. 1956 hatten die Vertriebenenbetriebe sogar einen leichten Größenvorsprung (4,9 gegenüber 4,8); vgl. Handwerkszählung 1949, Bd. 16, S. 19, Tab. 35; Handwerkszählung 1956, H. 7, S. 39, Tab. 53. Vgl. auch EsenweinRothe, S. 79.

${ }^{342}$ Jolles, S. 243; vgl. ferner Heribert Müller, S. 10.

${ }^{343}$ Handwerkszählung 1956, H. 7, S. 40.

${ }^{344}$ Ebenda, H. 6, S. 60 und 152. Der Anteil der vor 1900 geborenen Personen war bei den SBZFlüchtlingen geringer als bei den Vertriebenen. Diejenigen SBZ-Flüchtlinge, die diesen Kohorten angehörten, nahmen allerdings in den 50er Jahren häufiger eine selbständige Tätigkeit auf als die vor 1900 geborenen Vetriebenen und Einheimischen. Vgl. hierzu Lüttinger, S. 110, Schaubild 4.5. 
Vertriebenenbetriebe überdurchschnittlich hoch lag ${ }^{345}$. Dieser Befund ist zum einen damit zu erklären, daß sich die Vertriebenenbetriebe in der Regel in den Vertriebenenhochburgen niederließen. Zum anderen drückte sich hierin aber auch ein gewisses Maß an landsmannschaftlicher Solidarität aus, was auf den sozialen Sonderstatus der selbständigen und unselbständigen Flüchtlinge hindeutet. Die beruflichen und sozialen Beziehungen der Vertriebenen-Unternehmer zu ihren einheimischen Berufskollegen lassen sich quellenmäßig nur schwer fassen. Boyer konnte im Rahmen seiner Untersuchung zur Gewerbepolitik in Bayern nachweisen, daß die Flüchtlingshandwerker von ihren einheimischen Kollegen vor allem als unliebsame Konkurrenz betrachtet wurden. Die ablehnende Haltung äußerte sich regelmäßig in den Gutachten, die Handwerkskammern und Innungen im Rahmen der staatlichen Bedürfnisprüfung anfertigten ${ }^{346}$. Man wird davon ausgehen können, daß die Masse der Flüchtlingshandwerker in den ersten Jahren nach dem Zweiten Weltkrieg in der Handwerksorganisation, zumal auf lokaler Ebene, einen Außenseiterstatus innehatten.

\section{Weibliche Betriebsinhaber im gewerblichen Mittelstand}

Die Frauen stellten im selbständigen Handwerk nur eine kleine Minderheit dar. 1931 belief sich der Frauenanteil an den handwerklichen Betriebsinhabern auf 12,1\% ${ }^{347} .1949$ lag diese Quote mit 14, 5\% zwar etwas höher; in den folgenden anderthalb Jahrzehnten war der Trend jedoch leicht rückläufig (1956: 13,3\% - 1963: 11,5\%) ${ }^{348}$.

Die Abnahme des Frauenanteils hing vor allem mit dem branchenstrukturellen Wandel zusammen. Als besonders folgenreich erwies sich die Schrumpfung der Bekleidungshandwerke. In dieser Handwerksgruppe war ca. jeder dritte Betriebsinhaber eine Frau (1949: 34,4\% - 1956: 32,9\%) $)^{349} .1949$ waren $73,5 \%$ und $195663,9 \%$ aller selbständigen Handwerkerinnen im Bekleidungssektor tätig350. Disaggregiert man die Gruppe der Bekleidungshandwerke nach Handwerkszweigen, so zeigt sich, daß 1949 allein im Damenschneiderhandwerk 56,7\% aller handwerklichen Betriebsinhaberinnen beschäftigt waren. Bis 1956 verringerte sich dieser Anteil auf 48,4\% ${ }^{351}$. Wie eng die Entwicklung des Frauenanteils im selbständigen Handwerk mit dem Niedergang des Damenschneiderhandwerks verknüpft war, ist daraus zu ersehen, daß sich zwischen 1949 und 1956 die Zahl der Damenschneiderinnen um 23322 verringerte, während die Gesamtzahl der Handwerkerinnen um 25827 zurückging. Ein nennenswerter absoluter Zuwachs an Betriebsinhaberinnen (insgesamt fast 5000 Frauen) war lediglich in der Handwerks-

${ }^{345}$ Vertriebenenbetriebe im westdeutschen Handel, S. 38.

${ }^{346}$ Boyer, Handwerksordnung, S. 442 f. Vgl. auch Woller, Gesellschaft, S. 274. Zu den Integrationsproblemen der Flüchtlingshandwerker vgl. ferner Erker, Vom Heimatvertriebenen zum Neubürger, S. 52-54.

${ }^{347}$ Wernet, Statistik, S. 44. Diese Prozentangabe beruht auf einer Erhebung in 49 Handwerkskammerbezirken. Es wurden rund $68 \%$ aller Handwerksbetriebe erfaßt. Wernet weist mit Recht darauf hin, daß insbesondere in den Metall-, Bau- und Holzhandwerken viele weibliche Inhaber den Betrieb ihres Mannes weiterführten, ohne im Unternehmen mitzuarbeiten.

348 Handwerkszählung 1956, H. 7, S. 35, Tab. 42; Handwerkszählung 1963, H. 4, S. 25, Tab. 25.

${ }^{349}$ Handwerkszählung 1956, H. 7, S. 35, Tab. 42.

${ }^{350}$ Berechnet nach Handwerkszählung 1956, H. 7, S. 24, Tab. 30, und S. 27, Tab. 32.

351 Ebenda. 
gruppe Metall sowie in den gesundheits- und körperpflegenden Berufen zu verzeichnen ${ }^{352}$. Zwischen 1956 und 1963 schieden weitere 20000 Damenschneiderinnen aus ihrer selbständigen Berufsstellung aus ${ }^{353}$, was sich wiederum maßgeblich auf die Gesamtquote der handwerklichen Betriebsinhaberinnen auswirkte. Die Marginalisierung des Bekleidungshandwerks stellte die vom Markt ausscheidenden Inhaberinnen vor ernsthafte Probleme, da in der Textilindustrie der Bedarf an qualifizierten Arbeitskräften äußerst gering war. Im Textileinzelhandel wiederum wurden bevorzugt junge Frauen beschäftigt ${ }^{354}$. Es gibt zudem vereinzelte Hinweise, daß die Handwerkerinnen auf dem Arbeitsmarkt wesentlich immobiler waren als die Männer. Sie wichen eher in die Schwarzarbeit aus, „als eine ihnen völlig berufsfremde Arbeit aufzunehmen“355.

Bemerkenswert ist, daß der Anteil, den die weiblichen Selbständigen an der Gesamtzahl der im Handwerk beschäftigten Frauen hatten, zwischen 1949 und 1963 signifikant zurückging (von 24,7 auf 9,9\%) ${ }^{356}$. Im Einzelhandel vollzog sich ein ähnlicher Trend: Hier nahm der Anteil der weiblichen Inhaber an den weiblichen Beschäftigten zwischen 1950 und 1961 von 26,1 auf 17,5\% ab ${ }^{357}$. Im Unterschied zum Handwerk stieg jedoch im Einzelhandel der ohnehin recht hohe Anteil der weiblichen Betriebsinhaber an den selbständigen Einzelhändlern in den 50er Jahren (1950: 36,4\% - 1961: $41,7 \%$ ). Im Einzelhandel mit Nahrungs- und Genußmitteln sowie Gemischtwaren war die Inhaberinnenquote im Vergleich zu den übrigen Einzelhandelsgruppen am höchsten. 1961 war etwa jeder zweite Lebens- und Gemischtwareneinzelhändler eine Frau. Eine klare Minderheitenposition nahmen die Betriebsinhaberinnen lediglich in den Einzelhandelszweigen ein, die hauptsächlich technische Artikel vertrieben, wie z. B. dem Einzelhandel mit Eisen- und Metallwaren und dem Einzelhandel mit Fahrzeugen, Maschinen und Büroeinrichtungen ${ }^{358}$.

Was die geschlechtsspezifische Betriebsgrößenklassenverteilung betrifft, so gilt grundsätzlich der Satz: Je kleiner der Betrieb, desto höher der Anteil der weiblichen Betriebsinhaber ${ }^{359}$. Die amtlichen Statistiken geben leider keine Auskunft darüber, inwieweit diesbezüglich im Laufe der 50er Jahre die geschlechtsspezifischen Ungleichheiten abgebaut wurden. Der Zusammenhang zwischen häuslicher und beruflicher Tätigkeit der selbständigen Frauen liegt ebenfalls weitgehend im dunklen. Hagemanns Stichprobe zum Lebensmitteleinzelhandel deutet darauf hin, daß die Inhaberinnen von Kleinstbetrieben wesentlich seltener verheiratet waren als ihre männlichen Berufskollegen in vergleichbarer Stellung ${ }^{360}$. Ob dies als Indiz für die Notselbständigkeit alleinstehender Frauen zu deuten ist, müssen weitere Forschungen erweisen.

\footnotetext{
${ }^{352}$ Handwerkszählung 1949, Bd. 16, S. 9, Tab. 8; Handwerkszählung 1956, H. 7, S. 333, Tab. 40.

${ }^{353}$ Handwerkszählung 1963, H. 4, S. 24, Tab. 23.

${ }^{354}$ Lutum, S. 106.

355 Brodmeier, S. 74. Vgl. ferner Conradi, S. 105.

${ }^{356}$ Handwerkszählung 1963, H. 4, S. 23, Tab. 22; Handwerkszählung 1949, S. 9, Tab. 8.

${ }^{357}$ Stockmann, Frauenarbeit, S. $452 \mathrm{f}$.

${ }^{358}$ Arbeitsstättenzählung 1950, H. 1, S. 98; Arbeitsstättenzählung 1961, H. 2, S. 66.1925 lag der Anteil der Einzelhändlerinnen bei 30\%; vgl. Haug, S. 14 .

359 Für die 20er Jahre vgl. Haug, S. 16. Zu den Verhältnissen im Lebensmitteleinzelhandel der späten 50er Jahre vgl. Hagemann, S. 16.

360 Hagemann, S. 93, Tab. 28.
} 


\section{Zusammenfassung}

Betrachtet man die sozialgeschichtliche Entwicklung von Handwerk und Kleinhandel im Überblick, so zeigt sich, daß wesentliche Kennzeichen der mittelständischen Lebensform in der frühen Bundesrepublik fortbestanden. Hervorzuheben ist insbesondere, daß sich die für das Kleingewerbe typische personelle Verflechtung zwischen Familie und Betrieb in der Nachkriegszeit nicht aufzulösen begann. Im Handwerk nahm ihre Bedeutung sogar zu. Die im Zuge des betrieblichen Strukturwandels wachsenden betrieblichen Aufgaben im administrativen Bereich und im Verkauf - letzteres trifft vor allem auf das Handwerk zu - führten zu einer verstärkten Mitarbeit der Ehefrauen. Auch die räumliche Nähe zwischen Arbeits- und Privatsphäre blieb in den 1950er Jahren ein wesentliches Charakteristikum des gewerblichen Mittelstandes. Die in der Betriebsvererbung zum Ausdruck kommende Familienkontinuität war dagegen nach wie vor eher die Ausnahme als die Regel.

Ein weiteres zentrales Untersuchungsergebnis ist, daß man in bezug auf die materiellen Lebensbedingungen der selbständigen Mittelständler und der Arbeitnehmer kaum von einer Nivellierung der Ungleichheitsrelationen sprechen kann ${ }^{361}$. Die relativen und absoluten Einkommensunterschiede zwischen Mittelständlern und Facharbeitern scheinen sich in den 1950er Jahre sogar vergrößert zu haben. Dieser Prozeß vollzog sich allerdings vor dem Hintergrund eines kollektiven Einkommenszuwachses, der das Ende der arbeitertypischen Proletarität einleitete ${ }^{362}$, so daß die Einkommensungleichheit als schicht- bzw. berufsspezifisches Abgrenzungskriterium an Bedeutung einbüßte. Was die Ausstattung der Haushalte mit Konsumgütern betrifft, so waren Ende der 50er Jahre die Unterschiede zwischen den betrachteten Berufsgruppen zwar insgesamt zu gering, um sie als Ausdruck unterschiedlicher Soziallagen interpretieren zu können. Gleichwohl verdient es, festgehalten zu werden, daß in bezug auf die PKW-Besitzquote, einem zentralen Indikator für den sozialen Status, das Ausmaß der Ungleichheit seit Beginn der 50er Jahre kontinuierlich zunahm ${ }^{363}$. Auf dem Gebiet der Arbeitszeit begann sich die Schere der Ungleichheit in der zweiten Hälfte der 50er Jahre zu öffnen. Die berufsspezifischen Daten zum Hausbesitz deuten darauf hin, daß sich der Unterschied zwischen dem Hausbesitzeranteil im gewerblichen Mittelstand und dem entsprechenden Prozentsatz in der Arbeitnehmerschaft erst in den $60 \mathrm{er}$ Jahren verringerte. Die zwischen Arbeitern und Mittelständlern bestehenden Unterschiede in den Wohnverhältnissen waren auch in der zweiten Hälfte der 50er Jahre noch nicht eingeebnet.

Die Aussagen zu den berufsgruppenspezifischen Unterschieden zwischen Handwerkern und Einzelhändlern einerseits und der Arbeitnehmerschaft andererseits beruhen auf dem Vergleich von Häufigkeitsverteilungen und Mittelwerten. Nimmt man die be-

${ }^{361} \mathrm{Zu}$ einer ähnlichen Einschätzung gelangen Krisam, S. 153-168, und Kätsch, S. 140-145. Vgl. ferner Grümer, S. 67 f.; Braun, S. 221.

${ }^{362}$ Zur theoretischen Interpretation von Niveauverschiebungen ( ${ }_{n}$ Fahrstuhl-Effekt ${ }^{\circ}$ ) bei konstanten Ungleichheitsrelationen vgl. Ulrich Beck, S. 122-125. Der Abschied der Arbeiter von der Proletarität fand vor allem in den 1960er Jahren statt; vgl. Mooser, S. 224-236. Diese Beobachtung steht im Einklang mit den Ergebnissen unserer Untersuchung.

${ }^{363}$ Diese Feststellung stimmt mit der These von Schildt/Sywottek, passim, überein, ${ }_{n} \mathrm{da} ß$ sich der Massenkonsum als wichtiger Motor der Enttraditionalisierung und Nivellierung erst in den 60er Jahren voll auswirkte". 
rufsgruppeninternen Ungleichheiten in den Blick, so ist zunächst festzustellen, daß in bezug auf die Einkommens- und Vermögensverteilung sowie auf die Konsumgüteraustattung das Spektrum der Lebensverhältnisse im Handwerk fast ebenso heterogen war wie im Einzelhandel ${ }^{364}$. Weder im Handwerk noch im Einzelhandel bestanden einheitliche Existenzbedingungen. Dafür war das Einkommensgefälle innerhalb der mittelständischen Berufsgruppen zu stark ausgeprägt. Allerdings wurden die materiellen Lebensbedingungen im gewerblichen Mittelstand relativ zum Anstieg des Durchschnittseinkommen der Mittelständler etwas homogener. Die absoluten Einkommensunterschiede nahmen dagegen zu. Dies wirkte sich auf die Wohnqualität ebenso aus wie auf den Haus- und PKW-Besitz. Insbesondere im Hinblick auf die beiden letztgenannten Indikatoren erscheinen Handwerk und Einzelhandel, sieht man einmal von den absoluten Spitzenverdienern und den kaum lebensfähigen Kleinstbetrieben ab, als zweigeteilte Berufsgruppen. Im Vergleich zu den 20er Jahren ist diesbezüglich allerdings eine bemerkenswerte Umschichtung zu konstatieren: Der Anteil der proletaroiden Selbständigen ging - zumal im Handwerk - signifikant zurück. Der Typus des Kleinunternehmers mit gesicherter Existenzgrundlage war auf dem Vormarsch. Die Tatsache, daß auch gegen Ende des Untersuchungszeitraums eine beachtliche Minorität der Handwerker und Einzelhändler nicht mehr verdiente als industrielle Facharbeiter, steht hierzu nur scheinbar im Widerspruch, da sich auch die Lebensbedingungen der Arbeiterelite spürbar verbesserten.

Eine weitere berufsgruppeninterne Fragmentierung resultierte aus den z.T. erheblichen Einkommensunterschieden zwischen den einzelnen Branchen. Für das Handwerk konnte nachgewiesen weden, daß die Bedeutung der Branchenzugehörigkeit für den durchschnittlich erreichbaren Lebensstandard im betrachteten Zeitraum zunahm. Diese Entwicklung dürfte einem branchenübergreifenden Zusammengehörigkeitsbewußtsein entgegengewirkt haben.

Die Berufsvererbung war im gewerblichen Mittelstand im Vergleich zu anderen Berufgruppen eher unterdurchschnittlich. Die überwiegende Mehrheit der Nachkommen von selbständigen Handwerkern und Einzelhändlern übernahm nicht die Berufspositionen ihrer Väter oder andere Selbständigenpositionen, sondern wanderte in die Arbeiterschaft ab, wobei Handwerksberufe besonders häufig angesteuert wurden. Letzteres deutet zwar nicht auf eine intergenerationelle Kontinuität der Berufsstellung hin, wohl aber auf eine enge Verbundenheit mit dem Berufsfeld der Vätergeneration.

Die Analyse der sozialen Herkunft hat ergeben, daß die Mehrheit derjenigen Handwerker, die die Voraussetzung für die Eröffnung eines eigenen Betriebes erwarben, aus Selbständigenhaushalten stammten. Dieses Rekrutierungsmuster veränderte sich im Untersuchungszeitraum nur unwesentlich. Beachtlich ist der hohe Prozentsatz der aus der Arbeiterschaft stammenden Meisteranwärter. Wie jedoch die Daten zur Herkunft der selbständigen Handwerker zeigen, machte sich nur ein kleiner Teil dieser Arbeiterkinder selbständig. Im gewerblichen Mittelstand herrschte infolgedessen die Selbstrekrutierung vor. Diese scheint sich indes stärker auf die eigene Branche als auf den gesamten Berufsstand oder auf den gewerblichen Mittelstand als ganzen bezogen zu haben. Betrachtet man die Herkunftsanteile der verschiedenen Berufsgruppen im Überblick, so fällt auf, daß zwischen Einzelhandel und Handwerk der intergenerationelle Aus-

364 Seit dem Kaiserreich hatte sich hieran offenbar nicht viel geändert; vgl. Volkov, S. 135. 
tausch am intensivsten war. Die selbständigen Mittelständler blieben mithin weitgehend unter sich. Öffnungstendenzen im Sinne einer Heterogenisierung der Herkunftsstruktur sind in den 1950er Jahren nicht erkennbar. Das Gegenteil ist angesichts durchschnittlich steigender Betriebsgrößen und den damit verbundenen Kapitalerfordernissen wahrscheinlich.

Die berufgruppeninternen sozialen Beziehungen der Handwerker und Einzelhändler waren im Untersuchungszeitraum von einer zunehmenden Versachlichung gekennzeichnet. Besonders deutlich läßt sich dieser Trend in den örtlichen Berufsverbänden der Handwerker nachweisen, wo die gemeinschaftsbildenden Elemente seit Beginn der 50er Jahre immer stärker zugunsten ökonomischer und interessenpolitischer Gesichtspunkte zurückgedrängt wurden. Inwieweit sich hierin eine Erosion subkultureller Bindungen widerspiegelte, läßt sich nur vermuten. Im Einzelhandel war die Ausgangsposition der beruflichen Zusammenschlüsse in zweifacher Hinsicht eine andere: Zum einen war die Bindung der sozialen Basis an die örtlichen Einzelhandelsverbände weniger stark, und zum anderen spielte der Aspekt der berufsständischen Solidarität in den fachlichen Vertretungen der Einzelhändler von vornherein eine geringere Rolle. Obgleich sich zweckrationale Beziehungsmuster in den mittelständischen Berufsverbänden immer stärker durchsetzten, ist davon auszugehen, daß allein durch den organisatorischen Zusammenschluß der Berufsangehörigen ein gewisses Maß an gemeinschaftlichem Bewußtsein erzeugt bzw. bewahrt wurde.

Was die außerberuflichen gesellschaftlichen Kontakte betrifft, so verkehrten Handwerker und Einzelhändler zwar vornehmlich mit Gleichgestellten, darüber hinaus bestanden aber auch Kontakte zur Unter- und Oberschicht. Das breite Spektrum der Verkehrskreise resultierte nicht zuletzt aus der inneren Fragmentierung der mittelständischen Berufsgruppen, die ökonomisch marginalisierte Selbständigenexistenzen ebenso umfaßten wie Inhaber von Großbetrieben. Gleichwohl bleibt festzuhalten, daß die Unterschiede in den sozialen Beziehungsmustern und die Statusdifferenzierung im gewerblichen Mittelstand weniger stark ausgeprägt waren als die Streuung nach sozialökonomischen Merkmalen. So nahmen auch jene Kleingewerbetreibenden, deren Einkommen das eines Arbeiters nicht überstieg, in der Wahrnehmung der Bevölkerung einen mittleren Platz in der gesellschaftlichen Prestigeordnung ein. Die Merkmale "Selbständigkeit" und „Ausbildungsstand" erfreuten sich offenbar besonderer Wertschätzung. Dies erklärt auch, warum die Selbständigen in Handel, Handwerk und Gewerbe als eigene soziale Gruppierung innerhalb der Mittelschichten identifiziert wurden ${ }^{365}$. Der überwiegende Teil der Handwerker und Einzelhändler ordnete sich selbst ebenfalls in den Mittelstand ein und betonte damit den Unterschied zu den Arbeitern. Die meisten Kleingewerbetreibenden begründeten ihre Mittelstandszugehörigkeit vor allem mit dem Hinweis auf soziokulturelle Verhaltensmerkmale, wobei allerdings unklar ist, ob es sich hierbei um ideologische Projektionen oder um die Manifestation einer tatsächlich vorhandenen Mittelstandsmentalität handelte. Bemerkenswert ist die Tatsache, daß

365 Eine ähnliche Auffassung vertrat übrigens auch Schelsky, der den alten Mittelstand der bäuerlichen Landwirtschaft, des Handwerks und Handels als eigenständige soziale Gruppierung ansah. Hauptkennzeichen dieser Gruppe waren seiner Meinung nach jedoch nicht spezifische Lebensbedingungen oder Sozialbeziehungen, sondern die Tatsache, daß die genannten Berufsgruppen nin höherem Maße Freiheit und Risiko in der Disposition der eigenen beruflichen und wirtschaftlichen Tätigkeit haben“; Schelsky, Bedeutung des Schichtungsbegriffes, S. 335. 
die selbständige Berufsstellung im Selbstverständnis der befragten Handwerker und Einzelhändler einen geringeren Rang einnahm als in der Fremdwahrnehmung durch die Bevölkerung. Aufs Ganze gesehen, ist davon auszugehen, daß die Abgrenzung gegenüber Arbeitnehmern in dem Maße an sozialer Bedeutung verlor, wie sich die traditionellen Milieugrenzen auflösten. In diesem Zusammenhang ist insbesondere auf die Erosion des Arbeitermilieus zu verweisen. Die gesamtgesellschaftliche Enttraditionalisierung, die ja im Untersuchungszeitraum noch keineswegs abgeschlossen war, machte den Mittelstandsbegriff als Sozialkategorie nicht obsolet. Sie führte aber dazu, daß die Mittelstandszugehörigkeit als identitätsstiftendes Element zunehmend in den Hintergrund trat.

Die Frage, ob die Selbständigkeit im Untersuchungszeitraum an Attraktivität verlor oder gewann, erfordert eine differenzierte Antwort. Die Nachteile, die die selbständige Tätigkeit mit sich brachte (unternehmerisches Risiko, hohe Arbeitsbelastung), kristallisierten sich vor dem Hintergrund des an Anziehungskraft gewinnenden Arbeitnehmerstatus (soziale Sicherheit, Freizeit usw.) immer deutlicher heraus. Dies ist einer der wesentlichen Gründe dafür, warum die Existenz als Inhaber eines Kleinstbetriebes zunehmend unattraktiver wurde. Eine Verlockung stellten dagegen die zunehmenden Expansionsmöglichkeiten und - damit einhergehend - die steigenden Verdienstchancen der Inhaber rationell wirtschaftender mittelständischer Betriebe dar; dies wiederum macht verständlich, weshalb Ende der 50er Jahre wieder mehr Menschen in eine selbständige Berufsstellung drängten. 